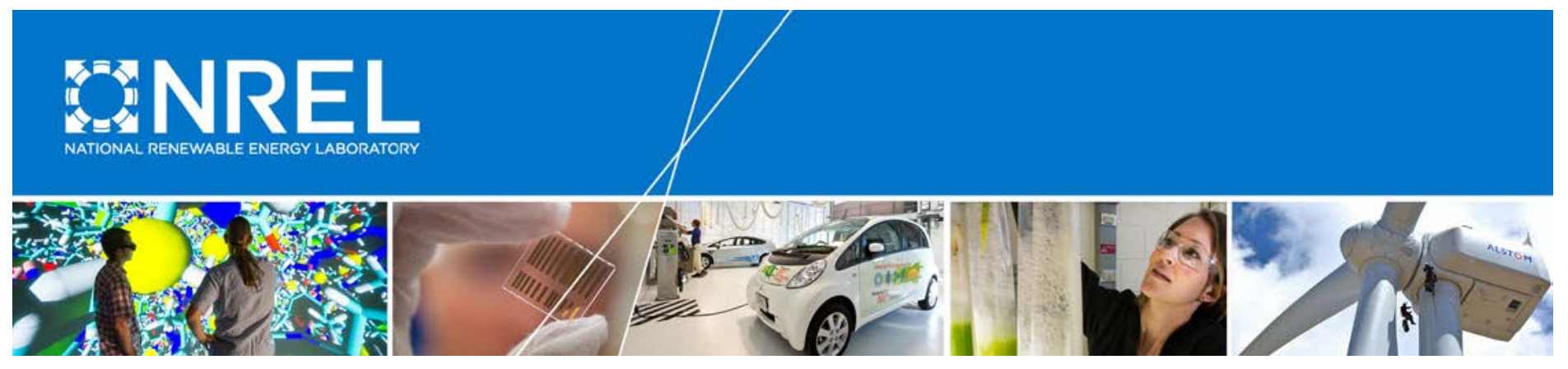

\title{
Near-Blackbody Enclosed Particle-Receiver Development
}

Zhiwen Ma

National Renewable Energy Laboratory

Bartev Sakadjian

Babcock \& Wilcox Research Center

NREL is a national laboratory of the U.S. Department of Energy Office of Energy Efficiency \& Renewable Energy Operated by the Alliance for Sustainable Energy, LLC

This report is available at no cost from the National Renewable Energy Laboratory (NREL) at www.nrel.gov/publications.

Technical Report

NREL/TP-5500-67997

December 2015

Contract No. DE-AC36-08G028308 


\section{Near-Blackbody Enclosed Particle-Receiver Development}

Zhiwen Ma

National Renewable Energy Laboratory

Bartev Sakadjian

Babcock \& Wilcox Research Center

Prepared under Task No. CP13.F201

NREL is a national laboratory of the U.S. Department of Energy Office of Energy Efficiency \& Renewable Energy Operated by the Alliance for Sustainable Energy, LLC

This report is available at no cost from the National Renewable Energy Laboratory (NREL) at www.nrel.gov/publications.

National Renewable Energy Laboratory 15013 Denver West Parkway Golden, CO 80401

303-275-3000 • www.nrel.gov

\section{Technical Report}

NREL/TP-5500-67997

December 2015

Contract No. DE-AC36-08GO28308 


\section{NOTICE}

This report was prepared as an account of work sponsored by an agency of the United States government. Neither the United States government nor any agency thereof, nor any of their employees, makes any warranty, express or implied, or assumes any legal liability or responsibility for the accuracy, completeness, or usefulness of any information, apparatus, product, or process disclosed, or represents that its use would not infringe privately owned rights. Reference herein to any specific commercial product, process, or service by trade name, trademark, manufacturer, or otherwise does not necessarily constitute or imply its endorsement, recommendation, or favoring by the United States government or any agency thereof. The views and opinions of authors expressed herein do not necessarily state or reflect those of the United States government or any agency thereof.

This report is available at no cost from the National Renewable Energy Laboratory (NREL) at www.nrel.gov/publications.

Available electronically at SciTech Connect http:/www.osti.gov/scitech

Available for a processing fee to U.S. Department of Energy and its contractors, in paper, from:

U.S. Department of Energy

Office of Scientific and Technical Information

P.O. Box 62

Oak Ridge, TN 37831-0062

OSTI http://www.osti.gov

Phone: 865.576.8401

Fax: 865.576.5728

Email: reports@osti.gov

Available for sale to the public, in paper, from:

U.S. Department of Commerce

National Technical Information Service

5301 Shawnee Road

Alexandria, VA 22312

NTIS http://www.ntis.gov

Phone: 800.553 .6847 or 703.605 .6000

Fax: 703.605.6900

Email: orders@ntis.gov 
Project Title:

Project Period:

Budget Period:

Budget Period Budget:

Reporting Period:

Reporting Frequency:

Submission Date:

Recipient:

Recipient DUNS \#:

Address:

Award Number:

Awarding Agency:

Working Partners:

Cost-Sharing Partners:

Principal Investigator:

Submitted by:

GO Contracting Officer: Golden, CO

Technology Project Officer: Christine Bing (HQ)

DOE Technical Manager: Levi Irwin, Andru Prescod (HQ)

10/01/12-9/30/15

04/01/15-09/30/15

10/01/12-09/30/15

Final Report for Project Closeout

11/04/15

805948051

Golden, CO 80401

DE-EE0001586

DOE EERE SETP CSP subprogram

Babcock \& Wilcox Company

Utah State University (USU)

Ohio State University (OSU)

Colorado School of Mines (CSM)

University of Texas, El Paso (UTEP)

Advanced Thin Film Technology (ATFI)

cock \& Wilcox Company (B\&W)

USU, OSU, CSM, UTEP, ATFI

Allied Mineral Product, Inc.

Thermal Spray Technologies

Zhiwen Ma

Sr. Engineer, Ph.D.

Phone: 303-275-3784

Fax: 303-384-7595

Email: zhiwen.ma@nrel.gov

Zhiwen Ma

Near-Blackbody Enclosed Particle-Receiver Development

National Renewable Energy Laboratory (NREL)

15013 Denver West Parkway, MS RSF 033 


\section{Project Objective:}

This 3-year project develops a technology using gas/solid, two-phase flow as a heattransfer fluid and separated, stable, solid particles as a thermal energy storage (TES) medium for a concentrating solar power (CSP) plant, to address the temperature, efficiency, and cost barriers associated with current molten-salt CSP systems. This project focused on developing a near-blackbody particle receiver and an integrated fluidized-bed heat exchanger with auxiliary components to achieve greater than $20 \%$ cost reduction over current CSP plants, and to provide the ability to drive high-efficiency power cycles.

Table of Contents

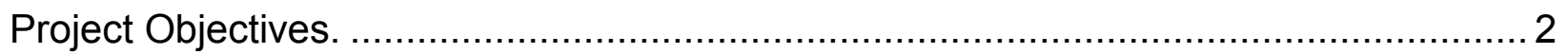

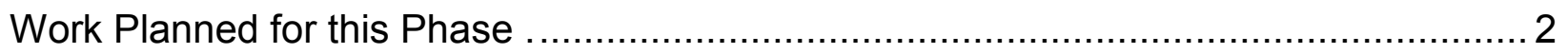

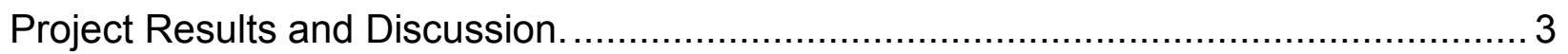

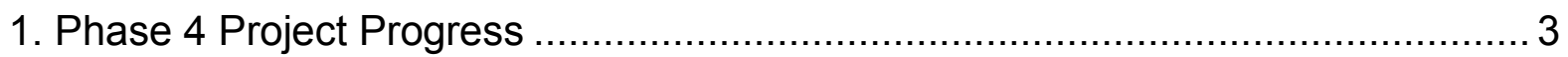

2. Additional Outcomes and Lessons Learned from the Coating Development ....... 16

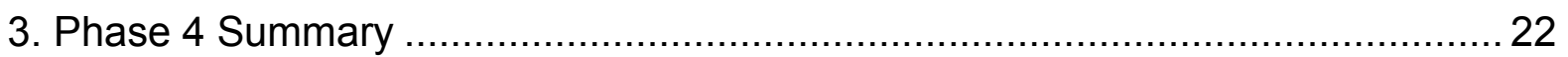

4. Overall Project Outcomes and Technical Advancement .................................... 23

5. Intellectual Property Outcome and Technology Development Path ..................... 49

6. Summary of the Overall Project Development ................................................. 51

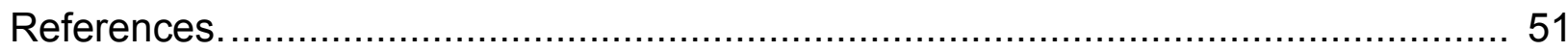

\section{Work Planned for this Phase:}

Subtask 4.1.1. Stability test on the intermediate-temperature specular-reflective coatings.

a. Develop Sol-Gel protected front surface silver coating methods and measure reflectivity. We will investigate and optimize sol-gel coating parameters.

b. Work with Chemat to leverage its experience in sol-gel coating, and recent activity in sol-gel protective coating on an Ag layer.

Subtask 4.1.2. High-temperature reflectivity coating stability test.

Test thermal-sprayed ceramic coating (alumina and zirconia/yttrium) durability. Improvement will focus on identifying bonding reliability by testing multiple sample selections.

Subtask 4.1.3. Study the coating regenerative ability after five or ten years of usage. Peel test of stable high-temperature diffuse-reflective coatings.

This report updates the coating selections, testing results, and milestone status from Phase 4, and summarizes major outcomes relevant to the final deliverables out of the three-year project. 


\section{Project Results and Discussion:}

The NREL near-blackbody enclosed particle receiver with integrated heat exchanger project achieved the initial goals in particle-based CSP system design and major components development. The original tubular absorber design evolved to a planar cavity design to deal with coating requirements, manufacturing complexity, and lack of particle contact with the tubular absorber bottom. The new receiver concept and the developed system configuration and components made promising progress for the particle system to be the next generation CSP thermal system for dispatchable power generation with the low-cost, high-temperature TES capability.

The Phase 4 study continued the coating development from Interim Phase 3 and focused on evaluating coating endurance for long term serviceability. Our goals are to minimize the risks in coating materials that are important for spreading flux along the absorber interior surface such that the receiver can accept high-incident fluxes, and to study the coating durability in the application conditions. For effective coating development, we worked closely with several coating-specialized companies to try offthe-shelf coating materials and methods that could be ready to use in a prototype receiver. Meanwhile, we also looked into alternative receiver designs that differ from the hexagonal tube array and water jacket concept, so as to remedy the challenges in hydraulic design, hexagonal tube array fabrication, high-stress structure, coating reliability, and reflective surface application and maintenance. In this report, we first update the progress made for the Phase 4 tasks on coating materials and testing, and then present outcomes and lessons learned for different coating options. In addition to the coating focus, we are aiming at a realizable, robust, simple, and inexpensive receiver design that can resolve or avoid the reflective material needs and any fundamental concerns.

The technical development progress and milestone status in Phase 4 are provided in the first part of the report, and the overall three-year project achievements, lessons learned, and the recommended path forward for a fluidized-bed (FB)-CSP system using solid particles towards commercialization are summarized in the last part of this final report. The report documents the major technical outcomes of the project for future commercialization assessment.

\section{Phase 4 Milestone Status}

In this project phase, we broadly tested reflective materials and used internal and external coating development resources to obtain a variety of coating samples. This effort also supported the coating development for the direct supercritical $\mathrm{CO}_{2}$ receiver shield and panel reflective surfaces. A broad range of coating samples using different coating methods and materials were collected from different venders and coating companies. The samples were screened initially with visual examination, initial reflectivity measurement, and thermal stability testing. Our focus in Phase 4 was primarily on the promising coating methods and materials verified in Interim Phase 3 so that long-term durability can be obtained for meeting receiver service life requirements. Tested coating samples that likely satisfy milestone metrics are presented in this section, and lessons learned from testing other coating samples will be introduced in the next section as documentation for reference. 
Table 1 shows the status of Milestone 4.1.1. For the first 1,000 hour performance, the physical vapor deposition (PVD) silver coating meets nearly all milestone metrics. The PVD reflectivity rate of change is a challenge after 1,000 heating hours, because of the growth of micro-cracks with the accumulation of thermal cycles.

Table 1. Phase 4 milestone metrics and results from the most-promising samples.

\begin{tabular}{|c|c|c|c|c|c|c|}
\hline & $\begin{array}{c}\text { Metric Definition } \\
\text { (From } \\
\text { Measurement) }\end{array}$ & Success Value & $\begin{array}{l}\text { Measured } \\
\text { Value }\end{array}$ & $\begin{array}{c}\text { Assessment } \\
\text { Tool }\end{array}$ & $\begin{array}{l}\text { Goal } \\
\text { Met } \\
(\mathrm{Y} / \mathrm{N})\end{array}$ & $\begin{array}{l}\text { Supporting } \\
\text { Data (pg. } \\
\text { \#) }\end{array}$ \\
\hline & $\begin{array}{c}\rho_{\text {start }}=\rho_{0}-\Delta \rho \\
\text { Starting reflectivity } \\
\text { of } \\
\text { flare surface coating }\end{array}$ & $\geq 0.90$ & $\begin{array}{l}96.2 \% \\
\pm 0.1 \%\end{array}$ & $\begin{array}{l}\mathrm{t} \text {-test, } 95 \% \\
\text { confidence, } \\
\text { from } \\
\text { SOC410 } \\
\text { measurement }\end{array}$ & Y & $\begin{array}{l}\text { Pg. } 6 \text {, Fig. } \\
\text { 1, sample } \\
\text { with } 50, \\
100,150 \\
\mathrm{~mm} / \mathrm{min} \text {. }\end{array}$ \\
\hline 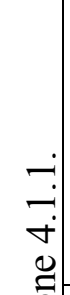 & $\begin{array}{l}\frac{\partial \rho}{\partial t} \\
\text { Rate of change in } \\
\text { reflectivity of flare } \\
\text { surface coating }\end{array}$ & $\begin{array}{c}\text { <average } \\
1 \% / \text { year } 1 \\
\text { Constraints: } \\
\geq 1000 \mathrm{~h} \text { at } \\
150^{\circ} \mathrm{C} \text {; air } \\
\text { atmosphere }\end{array}$ & $\begin{array}{c}<1 \% / \text { year } \\
\text { after } \\
2,000- \\
\text { heating } \\
\text { hours }\end{array}$ & $\begin{array}{c}\text { Standard } \\
\text { deviation of } \\
\text { the fit value } \\
\left(1 / n \sqrt{S S_{\text {res }}}\right. \\
<0.02 \text {. })\end{array}$ & $\mathrm{Y}$ & $\begin{array}{l}\text { Pg. } 6 \text {, Fig. } \\
\text { 1, sample } \\
\text { with } 50 \text {, } \\
100,150 \\
\mathrm{~mm} / \mathrm{min} .\end{array}$ \\
\hline 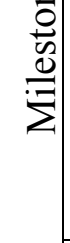 & $\begin{array}{l}\rho_{\text {start }, \text { spec }} \\
=\rho_{0, \text { spec }}-\Delta \rho_{\text {spec }} \\
\text { Starting specular } \\
\text { reflectivity of the } \\
\text { flare surface coating }\end{array}$ & $\begin{array}{l}0.80 \text { at full } \\
\text { acceptance of } \\
<105 \mathrm{mRad}\end{array}$ & $\begin{array}{l}81.5 \% \\
\pm 0.3 \%\end{array}$ & $\begin{array}{l}\mathrm{t} \text {-test, } 95 \% \\
\text { confidence, } \\
\text { from } \\
\text { SOC410 } \\
\text { measurement }\end{array}$ & $\mathrm{Y}$ & $\begin{array}{l}\text { Pg. } 7 \text {, Fig. } \\
\text { 2, sample } \\
\text { with } 50 \text {, } \\
100,150 \\
\mathrm{~mm} / \mathrm{min} \text {. }\end{array}$ \\
\hline & $\begin{array}{c}\frac{\partial \rho_{\text {spec }}}{\partial t_{\text {spec }}} \\
\text { Rate of change in } \\
\text { specular reflectivity } \\
\text { of the flare } \\
\text { surface coating }\end{array}$ & $\begin{array}{l}<\text { average } \\
1 \% / \text { year } \\
\text { Constraints: } \\
\geq 1000 \mathrm{~h} \text { at } \\
150^{\circ} \mathrm{C} \text {; air } \\
\text { atmosphere }\end{array}$ & $\begin{array}{l}>1 \% / \text { year } \\
\text { for sol- } \\
\text { gel after } \\
1000 \text { hrs. }\end{array}$ & $\begin{array}{c}\text { Standard } \\
\text { deviation of } \\
\text { the fit value } \\
\left(1 / n \sqrt{S S_{\text {res }}}\right. \\
<0.02 \text {. })\end{array}$ & $\mathrm{N}$ & $\begin{array}{l}\text { Pg. 9, Fig. } \\
4 \text {, sample } \\
\text { with } 50, \\
100,150 \\
\mathrm{~mm} / \mathrm{min} .\end{array}$ \\
\hline
\end{tabular}

After $>1,000$ heating hours, the total reflectivity of sol-gel protected silver coatings showed stabilization and rate of change level off. It is an encouraging sign for this group of samples to meet the milestone items 1 to 3 in 2,000-hour time frame. The thermal testing affects the sol-gal surface clarity, and results in continuing degradation of the specular reflectivity that missed the milestone item 4 for satisfactory rate of change. Pathways to achieve stable specular reflectivity were investigated with tests on Alanod $\circledast$ reflective material and gold coatings.

${ }^{1}$ The decay rate is defined as $\partial \rho / \partial t$ in the equation of $\rho(t)=\rho_{0}-\partial \rho / \partial t t-(1-\Delta \rho)\left(1-\exp \left(-3 /{ }_{\beta} t\right)\right)$.

- $\rho_{0}$ is the initial reflectivity measurement.

- $\frac{\partial \rho}{\partial t}$ is the degradation rate after stabilization (what we'd be judged by).

- $\Delta \rho$ is the drop in reflectivity during the initial stabilization period.

- $t$ is time in years.

- $\quad \beta$ is the stabilization period in years. 
Table 2 shows the results for high-temperature reflective coatings in Milestone 4.1.2. Two groups of coating samples can satisfy the initial reflectivity and reflectivity rate of change milestones. The thermal-sprayed ceramic coatings from TST and B\&W Vendor E show promising performance through 2,183 hours, and 1,783 hours, respectively. The TST sample shows no sign of degradation in this testing period.

Table 2. Milestone 4.1.2 status and results from the most-promising samples.

\begin{tabular}{|c|c|c|c|c|c|c|}
\hline & $\begin{array}{c}\text { Metric Definition } \\
\text { (From } \\
\text { Measurement) }\end{array}$ & Success Value & $\begin{array}{c}\text { Measured } \\
\text { Value }\end{array}$ & $\begin{array}{c}\text { Assessment } \\
\text { Tool }\end{array}$ & $\begin{array}{l}\text { Goal } \\
\text { Met } \\
(\mathrm{Y} / \mathrm{N})\end{array}$ & $\begin{array}{c}\text { Supporting } \\
\text { Data (pg. } \\
\text { \#) }\end{array}$ \\
\hline 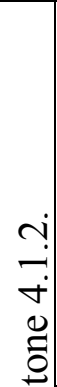 & $\begin{array}{c}\rho_{\text {start }}=\rho_{0}-\Delta \rho \\
\text { Starting reflectivity } \\
\text { of } \\
\text { mid-section surface } \\
\text { coating }\end{array}$ & $\begin{array}{c}0.60 \leq \rho_{\text {start }} \leq 0.90 \\
\text { solar weighted } \\
\text { hemispherical } \\
\text { reflectivity }\end{array}$ & $\begin{array}{l}68.1 \% \\
\pm 0.4 \% \\
\text { Alumina } \\
\text { coating; } \\
85 \% \\
\pm 0.4 \% \text { YSZ } \\
\text { coating. }\end{array}$ & $\begin{array}{c}\text { Statistical } \\
\text { hypothesis } \\
\text { testing of } \\
95 \% \\
\text { confidence } \\
\text { from } \\
\text { SOC410 } \\
\text { measurement }\end{array}$ & $Y$ & $\begin{array}{l}\text { Pg. 11, } \\
\text { Fig. 5; } \\
\text { Pg. 14, } \\
\text { Fig. 7.a. }\end{array}$ \\
\hline 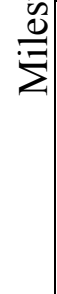 & $\begin{array}{l}\frac{\partial \rho}{\partial t} \\
\text { Rate of change in } \\
\text { reflectivity of mid- } \\
\text { section surface } \\
\text { coating }\end{array}$ & $\begin{array}{c}<\text { average } \\
1 \% / \text { year } \\
\text { Constraints: } \\
\geq 1000 \mathrm{~h} \text { at } \\
900^{\circ} \mathrm{C} \pm 25^{\circ} \mathrm{C} \text {; air } \\
\text { atmosphere }\end{array}$ & $\begin{array}{l}<1 \% / \text { year } \\
\text { Alumina } \\
\text { coating; } \\
<1 \% / y e a r \\
\text { YSZ } \\
\text { coating. }\end{array}$ & $\begin{array}{c}\text { Standard } \\
\text { deviation of } \\
\text { the fit value } \\
\left(1 / n \sqrt{S S_{\text {res }}}\right. \\
<0.02 .)\end{array}$ & $Y$ & $\begin{array}{l}\text { Pg. 11, } \\
\text { Fig. 5; } \\
\text { Pg. 14, } \\
\text { Fig. 7.a. }\end{array}$ \\
\hline
\end{tabular}

We have explored a variety of coating samples with different coating materials and methods. The development is intended to verify intermediate- and high-temperature reflective coatings for the solar receiver application. As listed in Tables 1 and 2, we have accomplished five of the six coating development milestones.

To examine the coating reliability for service life and bonding quality, we conducted an endurance test by following the tape-peel testing standard on coating durability. The results will be discussed in Subtask 4.1.3. Thermal testing under the specified temperatures was performed with the goal of meeting the $1 \% / y$ ear rate of degradation within $90 \%$ to $60 \%$ reflectivity range. The bonding integrity is targeted to meet the $5-10-$ year service life. The following sections will provide testing results of different coatings that are most promising to meet the milestones, in addition to results and lessons learned from the broad coating study.

\subsection{Subtask 4.1.1: Intermediate-Temperature $\left(150^{\circ} \mathrm{C}\right)$ Specular Reflective Coating Development}

Within Subtask 4.1.1, we worked on evaluating intermediate-temperature specularreflective coating performance under active-cooling conditions up to $150^{\circ} \mathrm{C}$. This subtask examines the performance of PVD and sol-gel protected silver coatings on a stainless-steel substrate in order to evaluate the coating durability. The two most important factors in determining the performance of these coatings are initial specular reflectivity and stability. Initial specular reflectivity was easier to achieve while the stability of the specular reflectivity was more challenging. 
Figure 1 shows the total reflectivity change over time at temperature for different sol-gel withdrawal speeds with the samples made by NREL. To satisfy this application temperature, the silver-coated reflective samples were heated in the furnace at $150^{\circ} \mathrm{C}$ over 2,500 hours to test their durability. The sol-gel coated silver-electroplated surfaces obtained high total average reflectivity of around $96 \%$, a $1 \%-2 \%$ improvement over the Ag electroplated substrate potentially due to the sol-gel planarization effect. After 1,000 hours at $150^{\circ} \mathrm{C}$, the total reflectivity of most of these samples remained above $90 \%$ and total reflectivity for samples with withdrawal speed between $50 \mathrm{~mm} / \mathrm{min}$ and 150 $\mathrm{mm} / \mathrm{min}$ appears to level off after 1,500 hours to an average of $\sim 90 \%$, and remains at that level of reflectivity after 2,300 hours.

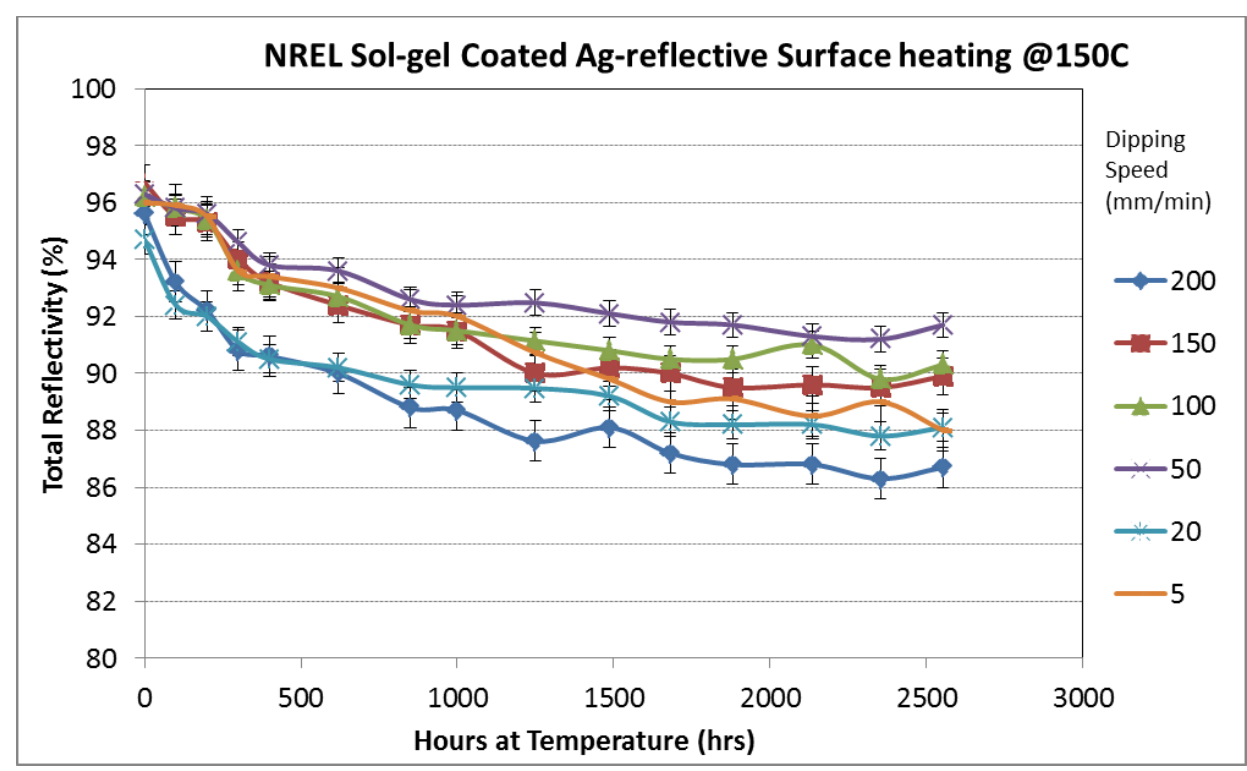

Figure 1. Total reflectivity change versus time for NREL sol-gel coated samples held at test temperature of $150^{\circ} \mathrm{C}$.

Based on the sol-gel application process, a thicker coating layer can form at faster withdrawal speed, likely because the minuscule of the sol-gel liquid spreads less and thickens the layer with faster withdrawal speed. The relation between the dipping withdrawal speed and the coating thickness may indicate that very thin and thick coatings would perform poorly but medium-thickness coatings have similar total reflectivity degradation characteristics. Visual inspection of the coated samples revealed surface non-uniformity for both high and low dipping speeds due to too thick or too thin sol-gel covering induced unevenness. These observations correspond well with the literature on sol-gel coatings [1], which suggests an optimal intermediate dipping speed on the order of $100 \mathrm{~mm} / \mathrm{min}$. Based on the testing results and observations, we identified that suitable dipping speeds range from $50 \mathrm{~mm} / \mathrm{min}$ to $150 \mathrm{~mm} / \mathrm{min}$, and we adopted a coating speed of $100 \mathrm{~mm} / \mathrm{min}$ as a reference in further coating study.

Figure 2 shows the specular reflectivity of the samples over time at $150^{\circ} \mathrm{C}$, and shows a trend of continuing degradation in comparison to the total reflectivity. This group of silver-electroplated samples has inferior specular reflectivity because they were shipped after electrodeposition in a way that allowed them to rub against each other. The electroplated silver-coated substrates arrived scratched as a result. The average specular reflectivity of these samples prior to sol-gel coating was approximately $82 \%$, 
and the coating process decreased their specular reflectivity by $2 \%$. Four additional samples were obtained later and carefully handled during shipping. These new samples were found to have an initial specular reflectivity between $92.7 \%$ and $93.9 \%$, indicating that Ag-electroplated materials can have high initial specular reflectivity if proper care is taken to avoid scratching.

Even though the initial specularity is low, useful information can still be gained by observing the degradation of these samples. From the specular reflectivity change over time at $150^{\circ} \mathrm{C}$ as indicated in Figure 2, the thinnest coating $(5 \mathrm{~mm} / \mathrm{min})$ shows the worst performance by far while the other coatings are closely grouped together.



Figure 2. Specular reflectivity change versus time for NREL sol-gel coated samples held at test temperature of $150^{\circ} \mathrm{C}$.

These samples' specular reflectivity degradation behavior is very consistent across dipping speeds (except for the $5 \mathrm{~mm} / \mathrm{min}$ sample) when the results are normalized. This indicates that withdrawal speed does not seem to affect the rate at which each sample's specular reflectivity decreases from the starting value unless the coating is very thin. The consistent degradation rates with this group of NREL samples indicates that improvement should be made in the sol-gel composition and curing procedure, so as to improve the clarity and smoothness of the coating layer throughout the heating process to preserve the specularity.

Figure 3 shows the change of the total reflectivity with respect to the thermal testing hours for silver samples coated with a silica sol-gel by Chemat. Chemat is a sol-gel specialized company that has prior experience in sol-gel coating reflectors (both aluminum and silver reflective surfaces). The initial sample testing of Chemat's sol-gel protected silver coating shows excellent transparency, with an initial increase of the total reflectivity of $2 \%$.

Chemat's samples showed less total reflectivity change with heating time and the same trend observed in NREL's samples of stable total reflectivity after $>2,000$ hours. All testing results in Figure 3 show similar trends: the total reflectivity degradation stabilized at 1,500 heating hours, and after 2,000 heating hours, the total reflectivity of certain 
samples trended up and improved slightly with heating hours. Although we cannot forecast the ultimate trend of the total reflectivity yet, this indicates thus far that the silver layer is free from oxidation, and the sol-gel coating is still effective in preventing oxygen diffusion. Oxidation would decrease the total reflectivity immediately. These results indicate that Chemat's coating is protecting the surface from oxidation very well.



Figure 3. Total reflectivity versus time for Chemat sol-gel coated samples held at test temperature of $150^{\circ} \mathrm{C}$.

Figure 4 shows the specular reflectivity for Chemat sol-gel coated samples and their specular-reflectivity change with time. Contrary to the total reflectivity, the specular reflectivity drops continuously. The fact that the total reflectivity remains high indicates that the specularity decrease is not driven by oxidation. Sol-gel layer or silver coating roughness may be the reason for the decrease in the surface specularity. Although the specular reflectivity of Chemat samples trended down, the silver samples protected by a Chemat sol-gel have shown better stability for over 2,000 hours than most of other specular-reflective samples, including PVD silver reflective samples that degraded after 1,000 heating hours at $150^{\circ} \mathrm{C}$.

As shown in Figure 4, the specular reflectivity of the Chemat sol-gel coating samples varies widely. In addition, a large drop in specular reflectivity during the coating process hindered the performance of these samples, which was not observed for the NREL solgel samples. Their initial specular reflectivity decreased by as much as $8 \%$ during the coating process, which is much higher than NREL's reduction of $2 \%$. Both Chemat and NREI used similar scratched silver-electroplated substrates, and were handled carefully in the sol-gel coating process. Therefore, Chemat believes that this drop is due to the low $\mathrm{pH}$ of their coating solution, which may be attacking the silver surface during dipping. They are investigating this effect and believe they can fix the problem by changing the $\mathrm{pH}$ prior to dipping. Chemat coated their samples with withdrawal speeds of $132 \mathrm{~mm} / \mathrm{min}$ and $228 \mathrm{~mm} / \mathrm{min}$ and sintered in both argon and air. The wide spread in specular reflectivity provided little indication of the effect of these conditions on this parameter. Specular reflectivity may decrease as diffuse degradation spots appear and 
begin to expand. Looking across many of the samples, this seems to be more of a trend then a sudden change. Further efforts by Chemat to improve the coating quality beyond current off-the-shelf methods may need significant development efforts. Overall, these results indicate the sol-gel potential for ensuring a long service life for the reflective heat shield. However, additional funding support is needed to improve the sol-gel process to promote stability of specular reflectivity.

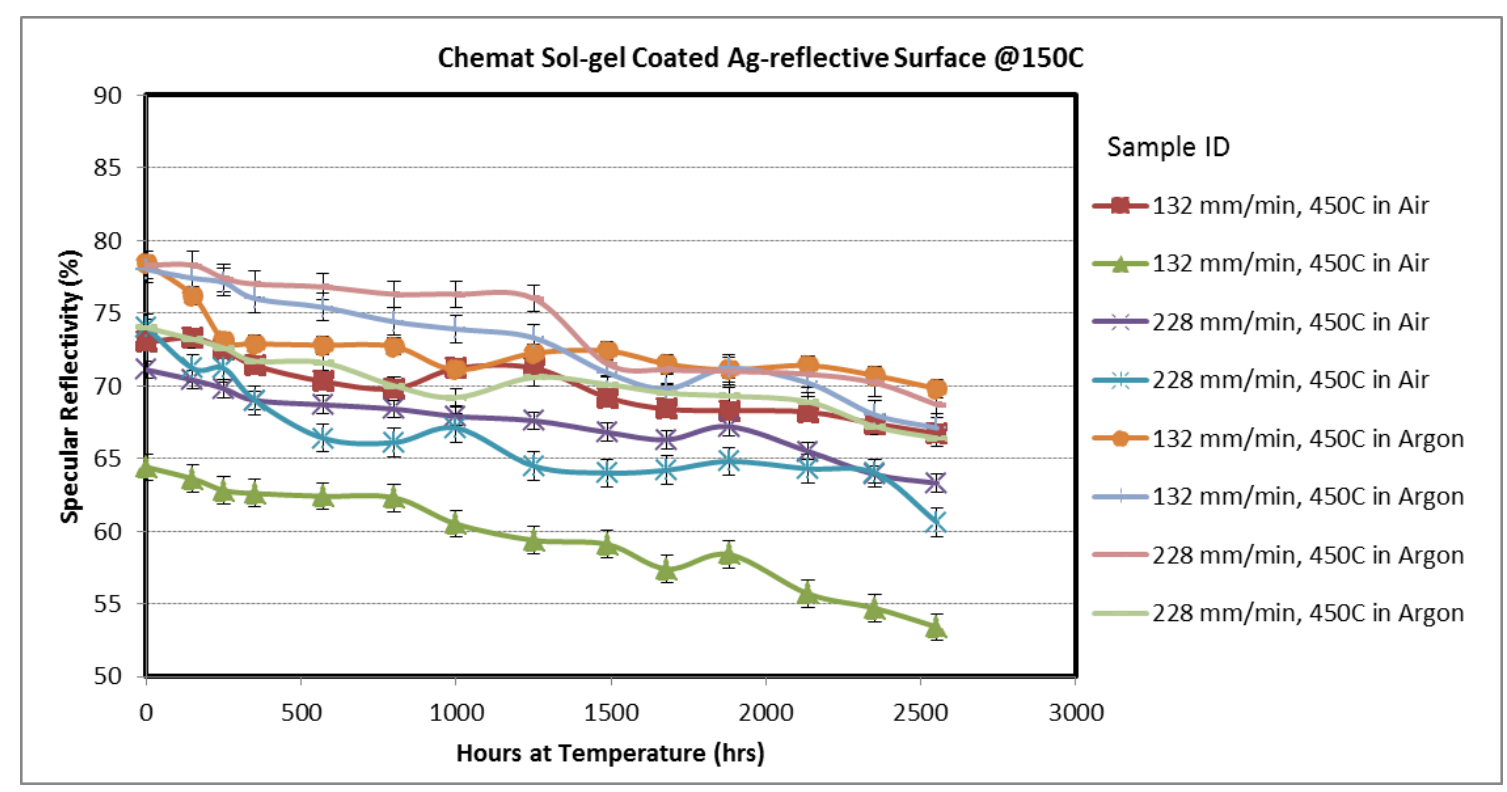

Figure 4. Specular reflectivity versus time for Chemat sol-gel coated samples held at test temperature of $150^{\circ} \mathrm{C}$.

The durability test on sol-gel samples indicates that the total reflectivity can remain above $90 \%$ over 2,500 heating hours and appears stable. Our efforts to modify the solgel composition to improve specular reflectivity durability in Phase 4 have not yielded a positive outcome yet. We believe industry experience from sol-gel specialized companies such as Chemat or Alanod will be critical in improving the degradation rate for the specular-reflective surface at $150^{\circ} \mathrm{C}$.

\subsection{Subtask 4.1.2: High-Temperature Diffuse-Reflective Coating Development}

Within Subtask 4.1.2, NREL tested diffuse-reflective coating performance under hightemperature operating conditions (up to $900^{\circ} \mathrm{C}$ ). The high-temperature diffuse-reflective coating test was focused on thermal-sprayed ceramic coatings and Applied Thin Film Inc. (ATFI) Cerablak high-temperature coatings. Thermal-sprayed alumina and YSZ (yttria-stabilized-zirconia) coatings show high diffuse reflectivity and promising endurance. The continued endurance test under the high-temperature condition verified the ceramic coatings for long-term usage. Experiments show that none of the hightemperature reflective paints, including commercial off-the-shelf paints and ATFI Cerablak coatings, are able to withstand the thermal test at $875^{\circ} \mathrm{C}$. Thermal sprayed ceramic coating samples from two venders were tested successfully and are discussed here.

\subsubsection{Durability Test of the Ceramic Coatings from Thermal Spray Technologies for High-Temperature Reflective Surfaces}


Thermal Spray Technologies, Inc. (TST) develops coating solutions that maximize surface protection under high-temperature or high-erosion conditions. TST is a highvolume OEM company and specializes in thermal-spayed alumina coating, polishing, and grinding. TST engineers a range of coatings for use in solar energy applications, such as protecting solar energy equipment from potential hazards. Thermal spray methods melt particles of the coating material directly or indirectly as they pass through the high-temperature zone of a plasma or flame torch at high velocity. The melted particles impinge onto the substrate surface where they form a continuous film that rapidly freezes to form the protective coating. Thermal spray or plasma spray can improve the adhesion of the coating with the substrate. Though, at high temperature the coating layer might crack or delaminate because of the thermal expansion coefficient mismatch between substrate and bond layer or ceramic coating surface and bond layer. Thermal spray of alumina or zirconia has been developed for decades and has broad industry applications from high-temperature corrosion protection to thermal barrier coatings on gas-turbine blades. The alumina or zirconia sprayed layer is white in color and has the desired reflectivity for our receiver application.

Given the difficulty to obtain high-temperature coating stability, we discussed thermalspray bonding reliability with TST, who provided background information on overcoming the thermal expansion mismatch, bond layer formation, and the effects of substrate metal selection on coating reliability. Thermal spray or plasma spray can improve the adhesion of the coating with the substrate. In addition to coating adhesion, the key to reliable high-temperature coatings is to overcome the thermal expansion coefficient (TEC) mismatch. The TEC issue was dealt with by using a bond layer between the substrate and the ceramic coating. The bond layer acts as a buffer between the coating and the substrate. The bond layer used by TST consists of combinations of alumina and $80 / 20 \mathrm{NiCr}$ alloy, with a thickness of $75-\mu$ in on the 300 series stainless-steel substrate. The TEC difference between the stainless steel $\left(9-p p m /{ }^{\circ} \mathrm{C}\right)$ and alumina $\left(4-\mathrm{ppm} /{ }^{\circ} \mathrm{C}\right)$ is $5-\mathrm{ppm} /{ }^{\circ} \mathrm{C}$, which is larger than the TEC difference between most nickel alloys $(6-8$ $\mathrm{ppm} /{ }^{\circ} \mathrm{C}$ ) and alumina. Thus, if the coating works for stainless steel substrate, it should also work well with a nickel alloy substrate. The applicable temperature for a stainless steel substrate can be up to $1,100^{\circ} \mathrm{C}$ according to the TST technologist. TST stated that the ceramic coating can be used under outdoor conditions. It can tolerate moisture from condensed water, but moisture induced corrosion on the substrate could cause delamination. The stainless steel substrate should resist corrosion at the ambient conditions. However, if it is necessary to prevent corrosion from moisture, the operation may circulate cold particles $\left(\sim 250^{\circ} \mathrm{C}\right)$ through the receiver to prevent water condensation.

To test the coating thermal stability, the sample was heated to $875^{\circ} \mathrm{C}$ as specified in the SOPO. The coating shows excellent bonding stability so far. We measured the sample reflectivity every $100 \mathrm{hrs}$ for the first $300 \mathrm{hrs}$ and every $200 \mathrm{hrs}$ afterwards. Figure 5 shows the total reflectivity change of the lapped alumina sample with hours at temperature. The total reflectivity decreased initially from $68.1 \%$ to $66.4 \%$ at 600 hours, and then increased to $69.3 \%$ at 2,183 hours.

The lapped TST alumina coated sample did not show an initial burnout effect. This may be due to the lapping process, which may remove the surface contamination to obtain a 
clean and pure layer. The sample reflectivity dropped slightly at the initial test. Then the sample reflectivity increased gradually with the testing hours and remained fairly stable with $>2,000$ hours testing time. The coating bonding stability was demonstrated through thermal testing and validated the TST thermal spray capability. An un-lapped, as-coated TST alumina sample failed at 1,000 heating hours of thermal test. The different coating reliability between the as-coated sample and the lapped sample is still not fully understood. One possibility is that the lapping process might press the coating layer dense, and seal the micro-pores from oxygen diffusion, though this reasoning is speculative and needs in-depth investigation and testing. The coating reflectivity may be further tuned as needed by modifying the powder material and coating procedure. Therefore, the preliminary test results are encouraging for TST coating to achieve a high-temperature diffuse-reflective surface for flux spreading in the NBB-type solar receiver.

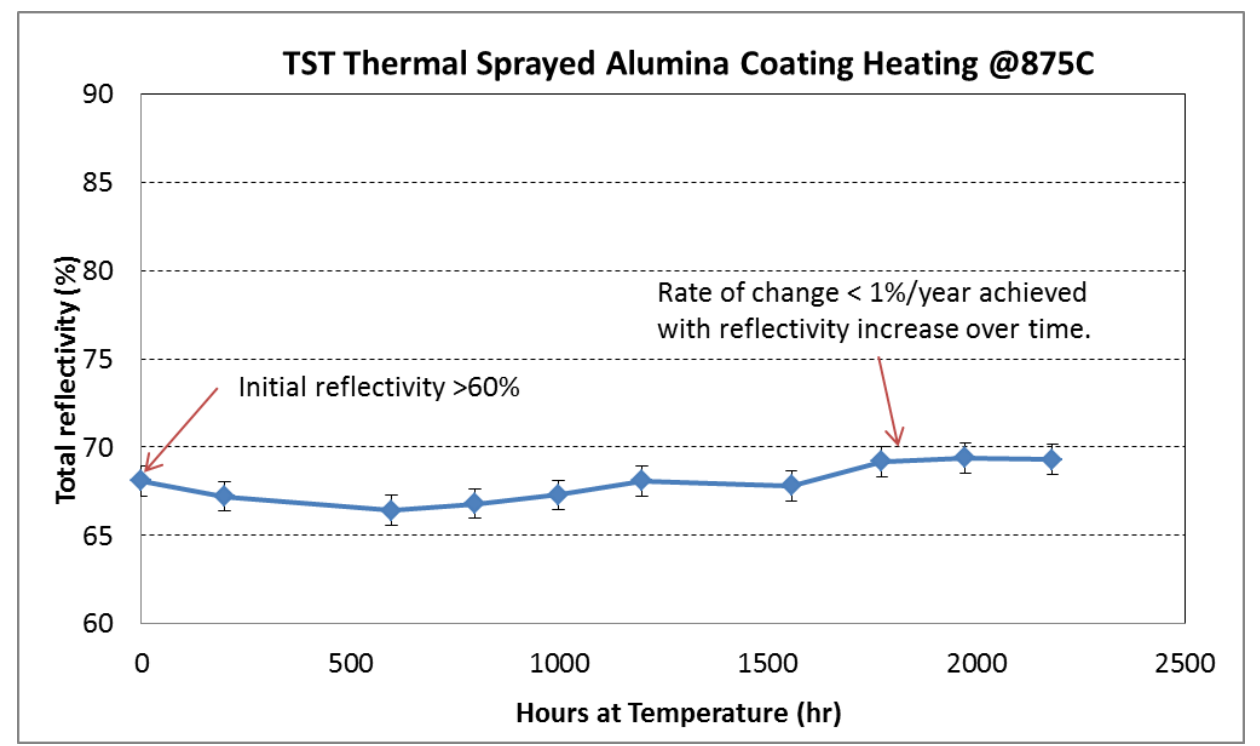

Figure 5. Total reflectivity change with heating hours for TST alumina coated sample (Indication of meeting Milestone 4.1.2).

The testing results from Figure 5 are positive for the high-temperature coating to meet Milestone 4.1.2 for both the reflectivity and its degradation rate. The sample maintains a total reflectivity of above $65 \%$, while the reflectivity slightly increases with heating hours. We haven't fully interpreted the slight increase in reflectivity with the heating process yet, but the positive tendency indicates little or no reflectivity degradation with this coating sample since 600 heating hours.

Figure 6 shows the two ceramic sprayed samples on top of 300 series stainless steel substrate. Sample 1 is as sprayed with a surface roughness in the range of 200-230 Ra (Roughness average in micro inch). Sample 2 was lapped to obtain a smooth surface with roughness of 4-8 Ra. The lapped surface was intended to test if a smooth ceramic surface can display specular reflection. The reflectivity measurements indicated that the lapped alumina coating cannot obtain specular reflection.

Figure 6 shows the sample coating condition after 1,775 hours at $875^{\circ} \mathrm{C}$. The surface is still clean and bright as the initial condition, although the picture background introduces 
a false gray appearance when comparing Figure 6.b to Figure 6.c. Visual observation indicates no change after the long-term high-temperature testing, despite the difference in picture exposure from the initial picture in Figure 6.b.

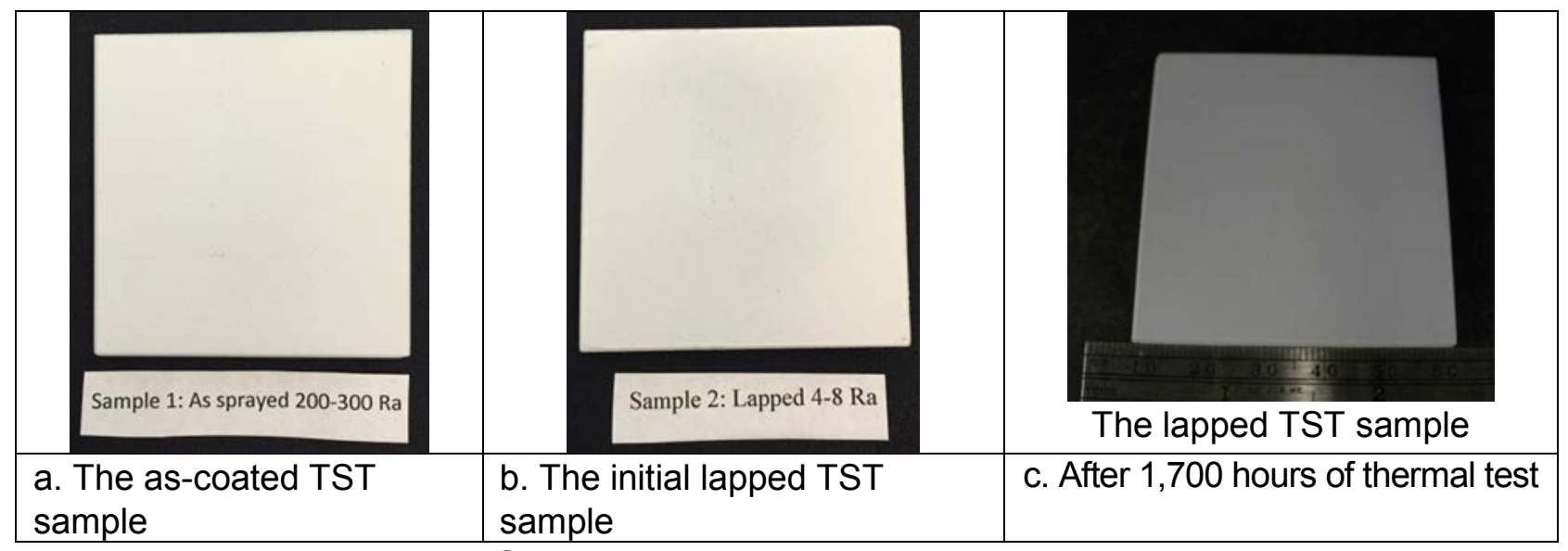

Figure 6. TST Thermal sprayed alumina coating samples.

Given the exceptional performance of the lapped TST thermal sprayed alumina coating, we ordered more coating samples with a variety of coating conditions. Recently, TST delivered the coating samples that are listed in Table 3 for broad testing of reflective performance and coating reliability. We characterized coating performance with the large TST sample base and for multiple coating materials including bond layers and top coatings using alumina and yttrium-stabilized zirconia (YSZ), in order to validate the applicability of stable high-temperature coatings for the solar receiver.

TST applied two bond-coating layers which are named as BC and MC in Table 3. The coatings were applied on SS310 (sample ID starting with SS) and Haynes 230 (sample id starting with $\mathrm{H}$ ) substrates. The bond-coating layers are combinations of alumina and $\mathrm{NiCr}$ alloy layer. The purpose of the bond coating is to improve the adherence of the top coatings and provide thermal expansion compatibility between the substrate and the top coating. The measured bond layer reflectivity is low, possibly due to oxidation after the spray coating process. After heating at $875^{\circ} \mathrm{C}$, the reflectivity of $\mathrm{BC}$ and $\mathrm{MC}$ dropped even lower, and further oxidation likely occurred in the heating process. The reflectivity measurements show that early alumina-coated samples that went through thermal test had low reflectivity, perhaps because the top coating layers were thin and partially translucent to the bond layer. Newly-obtained alumina coating samples all show high initial reflectivities between $80 \%$ and $90 \%$, which is near the reflectivity of pure alumina. Initial sample \#1 and \#2 showed different behavior between the as-coated sample and the lapped sample. However, this difference was not shown in the newly obtained samples. We considered the inconsistency between the initial TST samples and the recently obtained samples. Both samples used similar coating procedure and coating bond layers. The lower reflectivity of the earlier TST thermal sprayed alumina coating as compared to new alumina-coated samples may be the difference of the coating thicknesses.

In contrast to the alumina coatings that did not show the burnout effect, i.e., little change of reflectivity before and after high-temperature heating, TST YSZ coatings showed 
significant improvement after initial heating of 200 hours at $875^{\circ} \mathrm{C}$, while the reflectivity increased by nearly $20 \%$ for most of the YSZ samples. The reflectivity increase after initial burnout is consistent with those YSZ samples that were supplied by B\&W Vender $D$ and $E$. YSZ samples have a rough surface and were not ground or lapped.

Table 3. Reflectivity measurement of thermal spray ceramic coating.

\begin{tabular}{|c|c|c|c|}
\hline $\begin{array}{c}\text { Sample } \\
\text { Id. }\end{array}$ & Coating conditions & Total reflectivity $\boldsymbol{\rho}_{\boldsymbol{t}}$ & $\begin{array}{c}\text { Reflectivity after } \\
\text { burnout }\end{array}$ \\
\hline$\# 1$ & As sprayed 200-300 Ra & $71.2 \%,\left(\rho_{s}=0.4 \%\right)$ & $74 \%$ \\
\hline \#2 & Lapped 4-8 Ra & $68.1 \%,\left(\rho_{s}=0.6 \%\right)$ & $66 \%$ \\
\hline SS1 & Alumina, Not Lapped & $87.3 \% \pm 0.3 \%$ & Applied peel test \\
\hline SS2 & Alumina, Not Lapped & $86.7 \% \pm 0.1 \%$ & $87.1 \% \pm 0.4 \%$ \\
\hline SS3 & Alumina, Not Lapped & $86.8 \% \pm 0.3 \%$ & $86.6 \% \pm 0.4 \%$ \\
\hline SS4 & YSZ, Not Lapped & $57.8 \% \pm 0.3 \%$ & Applied peel test \\
\hline SS5 & BC/MC only & $22.7 \% \pm 1 \%$ & Applied peel test \\
\hline SS6 & Alumina, Lapped & $79.5 \% \pm 0.2 \%$ & $79.5 \% \pm 0.2 \%$ \\
\hline SS7 & BC only & $21.5 \% \pm 1.5 \%$ & $6.8 \% \pm 0.1 \%$ \\
\hline SS8 & Alumina, Lapped & $79.8 \% \pm 0.2 \%$ & $79.3 \% \pm 0.1 \%$ \\
\hline SS9 & YSZ, Not Lapped & $57.5 \% \pm 0.2 \%$ & $78.3 \% \pm 0.3 \%$ \\
\hline SS10 & YSZ, Not Lapped & $57.1 \% \pm 0.6 \%$ & $78.3 \% \pm 0.3 \%$ \\
\hline H1 & YSZ, Not Lapped & $55.8 \% \pm 0.2 \%$ & $76.7 \% \pm 1.0 \%$ \\
\hline H2 & YSZ, Not Lapped & $55.8 \% \pm 0.3 \%$ & Applied peel test \\
\hline H3 & Alumina, Not Lapped & $83.5 \% \pm 0.2 \%$ & Applied peel test \\
\hline H4 & BC/MC only & $22.6 \% \pm 1.1 \%$ & Applied peel test \\
\hline H5 & Alumina, Not Lapped & $83.1 \% \pm 0.9 \%$ & $83.3 \% \pm 0.1 \%$ \\
\hline H6 & BC only & $20.4 \% \pm 0.8 \%$ & $6.1 \% \pm 0.1 \%$ \\
\hline H7 & Alumina, Not Lapped & $84.2 \% \pm 0.4 \%$ & $84.9 \% \pm 0.2 \%$ \\
\hline H8 & Alumina, Lapped & $82.5 \% \pm 0.1 \%$ & $83.9 \% \pm 0.1 \%$ \\
\hline H9 & Alumina, Lapped & $79.1 \% \pm 0.5 \%$ & $79.6 \% \pm 0.5 \%$ \\
\hline H10 & Alumina, Lapped & $79.3 \% \pm 0.3 \%$ & $79.8 \% \pm 0.1 \%$ \\
\hline H11 & YSZ, Not Lapped & $55.9 \% \pm 0.5 \%$ & $77.9 \% \pm 1.0 \%$ \\
\hline
\end{tabular}

Some samples from each coating types were selected to perform the peel test for coating reliability assessment. TST thermal-sprayed ceramic coatings have broad industry applications. According to a discussion with a TST representative, the thermalspray process can be scaled to a large-scale manufacturing process with automatic coating procedure.

\subsubsection{Durability Test of Vendor E Yttrium-Stabilized Zirconia Sample}

We now have received a variety of samples from vendor $E$ who specializes in providing thermal barrier coatings (TBC's and YSZ's coatings) used in aircraft and land based turbines. These TBC's coatings are applied to reduce the temperature seen by metallic components allowing for gas turbines to operate at higher operating conditions and higher efficiencies.

Vendor E provided both YSZ and alumina based coatings. This supplier also introduced different sealants on the surface to minimize the amount of oxidation. Based on the testing to date, the Vender E alumina-based coatings have failed. On the YSZ-based samples, there are five different types of sealants (sealants A-E) as well as samples 
with No sealants (NS). The intent of the sealers is to minimize liquid and gas permeation during operation to reduce the amount of corrosion, oxidation and associated delamination that may occur. The ceramic coatings often produce diffusive surfaces due to porosity and surface roughness. The coating samples were either polished (P) or not polished (NP). Polishing was intended to provide some degree of specular reflectivity and in fact it did provide up to $10 \%$ specular reflectivity on the asreceived samples. These YSZ coating samples were studied and compared to the YSZ samples supplied by vendor $D$, which appeared to provide desirable optical properties but delaminated after 1,000 heating hours.

Table 4. Vender $\mathrm{E}$ sample coating application methods

\begin{tabular}{|c|c|c|c|c|c|}
\hline Sample & Coating Methods & \multirow{2}{*}{$\begin{array}{c}\text { Total } \\
\text { ID }\end{array}$} & Explanation & Reflectivity & \multicolumn{2}{|c|}{ Change Rate } \\
\cline { 5 - 6 } & reflectivity & after burnout & After 1,000-hr & Pass \\
\hline 3A-2P & YSZ, Polished, Sealant A & $69.6 \% \pm 0.4 \%$ & $81.9 \% \pm 1.0 \%$ & $18 \% /$ year & No \\
\hline 3B-2P & YSZ, Polished, Sealant B & $70.8 \% \pm 0.2 \%$ & $83.1 \% \pm 0.4 \%$ & $8.7 \% /$ year & No \\
\hline 3C-2P & YSZ, Polished, Sealant C & $68.7 \% \pm 0.3 \%$ & $85.8 \% \pm 0.4 \%$ & $0.006 \% /$ year & Yes \\
\hline 3D-2P & YSZ, Polished, Sealant D & $68.5 \% \pm 1.0 \%$ & $84.9 \% \pm 1.1 \%$ & $0.153 \% /$ year & Yes \\
\hline 3E-2P & YSZ, Polished, Sealant E & $68.9 \% \pm 0.5 \%$ & $82.5 \% \pm 0.9 \%$ & Peel test & \\
\hline 3NS-2P & No-seal, polished & $69.1 \% \pm 0.4 \%$ & $83.6 \% \pm 0.3 \%$ & $1.56 \% /$ year & No \\
\hline 3NS-2NP & No-seal, not polished & $69.6 \% \pm 0.3 \%$ & $85.0 \% \pm 0.2 \%$ & $2.15 \% /$ year & No \\
\hline
\end{tabular}

The long term exposure testing performed to date shows promise for three of the samples as seen in Figure 7.a (3C-2P and $3 \mathrm{D}-2 \mathrm{P})$ to meet the $<1 \% /$ year reflectivity rate of change metrics. Those samples showed reflectivity stabilized after 1000 hours with coating intact to the test end, and can meet the Milestone 4.1.2. metrics. Figure 7.b shows that other four samples (3A-2P, 3B-2P, 3NS-2P, 3NS-2NP, and 3E-2P. Sample $3 \mathrm{E}-2 \mathrm{P}$ was taken off the thermal test for a peel test) were not holding the reflectivity and show degradations.

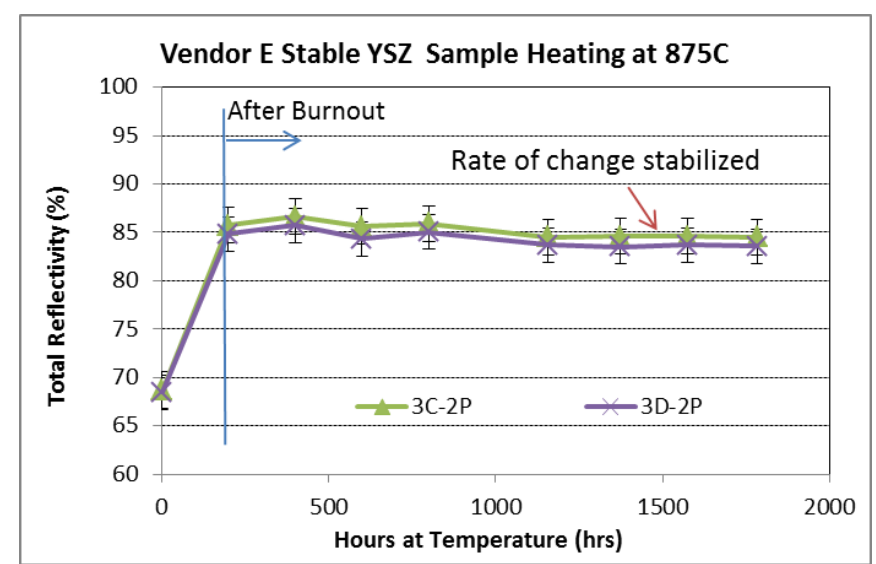

a. Stable YSZ samples

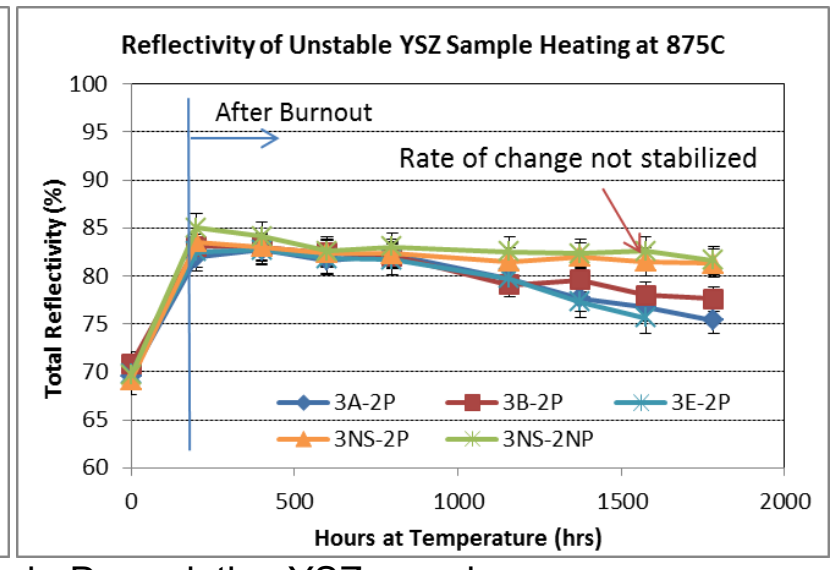

b. Degradation YSZ samples

Figure 7: Samples from Vendor $\mathrm{E}$ - long term durability tests by heating at $875^{\circ} \mathrm{C}$

So far, TST thermal sprayed alumina sample meets the milestone metrics and are the most promising for high-temperature reflective coatings. The three types of YSZsamples from B\&W Vender $E$ also show stable reflectivity after 1,783 heating hours and the potential to meet the milestone metrics of high-temperature reflective coatings. For the long-term usage, we also performed Task 4.1.3 as described in the next section. 


\subsection{Reflective Surface Repair and Reproducibility}

\subsubsection{Information on Coating Regeneration:}

Within Subtask 4.1.3, we discussed the ability for coatings to be regenerated every five to ten years, and the generating methodology for the identified coatings with the relevant coating companies. We visited Chemat on sol-gel coating application procedure, and obtained first-hand coating regeneration information in a face-to-face discussion with TST.

For the sol-gel protected silver coating, reworking the silver coatings needs equipment such as the electroplating bath for electroplated surfaces, or vacuum chamber for PVD coatings. Thereby, the coating rework process cannot be performed in the field, and the reflective components need to be brought back to the coating shop to repeat the whole coating process. After the old coating is removed and surface is properly treated, reapplying the coating in the facility is similar to the original coating process. The cost of regeneration may be higher than the new coating because of the need to scrap the old coating and to prepare the surface.

We discussed the high-temperature coating repair and regeneration with a TST representative. Certain thermal sprayed coatings may be reparable on-site, depending on the coating type. In that way, the local coating damage may be reparable economically without disassembly or reassembly of the receiver. Regeneration of the ceramic in the shop has been investigated by TST. They use mostly mechanical methods to strip the used coating. Coating removal by a chemical agent may be viable for less effort.

In general, the coating can be maintained and repaired either on site or back at the coating facility. However, the cost for reapplying coating has to be investigated separately for specific coatings based on service life and the substrate reprocessing requirements. No general information on regenerative cost is available at this moment.

\subsubsection{Coating Peel Test:}

The bond quality was assessed using standard test methods for measuring adhesion by tape-peel test, a procedure described in ASTM Standard D3359-97. To test adhesion, the sample is scored through the film of interest, a pressure sensitive tape is applied over the test area, then the tape is removed at an angle as close to $180^{\circ}$ as possible. The standard calls for one of two different methods that dictate the scoring pattern to be used. Method A, the X-cut tape test, is intended to be used in the field or on thicker samples. In this method, two scores are made, intersecting near the middle with the inner angle between $30^{\circ}$ and $45^{\circ}$. Method $\mathrm{B}$, the cross-cut tape test, is more appropriate for lab settings and thinly coated $(<125 \mu \mathrm{m})$ samples. Method B calls for multiple cuts to be made in the film in a cross-hatch pattern with the spacing determined by the film thickness. After the cuts are made, and the tape is applied and removed, the sample is qualitatively rated on a scale of 0 (most material removed) to 5 (no material removed). 
Peel tests were performed on a sol-gel protected Ag-coating sample, PVD silver-coating sample, gold reflective sample, and an Alanod MIRO-SUN® sample for assessing the reliability of the intermediate-temperature specular reflective surfaces. Selected samples with thermal-sprayed ceramic coatings from TST and B\&W vender $E$ were also tested. Because of the thickness and hardness of the thermal-sprayed coating, cuts on these samples were made with a low-speed diamond saw. Some chipping of the alumina thermal-spray coating was induced by the diamond saw and may have contributed to material removal from the Haynes sample tested. No specific ASTM Standard may be applied to the ceramic coating because of its brittle mechanical property. The testing results were only a relative comparison of the quality of the ceramic coatings among the selected samples. The sol-gel and PVD samples had been exposed at $150^{\circ} \mathrm{C}$ for 1,922 hours prior to adhesion testing. All other samples were tested as received. Results from the adhesion test are reported in Table 5.

Table 5. ASTM D3359-97 adhesion test results

\begin{tabular}{clll}
\hline Sample & Sample Description & Rating & \% Area Removed \\
\hline ID & Test Method $A$ \\
SS1 & Alumina on Stainless & 5A & None \\
SS4 & YSZ on Stainless & 4A & Trace peeling along incisions \\
SS5 & BC/MC on Stainless & 4A & Trace peeling along incisions \\
H2 & Alumina on Haynes & 3A & Jagged removal along incisions up to 1/16 in. \\
H3 & YSZ on Haynes & 4A & Trace peeling along incisions \\
H4 & BC/MC on Haynes & 4A & Trace peeling along incisions \\
\hline \multicolumn{5}{c}{ Test Method B } \\
Sol-Gel Protected Ag- \\
5 & Coated & 4B & $<5 \%$ \\
O-4P & PVD Ag-Coated & $4 B$ & $<5 \%$ \\
O-1G & PVD Gold-Coated & $5 B$ & None \\
A1 & Alanod MIRO-SUN & 5B & None \\
\hline
\end{tabular}

\section{Additional Outcomes and Lessons Learned from the Coating Development}

Lessons were learned in screening reflective materials to meet the optical requirements of the prototype and commercial receivers. Those lessons and discoveries in the coating studies are documented in this section as references for future coating application.

\subsection{Long-term test of intermediate-temperature specular-reflective coatings}

Among the many specular-reflective coatings investigated, we identified two coating methods including sol-gel protected silver coating and PVD-gold coating that have the potential to satisfy the optical and durability requirements of the actively-cooled reflective heat-shield design. Silver has the best solar-weighted reflectance of any metal surface and can be easily electroplated to stainless steel surfaces including complex geometries like the tube flare zone in the reflective-flare design. But unprotected silver surfaces readily oxidize in air, especially at elevated temperatures. To guard against silver oxidation, a protective, transparent top coating must be applied to the reflective 
silver coating. CVD deposited thin films of silica have been used to protect front surface silver mirrors with some success and recent developments in silica sol-gel technology have led to the development of sol-gel methods that produce thin films of silica $(<200$ $\mathrm{nm}$ ) to be successfully applied as coatings to protect against oxidation of metals at elevated temperatures and maintain optical reflectance [2,3]. In addition, sol-gel dipcoating methods are practical alternatives to conventional CVD processes, especially for coating large, complex geometries of receiver tube panels.

Intermediate-temperature specular reflective solutions are listed in Table 6. Besides the sol-gel method applied by NREL and Chemat that was introduced in the previous section, Alanod MIRO-SUN®, PVD-silver coating with $\mathrm{SiO}_{2}$ protective layer, gold coating samples were also tested in this project. We also investigated the silver glass mirrors used in the secondary concentration [4], and concluded that its temperature range, humidity tolerance, and attachment substrate are unsuitable for the reflective shield requirements in our receiver design and operating condition.

Table 6. Coating material options and methods for the entrance (flare) section.

\begin{tabular}{lllll}
$\begin{array}{l}\text { Coating } \\
\text { Candidates }\end{array}$ & $\begin{array}{l}\text { Coating } \\
\text { description }\end{array}$ & $\begin{array}{l}\text { Reflectivity } \\
\text { S Specularity }\end{array}$ & $\begin{array}{l}\text { Coating Process/ } \\
\text { Application } \\
\text { Conditions }\end{array}$ & $\begin{array}{l}\text { Usability for Solar } \\
\text { Receiver }\end{array}$ \\
\hline $\begin{array}{l}\text { NREL/Chem } \\
\text { at }\end{array}$ & $\begin{array}{l}\text { Sol-Gel } \\
\text { Protected Silver }\end{array}$ & $95 \% / 82 \%$ & $\begin{array}{l}\text { Specular stability to be } \\
\text { improved at } 150^{\circ} \mathrm{C}\end{array}$ & $\begin{array}{l}\text { Improve reflectivity } \\
\text { rate of change }\end{array}$ \\
\hline $\begin{array}{l}\text { Alanod } \\
\text { MIRO-SUN@ }\end{array}$ & $\begin{array}{l}150^{\circ} \mathrm{C} \text {, tested at } \\
\text { NREL }\end{array}$ & $\begin{array}{l}>90 \% / 87 \% \\
\text { (total) }\end{array}$ & $\begin{array}{l}\text { Apply to flat surface. } \\
\text { [5] }\end{array}$ & $\begin{array}{l}\text { Adhesive to join } \\
\text { MIRO-SUN sheet } \\
\text { to SS substrate }\end{array}$ \\
\hline Vendor A & $\begin{array}{l}\text { PVD Protected } \\
\text { Silver }\end{array}$ & $>95 \% / 95 \%$ & $\begin{array}{l}\text { Long term thermal } \\
\text { stability }\end{array}$ & $\begin{array}{l}\text { Active-cooled heat } \\
\text { shield reflector }\end{array}$ \\
\hline Gold coating & $\begin{array}{l}\text { Electroplating } \\
\text { or PVD coating }\end{array}$ & $87 \% / 85 \%$ & $\begin{array}{l}\text { Good long-term } \\
\text { stability below } 200^{\circ} \mathrm{C} \text {. }\end{array}$ & $\begin{array}{l}\text { Active-cooled heat } \\
\text { shield reflector }\end{array}$ \\
\hline $\begin{array}{l}\text { Sliver glass } \\
\text { mirror [4] }\end{array}$ & $\begin{array}{l}\text { Electroplating of } \\
\text { Ag with backing }\end{array}$ & $95 \% / 95 \%$ & $\begin{array}{l}\text { Tested up to } 80^{\circ} \mathrm{C} \\
\text { depending on the film } \\
\text { coating }\end{array}$ & $\begin{array}{l}\text { Active-cooled heat } \\
\text { shield reflector }\end{array}$ \\
\hline
\end{tabular}

We built Alanod reflective-flare tubes and tested at the NREL solar furnace for the flux spreading effects. The flux spreading by a specular-reflective mirror surface can be very effective; however, the adhesion of Alanod to the substrate for the absorber flare section can be a challenge for application in a large-scale particle receiver. We conducted coating studies with different coating materials and methods as listed in Table 6 . The outcome of the coating study indicates that achieving a stable specularreflective surface under elevated temperature in outdoor conditions could be challenge. The most promising method that withstood the long-term thermal testing is the aforementioned sol-gel protected Ag-coating.

\subsubsection{Alanod Performance Characterization}

MIRO-SUN® [5], a highly reflective material produced by Alanod, was studied for adhesion to a substrate surface as a specular-reflective heat shield. We considered the methods to adhere this material to the flare section of the receiver tube. Stringent tests have been performed on Alanod MIRO-SUN® reflector for outdoor usage by the manufacturer. Total reflectivity in the visible range stated for outdoor use is $90.6 \%$ 
reported in the Alanod brochure [5] and measured by the NREL Optical Material Lab. Alanod has stated verbally that the material can operate to a maximum temperature of $200^{\circ} \mathrm{C}$, and can undergo continuous use at temperatures up to $160^{\circ} \mathrm{C}$.

Figure 8.a shows the Alanod MIRO-SUN® reflective layer diagram with a top sol-gel coated $\mathrm{SiO}_{2}$ layer [4]. MIRO-SUN® has good optical properties in the VIS and solar spectra. Good abrasion resistance and adhesion properties support the corrosion resistance shown in accelerated and outdoor weathering. Figure $8 . b$ is a picture of the reflective surface after long-term heating (1,750 hours). Minor surface crack lines, which appeared after the long term thermal test, may explain the specular reflectivity change in Figure 9.b.

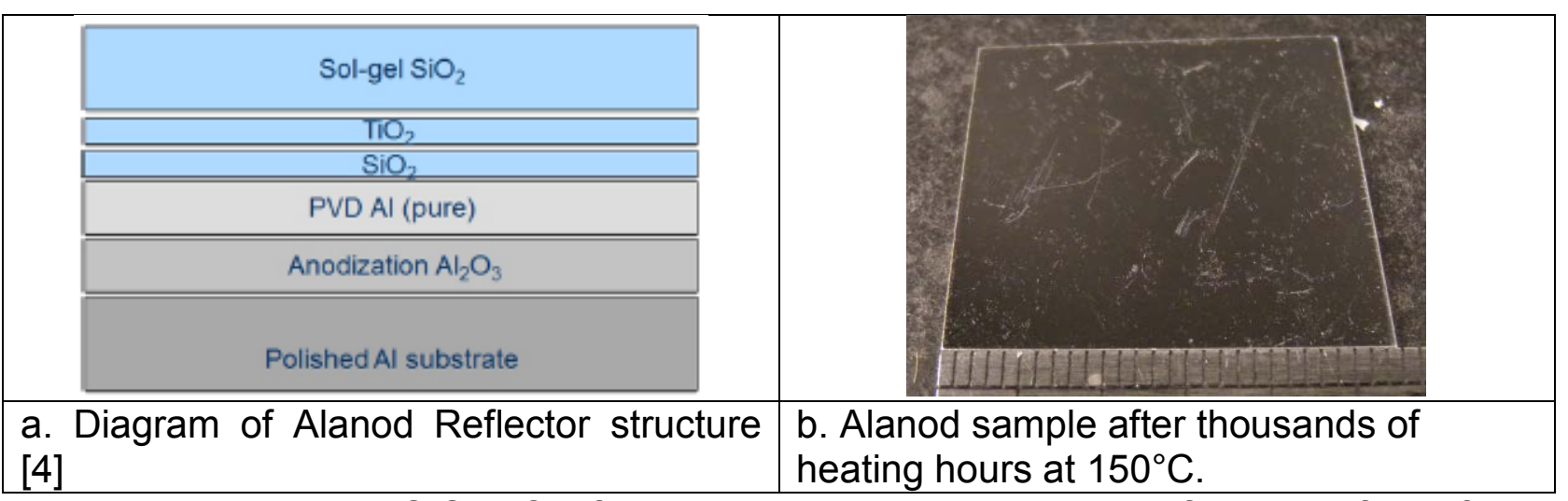

Figure 8. Alanod MIRO-SUN® reflective layer composition and the reflective surface after long-term heating (1,750 hours).

Figure 9 shows the long-term thermal testing results at NREL by heating the sample to $150^{\circ} \mathrm{C}$ inside a furnace. The results are consistent with the accelerated aging tests performed by Alanod, who have demonstrated a $1 \% / y e a r$ degradation rate.

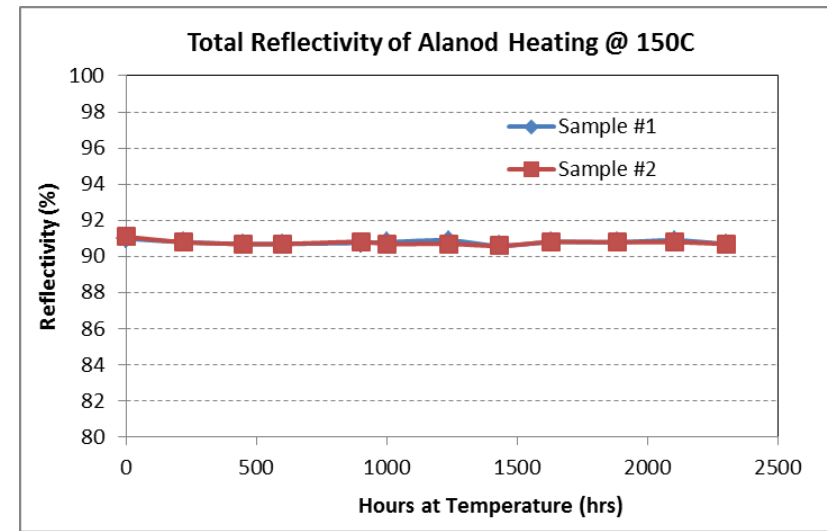

a. Alanod total reflectivity with heating hours.

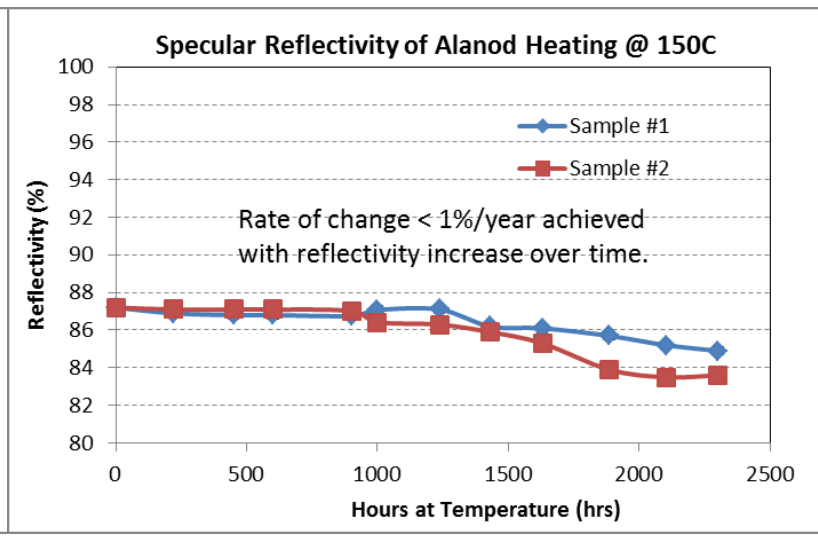

b. Alanod specular reflectivity with heating hours.

Figure 9. Long-term durability test of Alanod reflectivity at $150^{\circ} \mathrm{C}$ heating hours.

Figure 9 indicates that the specular reflectivity of Alanod is very stable in the first 1,000 hours, and then decays gradually over the long-term thermal testing, at a much slower rate than NREL and Chemat sol-gel coatings. The information collected from Alanod indicates that the reflectivity of the absorber's inner entrance reflective surface does not degrade by more than $30 \%$ over the 30 -year service life by assuming a constant 
degradation rate, which conditionally satisfies reflective surface life requirements. However, further sensitivity studies are needed to investigate the impact of decreasing reflectivity of the reflective material over the receiver life and adherence reliability when attached to a substrate, even though the Alanod reflectivity degradation rate may vary over the time. The specular reflectivity over 1,000 hours shows obvious degradation, although it holds better than the PVD sample and NREL sol-gel coated samples. The stability of the Alanod sol-gel silica top protective layer suggests that further improvement in the sol-gel silica protected silver-electroplated samples may be possible with additional experience and optimization by Alanod or Chemat.

\subsubsection{B\&W Vender A PVD-Au Coating Evaluation}

One promising heat shield solution involves precious metal coatings. In FY14, NREL analyzed gold and silver coatings for high-temperature reflective surfaces for temperatures up to $1,000^{\circ} \mathrm{C}$. Thermodynamic analysis using HSC software of the chemical stability between gold, silver, and the substrate elements (nickel, iron, chromium) showed that these elements are very chemically stable with respect to each other at high temperatures. Analysis also showed that gold is stable in air at all operating temperatures as a pure metal. These coatings were promising candidates because they are easy to apply using electrolytic deposition and this process is scalable to coat large pieces with complex shapes [6, 7].

Previously, gold and silver coatings were electroplated onto stainless steel and Inconel substrates and tested for durability. Sample reflectivity was measured at ambient temperature. The samples were heated to $500^{\circ} \mathrm{C}$ in air to assess their durability. Samples that were heated to $500^{\circ} \mathrm{C}$ for just a few days degraded significantly. Oxidation of the reflecting surface was clearly evident. Surface analysis of the samples indicated that nickel from the substrate material had diffused through the gold or silver layer to the surface and oxidized to nickel oxide (NiO). To avoid the nickel diffusion into the gold layer, lowering the application temperature is critical [8,9]. Figure 10 shows the long-term stability of the gold coating after 1,250 -hour testing at $200^{\circ} \mathrm{C}$. Both the total reflectivity and the specular reflectivity stabilized after 1,000 hours according to the testing data shown in Figure 10. The durability of the specular reflectivity with the PVDgold coatings may need long-term verification.

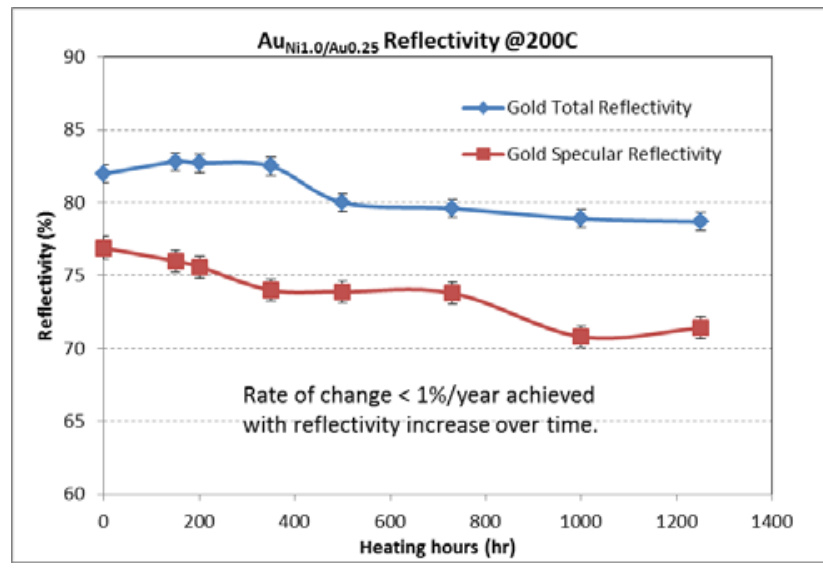

Table 7. Reflectivity measurement of B\&W Vender A PVD gold sample.

Figure 10. Gold coating thermal stability testing

\begin{tabular}{|c|c|c|c|c|}
\hline \multirow{2}{*}{$\begin{array}{l}\text { Sample } \\
\text { ID }\end{array}$} & \multicolumn{2}{|c|}{ Initial Ref. } & \multicolumn{2}{|c|}{$257 \mathrm{hr}$ at $150^{\circ} \mathrm{C}$} \\
\hline & Tot. & Spec. & Tot. & Spec. \\
\hline $0-1 \mathrm{G}$ & $87.6 \%$ & $87.2 \%$ & \multicolumn{2}{|c|}{ Peel test } \\
\hline $\mathrm{O}-2 \mathrm{G}$ & $87.7 \%$ & $87.1 \%$ & $86.5 \%$ & $85.9 \%$ \\
\hline O-3G & $87.7 \%$ & $87.3 \%$ & $86.4 \%$ & $85.9 \%$ \\
\hline O-4G & $87.7 \%$ & $87.3 \%$ & $86.6 \%$ & $86.1 \%$ \\
\hline $0-5 \mathrm{G}$ & $87.7 \%$ & $87.2 \%$ & $86.5 \%$ & $86.0 \%$ \\
\hline $0-6 \mathrm{G}$ & $87.6 \%$ & $87.1 \%$ & $86.2 \%$ & $85.7 \%$ \\
\hline & & & & \\
\hline
\end{tabular}
shows long-term stability of gold coating. 
To improve gold coating specular reflectivity, we recently obtained samples of PVD gold deposited on stainless steel substrate supplied by B\&W vender A and tested the initial reflectivity and the reflectivity after heating at $150^{\circ} \mathrm{C}$ for 257 hours. The advantage of the PVD Au-coating is the ability to obtain higher specular reflectivity than the electroplated Au-coating. Short-term testing results are promising with measured specular reflectivity exceeding $85 \%$ after 257 hours at $150^{\circ} \mathrm{C}$. The long-term stability of PVD gold-coated samples has not yet been obtained because of the short sample delivery and testing time; however, the relative stability of electroplated Au-coated samples suggests that the long term performance may be favorable.

Although we are only one milestone short of meeting the rate of change for specular reflectivity in Table 1, the testing results for Alanod- and gold- coated surfaces are encouraging for the possibility of meeting this milestone. For instance, applying Alanod sol-gel method on a silver coating surface and improving the sol-gel structure for the long-term thermal cycle requirement may stabilize the specular reflectivity for long-term usage. Gold coating stability in Figure 10 is promising; if the initial total reflectivity could be further improved and the long-term stability testing would be continued.

\subsection{Subtask 4.1.2: Additional High-Temperature Coating Test and Summary}

This subtask identified coating methods and compositions that meet the property and performance requirements for the high-temperature diffuse-reflective surfaces. This high-temperature reflective surface does not require high specularity because flux distribution is less sensitive to the specular reflection. This subtask was focused on total reflectivity and coating stability through high-temperature thermal cycles.

\subsubsection{B\&W Vendor C}

B\&W worked with Vendor C in the development of electroplated gold and rhodium (Rh) coatings for high-temperature potential. With the wide wavelength range of $400 \mathrm{~nm}$ to 2 $\mu \mathrm{m}$, it is difficult to determine a coating that provides the desirable reflectivity properties throughout the spectrum. This vendor supplied both gold and rhodium coatings. The gold samples have better reflectivity towards the upper end of the range while rhodium is better at the lower range than gold but inferior at the upper end than what is required. With both of these coatings, inter-metallic diffusion is a concern and therefore an intermediate coating is applied to try and prevent intermetallic diffusion. Besides the wavelength range and diffusion concerns, there are also concerns with high temperature endurance due to the intermetallic diffusion at high temperature $\left(>500^{\circ} \mathrm{C}\right)$. $\mathrm{B} \& \mathrm{~W}$ is continuing to test the coatings that have already been provided along with possibly developing some additional samples to obtain even better optical data. The initial reflectivity data as measured by NREL is summarized in Table 8.

Table 8. Gold and Rhodium coating reflectivity measurements.

\begin{tabular}{|c|c|c|}
\hline Coating Type & $\begin{array}{c}\text { Total Reflectivity - As } \\
\text { Received (\%) }\end{array}$ & $\begin{array}{c}\text { Specular Reflectivity - As } \\
\text { Received (\%) }\end{array}$ \\
\hline Gold - Intermediate Coat I & 84 & 65 \\
\hline Gold - Intermediate Coat II & 84 & 65 \\
\hline Rhodium - Intermediate Coat I & 67 & 51 \\
\hline Rhodium - Intermediate Coat I & 79 & 74 \\
\hline
\end{tabular}


Table 8 shows that the electroplated $\mathrm{Au}$ and $\mathrm{Rh}$ coating could not meet either intermediate-temperature. At high-temperature $\left(>500^{\circ} \mathrm{C}\right)$, both coatings showed discoloration maybe due to the intermetallic diffusion in the thermal testing.

\subsubsection{B\&W Vendor $D$}

This vendor provided B\&W sample coupons that were coated with alumina and YSZ based ceramic coatings. The YSZ based samples looked promising during initial testing so further testing was performed. The samples have undergone both cyclic and additional long term endurance testing. Cyclic tests performed at $75^{\circ} \mathrm{C}-400^{\circ} \mathrm{C}$ and $100^{\circ} \mathrm{C}-700^{\circ} \mathrm{C}$ on these samples did not show any degradation or delamination. However, long term exposure at $875^{\circ} \mathrm{C}$ has resulted in the delamination of the coated layer after 1,100 hours of exposure. The delamination of the coating may be due to various factors such as the different TEC issue of the coatings versus the metal substrate similar to TST alumina coatings. While the YSZ based coating layer appears to be intact itself, it was not able to remain adhered to the substrate. The visual observation indicates that delamination was likely caused by oxidation from exposed edges. Since we have other stable alternative samples, no further efforts were made to prevent the oxidation and improve adherence on Vender D coatings.

\subsubsection{High-Temperature Coating Summary}

Several types of coating samples have been tested to verify the coating materials and methods that are potentially applicable to the prototype and product receiver. Those coating methods and testing outcomes are summarized in Table 9.

Table 9. Summary of the sample sources and the coating solutions in the project.

\begin{tabular}{|c|c|c|c|c|}
\hline $\begin{array}{l}\text { Sample } \\
\text { Source }\end{array}$ & Coating Systems & $\begin{array}{l}\text { Temperature } \\
\text { Application }\end{array}$ & $\begin{array}{l}\text { Screening } \\
\text { Pass/Fail }\end{array}$ & $\begin{array}{l}\text { Usability for } \\
\text { Solar Receiver }\end{array}$ \\
\hline Vendor B & $\begin{array}{c}\text { Diffused Chrome } \\
\text { Chrome-silica } \\
\text { coating }\end{array}$ & $\begin{array}{c}\text { High } \\
\text { Temperature } \\
\left(900^{\circ} \mathrm{C}\right)\end{array}$ & Failed & $\begin{array}{l}\text { Disbond from } \\
\text { substrate }\end{array}$ \\
\hline Vendor C & $\begin{array}{l}\text { Au and } \mathrm{Rh} \text { with } \\
\text { refractory undercoat }\end{array}$ & $\begin{array}{c}\text { High or Low } \\
\left(150^{\circ} \mathrm{C}-900^{\circ} \mathrm{C}\right)\end{array}$ & $\begin{array}{l}\text { Not meet } \\
\text { reflectivity }\end{array}$ & $\begin{array}{l}\text { Unstable for } \\
\mathrm{T}>500^{\circ} \mathrm{C}\end{array}$ \\
\hline TST & $\begin{array}{c}\text { Thermal Sprayed } \\
\text { Alumina }\end{array}$ & High $\left(900^{\circ} \mathrm{C}\right)$ & Pass & $\begin{array}{l}\text { Can be scaled up } \\
\text { and usable. }\end{array}$ \\
\hline Vendor D & $\begin{array}{c}\text { Alumina, Zirconia, } \\
\text { Tribolite }\end{array}$ & High $\left(900^{\circ} \mathrm{C}\right)$ & Failed & $\begin{array}{l}\text { Not usable in } \\
\text { receiver for long- } \\
\text { term service }\end{array}$ \\
\hline Vendor E & Alumina, TBC's & High $\left(900^{\circ} \mathrm{C}\right)$ & $\begin{array}{l}\text { Two types } \\
\text { Pass }\end{array}$ & Two stable types \\
\hline Vendor $\mathrm{F}$ & $\begin{array}{l}\text { Oxide scale on } \\
\text { Haynes } 224\end{array}$ & $\begin{array}{c}\text { High or Low } \\
\left(150^{\circ} \mathrm{C}-900^{\circ} \mathrm{C}\right)\end{array}$ & Failed & $\begin{array}{l}\text { Not usable in } \\
\text { receiver }\end{array}$ \\
\hline $\begin{array}{l}\text { Vendor G } \\
\text { (ATFI) }\end{array}$ & $\begin{array}{l}\text { Al-O-P with C } \\
\text { encapsulation }\end{array}$ & $\begin{array}{c}\text { High or Low } \\
\left(150^{\circ} \mathrm{C}-900^{\circ} \mathrm{C}\right)\end{array}$ & Failed & $\begin{array}{l}\text { Spalling and } \\
\text { delamination }\end{array}$ \\
\hline Swain Tech & $\begin{array}{l}\text { Ceramic paint and } \\
\text { coating }\end{array}$ & High $\left(900^{\circ} \mathrm{C}\right)$ & Failed & Not usable \\
\hline Alfa Aesar & $\begin{array}{l}\text { Aerosol } \mathrm{Al}_{2} \mathrm{O}_{3} \text { or } \\
\mathrm{ZrO}_{2} \text { Refractory } \\
\text { Paints }\end{array}$ & High $\left(900^{\circ} \mathrm{C}\right)$ & Failed & $\begin{array}{l}\text { Not usable in } \\
\text { receiver for long- } \\
\text { term service }\end{array}$ \\
\hline
\end{tabular}


Table 9 shows the sample sources and the coating solutions studied in the project. We focused the testing work on the samples that passed the initial screening results. Those samples that passed the initial screening were also verified for their long-term stability. Table 9 also shows the lessons learned from our coating development that may be referable in a future search for more successful methods that could be used in a cavity receiver with a large aspect ratio for flux spreading purposes.

$B \& W$ worked with NREL to obtain a variety of coating samples for reflective surfaces in various sections of the particle receiver. Several coating suppliers have been approached by B\&W and have been working on alternative solutions with the intent of delivering samples that would be able to meet the specified reflective properties. Based on test results to date, the most promising coatings have been ceramic based coatings for the mid-section of the receiver tube and protected silver, rhodium or gold based coatings for the front section of the receiver tube where specular reflective properties have been important. The mid-section of the absorber tube needs to maintain high reflectivity at temperatures as high as $1,000^{\circ} \mathrm{C}$. Several coating methods in Table 9 may be applicable to this section as long as the allowable temperatures are satisfied. Other variables that have been factored into the various coatings include: selection of the substrate, method and degree of polishing, use of sealants and bond coats, consideration of initial application methods and maintainability as well as endurance at the desired temperatures and transient operating conditions.

\section{Phase 4 Summary}

Coating development and long-term proof of applicability could take significant time and effort. To meet the particle receiver coating needs in this interim period, we focused on known technology development and screened applicability for assisting flux spreading over the absorber tube under the designed temperature in the particle receiver.

- Sol-Gel coating, especially that applied by Chemat, shows good long-term usability for total reflectivity, but initial specular reflectivity and long-term specular reflectivity stability need further improvement. The PVD silver coated surface protected with $\mathrm{SiO}_{2}$ developed micro cracks during the long-term endurance test, likely due to thermal cycling stress.

- Thermal-sprayed surfaces can have high diffuse reflectivity, and are stable for temperatures to $1000^{\circ} \mathrm{C}$. High-temperature ceramic sprayed coating may be applicable for the high-diffusive reflecting surface. These coatings have proven based on usage in gas turbine blades.

- Thermal-sprayed ceramic coatings cannot achieve specular reflection after lapping, or grinding. However, the thermal-sprayed coating can have high diffuse reflectivity with stable bonding for temperatures between $1,000^{\circ} \mathrm{C}$ and $1,100^{\circ} \mathrm{C}$ according to the coating specification by TST. The long-term thermal test of a thermal-sprayed alumina coating at $875^{\circ} \mathrm{C}$ shows excellent stability.

- The thermal sprayed YSZ coating samples developed by Vender E were subjected to $>1,780$-hour thermal test and are performing well.

- None of the high-temperature paints, including ATFI Cerablak coatings, can survive thermal test above $875^{\circ} \mathrm{C}$. 


\section{Overall Project Outcomes and Technical Advancement}

The SunShot particle receiver with integrated heat exchanger project progressed from the originally proposed particle-system concept into a pre-commercial thermal-system design by working with our industry partner, The Babcock \& Wilcox Company (B\&W), and universities. The team successfully developed a fluidized-bed CSP system and heat exchanger designs for various power cycles. When the challenges in particle heat transfer and tube coating manufacturability arose, NREL proactively began investigating an alternative receiver configuration. The alternative configuration avoids using reflective coatings while simultaneously simplifying receiver module fabrication. This section will present the major results out of the project relevant to our final deliverables.

\subsection{Fluidized-Bed CSP Configuration and Project Final Deliverables}

4.1.1. System Configuration: The SunShot near-blackbody (NBB) particle receiver and integrated system project has made significant progress on the preliminary system and component designs (shown in Figure 11), and provided an in-depth understanding of receiver design elements, while advancing modeling/testing tools and generating information in the area of materials development.



Figure 11. Schematic of the FB-CSP Thermal System Integration.

This project, together with the previous NREL project, has introduced the concept of a fluidized-bed (FB) CSP system and performed feasibility assessments, design, engineering, and modeling of the associated particle-TES subsystem, FB-heat exchangers, periphery receiver components, and of the system as a whole. The project has primarily focused on the development of a NBB enclosed particle-receiver including the design approach and materials needs, to yield a viable high-temperature receiver design. The successful implementation of a solid particle receiver (SPR) therefore aims to enable FB-CSP plants to incorporate higher-temperature advanced power cycles for efficiency gains. This, coupled with capital cost reduction, provides the potential to significantly reduce the LCOE of CSP plants compared to the current state of the art. 
Additionally, FB-heat exchangers provide the means to achieve efficient heat transfer between particles and working fluids that would tie into the power cycles including subcritical and supercritical steam cycles, as well as advanced cycles such as the supercritical- $\mathrm{CO}_{2}\left(\mathrm{~s}-\mathrm{CO}_{2}\right)$ power cycle, or gas-turbine combined cycle (GTCC). Technology and knowledge developed within this project demonstrates the promise that an SPR based system holds over the current state-of-the-art molten-salt based CSP systems which continue to be of interest to our commercial partners.

4.1.2. Project Deliverable Status: The original deliverables consist of (1) the design of a particle-receiver (2) the fabrication of a prototype receiver with on-sun testing, and (3) a preliminary design of the FB-CSP system:

- With respect to Final Deliverable 1, we did a thorough design study, and analyzed the particle receiver design to meet the design metrics of $800^{\circ} \mathrm{C}$ particle-exit temperature and a thermal efficiency of $\geq 90 \%$. The analysis indicates that the product receiver design could meet the cost goal of $\$ 150 / \mathrm{kW}_{\text {thermal, }}$ with further efforts needed to meet the service lifetime after the design approach is finalized.

- Due to reflective material hurdles, tasks in the last phase were redirected toward reflective material development rather than prototype fabrication and testing. As such, we were unable to fabricate the prototype receiver and conduct the on-sun test according to Final Deliverable 2. However, we proposed an alternative receiver design that would avoid using reflective coating materials and help overcome the potential particle heat transfer deficiency. The development status of the current project and proposed future approach are explained in this report.

- Final Deliverable 3, a preliminary design of the FB-CSP thermal system integrated with different power cycles, was satisfactorily met by leveraging B\&W's industry experience in fluidization technology. The project successfully developed the FB-CSP system configuration and integration with heat exchangers for the conventional steam-Rankine power cycle and advanced highefficiency power cycles. B\&W performed detailed system analysis with the process flow diagrams of three power cycles, heat and mass balances, critical components sizing and layout, performance analysis, and cost estimations.

Several modeling and testing tools were developed to analyze and verify the receiver design and performance. We investigated intermediate- and high-temperature coatings based on the modified development goals for the last phase. The sol-gel protected silver coating and TST alumina coatings met the performance goals to certain levels.

\subsection{Development of the Near-Blackbody Enclosed Particle Receiver:}

The team has developed a conceptual design of a commercial sized receiver and a preliminary design of the prototype receiver with a water-cooled flare section, assuming successfully development of coating materials and methods. An alternative receiver design that spreads solar flux using a cavity geometric configuration with potential to improve overall heat transfer was proposed to overcome challenges associated with the current design. 


\subsubsection{Receiver Configuration and Design Analysis}

The NBB enclosed particle receiver evolved through a series of configurations based on design efforts and knowledge gained during this project. Initial design efforts evaluated mini-cavity hexagonal tube based arrangements and considered various materials and alternate tube shapes. Due to challenges associated with high temperature coatings in the flare section, the team evaluated various options and shifted to a water-cooled receiver design. The intent was to develop a feasible and affordable design for the prototype with available materials to provide the means to proceed towards building a prototype for testing within the funding constraints. Figure 12.a shows the water-cooled flare design. However, there remained some challenges found with the design that needed further evaluation including hydraulic design for boiling water and the need for high-pressure containment, water jacket structure and fabrication uncertainty, the need to limit heat transfer from hot particles to cooling water to minimize heat duty of the cooling water, and structural issues caused by the large temperature gradients. While all these issues bear certain risks and challenges in design and fabrication of the watercooled jacket and associated receiver feasibility, the highest risks still revolved around coatings and heat transfer to particles. Figure 12.b shows one of the alternate designs that potentially eliminate the need for cooling by lowering heat flux to the surfaces with a more complex tube arrangement.

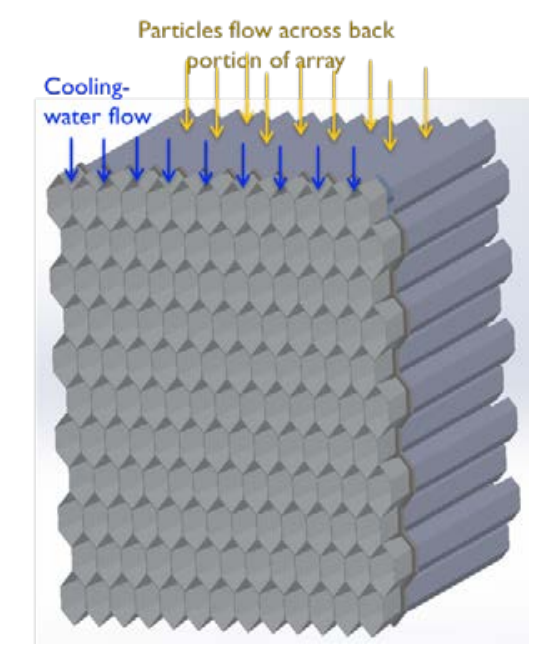

a. DS-3 Cooled flare

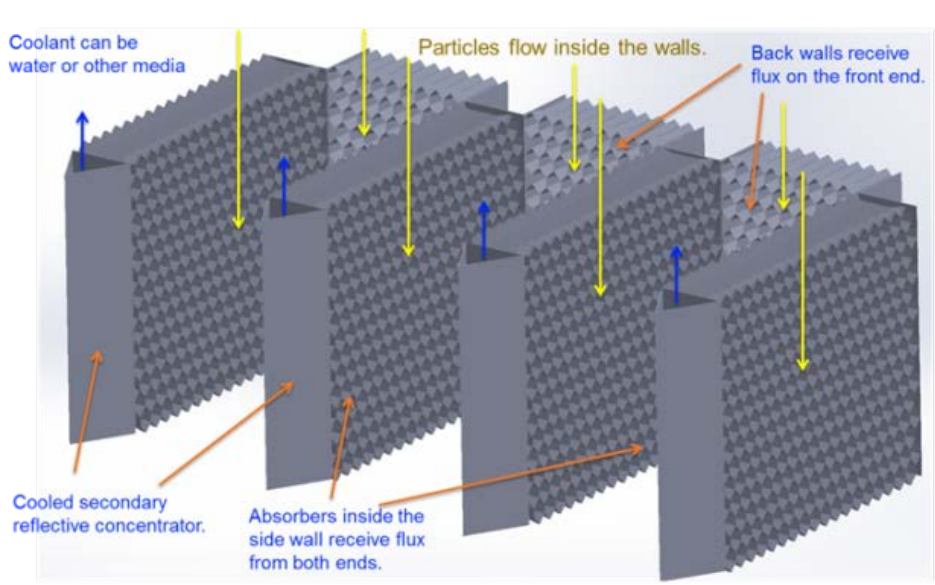

b. DS-4 Embedded-Cavity Design

Figure 12. Receiver design concepts.

During the design phase, B\&W developed a conceptual design of the commercial receiver in order to help guide the development of a prototype that would be representative of a commercial design. The concept led to a prototype design that incorporated important design elements of the commercial receiver and essentially mimicked the commercial scale design. The prototype was designed and sized with the aim of performing on-sun testing and evaluation at Sandia's solar facility. The prototype receiver design shown in Figure 13 is top supported with a removable water jacket/tube assembly. The water jacket is centered on the duct opening with a stud and slotted hole at the 12, 3, 6 and 9 o'clock positions and held to the duct with eight clamps (two per side) to allow independent thermal expansion of the water jacket and particle duct. The 
hex tubes are force fitted inside the water jacket stubs and tack welded to allow individual tube replacement. The receiver would also be equipped with a reflective, air cooled heat shield to protect the structure from light spillage, would be fully insulated, and would have an access panel on the backside of the particle duct for tube inspection.

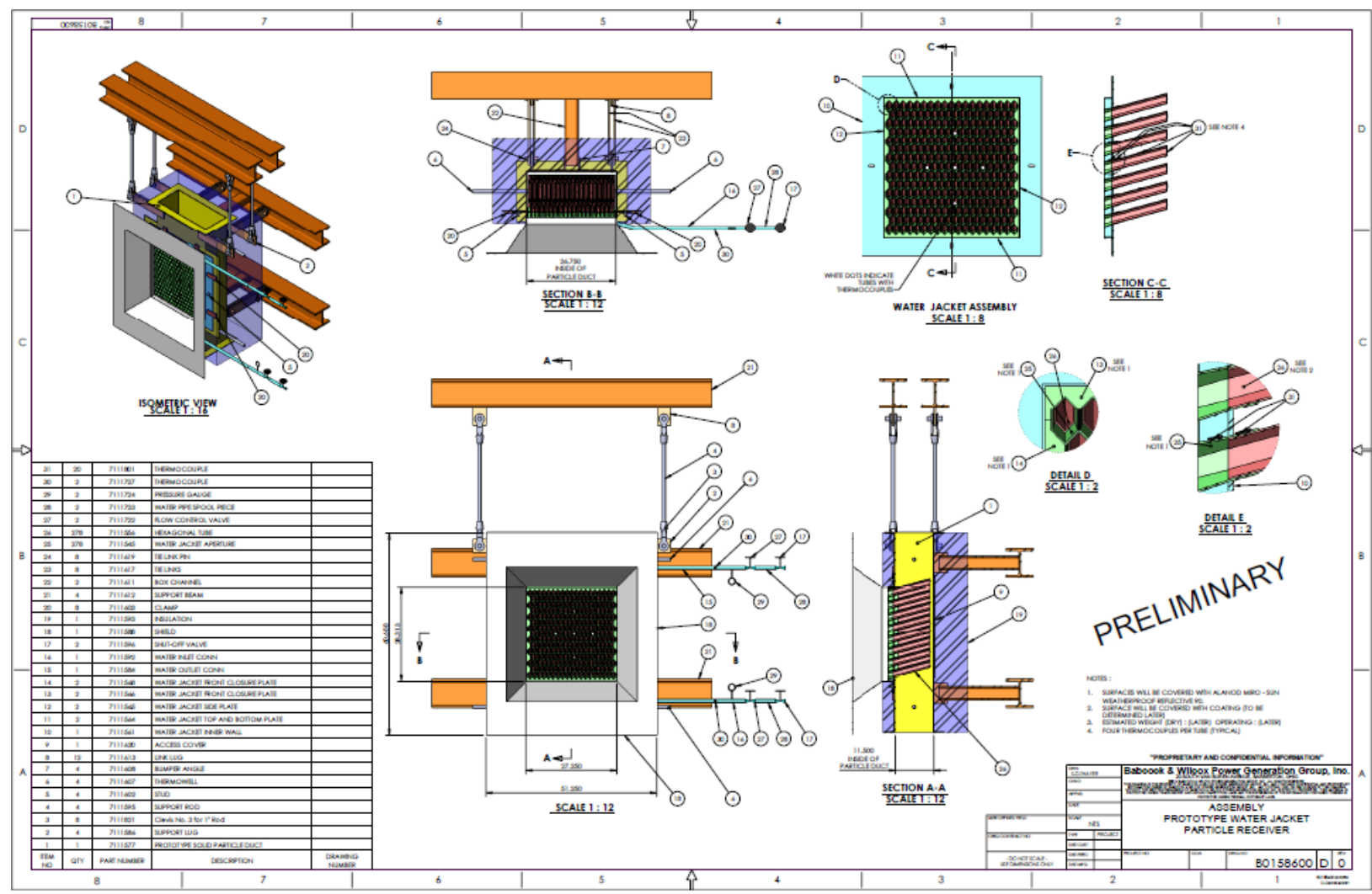

Figure 13. Prototype receiver engineering drawings based on the DS3 water-cooled design.

\subsubsection{Receiver Supporting Structure}

The receiver internal structural design activities focused on the support system for the commercial receiver. The structural design and analysis provided the design configuration for the commercial receiver structural layout to meet structural integrity and thermal/mechanical requirements. The commercial-size receiver size and layout would have been verified after the prototype test, and integrated with the particle dispenser, particle handling, hopper, down comer, solids return valve with TES connection, and tower configuration. As a proof-of-concept design, a preliminary structural arrangement was developed to support all loads from the receiver, particle dispenser, particle handling system components and other associated equipment. This preliminary arrangement, as shown in Figure 14 was laid out to accommodate access requirements to equipment for maintenance.

The allowable stress of steel in the bottom high-temperature section of the receiver is very low and cannot support the receiver from the bottom. The receiver was top supported, i.e., essentially hung from an internal structure, because the temperature at the top of the unit is much lower and at that temperature the steel maintains a high allowable stress. Figure 14.A depicts an arrangement where the horizontal beams at the 
top of the frame support rods that extend down to carry the receiver-module structure. The sectional view of the arrangement shows that the particle dispenser, transition hopper, and bucket lifters sit on top of the truss- support structure. Figure 14.B shows the receiver hanging on the truss-supporting structure (various members removed for clarity). Figure 14.C is the top view of the open-center structural support arrangement that offers the means to accommodate bucket lifters (or possibly a screw feeder) through the center of the structure while still supporting the receiver and peripheral equipment.

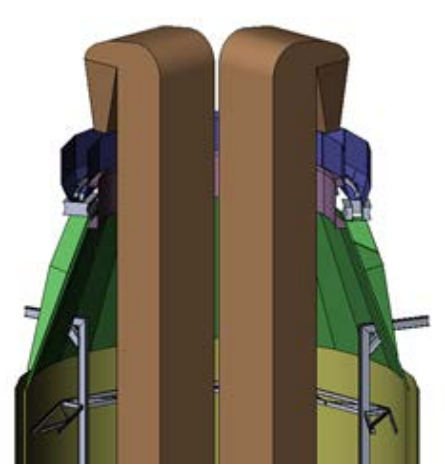

A



B



Figure 14. (A) Potential receiver support structural arrangements for receiver and periphery equipment including bucket lifters, particle dispenser, etc., (B) Sectional view of structural support with receiver peripheral components, (C) Top view of the truss-supporting structural arrangement in $\mathrm{B}$.

Load calculations for the receiver and equipment would need to be completed for the final commercial design. This exercise would include wind and seismic loads per IBC 2009. Barstow, CA USA was selected as the design site because site data from previous solar Molten Salt plant studies is readily available. In addition, consistent design criteria would allow for a fair LCOE evaluation when comparing this technology to Molten Salt systems. As Barstow, CA is a relatively "high seismic" area, a more robust structure is needed to resist the increased seismic loads (a conservative approach).

B\&W worked on other peripheral equipment including the particle-dispensing reserve hopper, distribution, and flow-control systems. Additional details on the particle dispenser, particle handling, hopper, down comer, solids return valve with TES connection, and tower configuration are detailed in the systems description section of this report.

\subsection{Modeling and Testing Tool Development for Design of Prototype and Product Receiver}

To simulate the NBB enclosed particle-receiver performance, we developed a variety of modeling and testing tools, for simulating solar-flux distribution and thermal performance. We tested the flux distribution by incorporating the reflective coating for on-sun testing at NREL's High Flux Solar Furnace (HFSF) and conducted testing of the particle flow and heat transfer on an inclined tube array. This section presents the modeling and testing approach and major results. 


\subsubsection{Modeling Tools and Receiver Performance Simulation}

Figure 15 shows four modeling tools that were used to simulate the receiver design. The tools provide the ability to model a solar field layout, to discretize the absorber tube geometry, to simulate the tube array thermal performance via a high fidelity differential model, and to assess the overall product receiver performance using an integral model for a specific solar field and heliostat aiming strategy. The solar field layout was simulated using NREL's SolarPILOT program as shown in Figure 15.a, which generates heliostat coordinate data as inputs to NREL's SolTrace program to predict the flux distribution on a receiver. Figure 15.b shows an absorber tube modeling program that generates SolTrace elements for simulations which produce absorbed flux boundary conditions that were used in the differential model as illustrated in Figure 15.d. The predicted solar flux distribution on the receiver aperture and performance relations obtained from the differential model are integrated in the integral model as shown in Figure 15.c to assess the overall product receiver performance and operating conditions.

\section{Flux Model | Solar Field/NSTTF Model}



a. Solar field layout and receiver flux distribution modeling by NREL SolarPILOT and SolTrace programs.

Integral Model | Receiver total efficiency
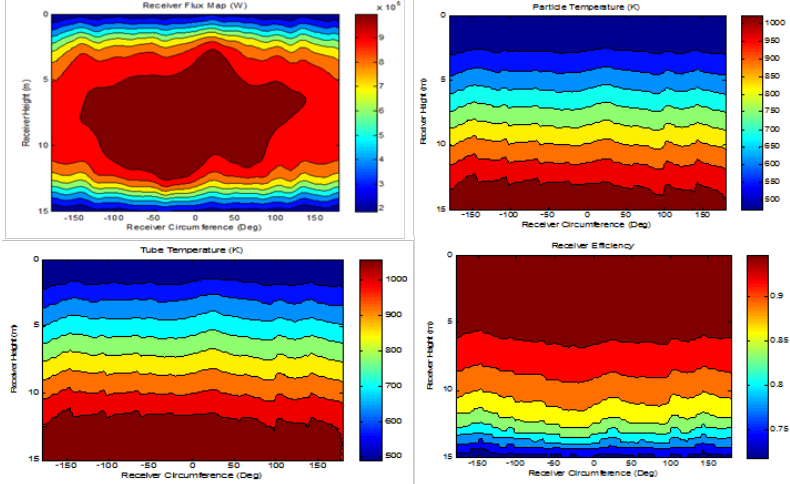

c. Integral model for simulating the overall receiver performance.
SolTrace Model | Elements Generator


b. SolTrace element generator for absorber tube surface flux modeling.

Differential//ntegrated Model | Thermal simulation

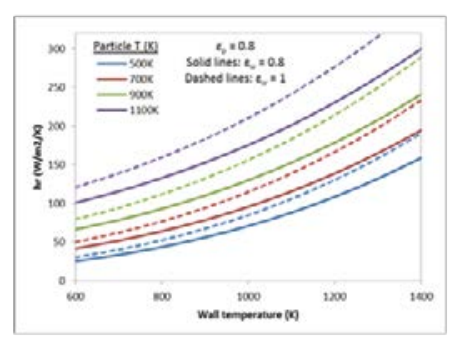

Figure 1 Radiative heat transfer coefficient

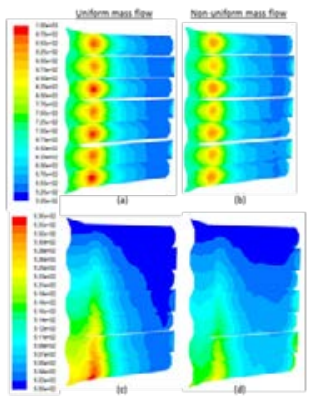

d. High-fidelity differential model to predict the performance for absorber tube array.

Figure 15. Modeling tools for particle-receiver performance simulation.

The modeling procedure starts from the solar field, uses the SolTrace model to predict the flux distribution on a solar absorber tube, and conducts a thermal simulation of the 
tube array performance. The tube array performance modeling results are combined in the integral model to predict the overall receiver performance, thermal efficiency, and operating method.

After heliostat fields were generated by SolarPILOT, all solar flux modeling was conducted using SolTrace by inputting the solar-field file to the SolTrace program. One small, simulating heliostat field generated by SolarPILOT is shown in Figure 16.a with the path of representative rays traced, and the flux distribution is plotted on the receiver aperture in Figure 16.b.

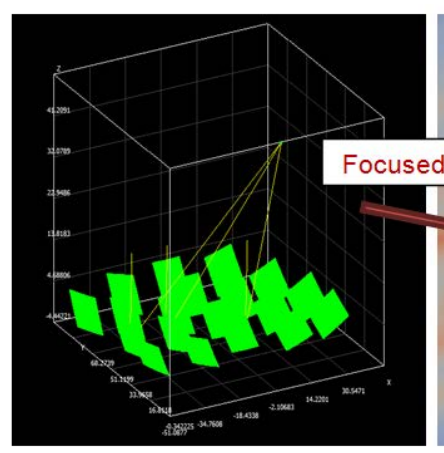

a. Simulating heliostat layout. b. Solar flux on the receiver aperture.
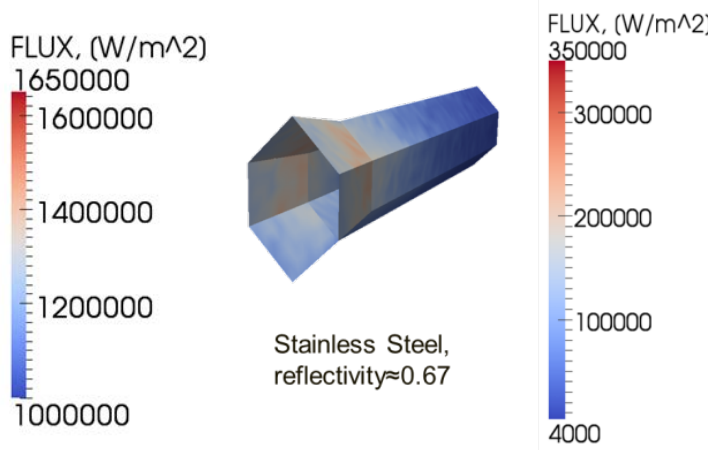

c. One illustration of the tube flux distribution.

Figure 16. Heliostat field used to simulate solar flux on receiver with the path of representative rays traced.

Given the selected heliostat layout, SolTrace performed detailed analysis of the solar flux incident on the receiver absorber tubes. Flux distributions were evaluated over ranges of both optical reflectivity and specularity error for each tube modeled. Optical reflectivities of $10 \%$ to $90 \%$ and specularity error of $0.01-\mathrm{mRad}$ to 1000 -mRadwere evaluated. Figure 16.c shows an exemplary absorbed flux distribution on the tube walls for stainless steel-like reflectivity values of the inner wall. These ranges provide guidance for desirable materials and surface conditions. Optimum properties varied slightly with changes in the geometry, but the trends remained the same throughout all geometries simulated.

Figure 17 plots the natural convection loss with respect to the tube temperature and inclination angle for a single absorber tube. Various inclination angles were investigated to determine how the losses would be reduced with this specific receiver geometry. Figure 17 shows that a horizontal tube incurs roughly three times more heat loss than a vertical tube, depending on the tube wall temperatures.

Previous research [8] shows a decrease in natural convection losses as the angle of inclination increases. This phenomenon is due to buoyancy effects which lead to the trapping of hot air in the top of the cavity above horizontal from the top of the aperture. This trapped air does not participate in the natural convection currents created by the temperature difference, significantly reducing convective losses. For a single tube, natural convection is in the laminar flow regime. An array of tubes as in the NBB receiver design was simulated by CFD. The results indicate that the air penetration into the tube becomes shallower as the surrounding air is heated, and thus the convective 
loss drops as the hot air rises to the top of the receiver. The CFD simulation on a tubular array can be performed for overall thermal performance.

In high-temperature receivers, IR re-radiation is very important to the efficiency because it accounts for the largest percentage of the loss; typically $>50 \%$ of the loss comes from the IR re-radiation. Figure 18 provides the IR re-radiation losses as a function of aperture flux. As shown in Figure 18, IR losses increase rapidly with the tube temperature beyond $800 \mathrm{~K}$. The percentage of the IR loss can be reduced by increasing the aperture flux, because the tube absorbs more solar heat relative to the amount of IR heat loss. Hischier et al. [10] experimentally measured itemized losses for a singlecavity cylindrical tube with a $2.1 \mathrm{MW} / \mathrm{m}^{2}$ aperture flux. The results from Hischier et al. were plotted alongside and are given as a range based on the uncertainty of the average temperature pulled from their data. Infrared re-radiated loss is high at low aperture flux $\left(1 \mathrm{MW} / \mathrm{m}^{2}\right.$ vs. $\left.2 \mathrm{MW} / \mathrm{m}^{2}\right)$, and it increases rapidly after the absorber tube temperature is above $800 \mathrm{~K}\left(527^{\circ} \mathrm{C}\right)$.

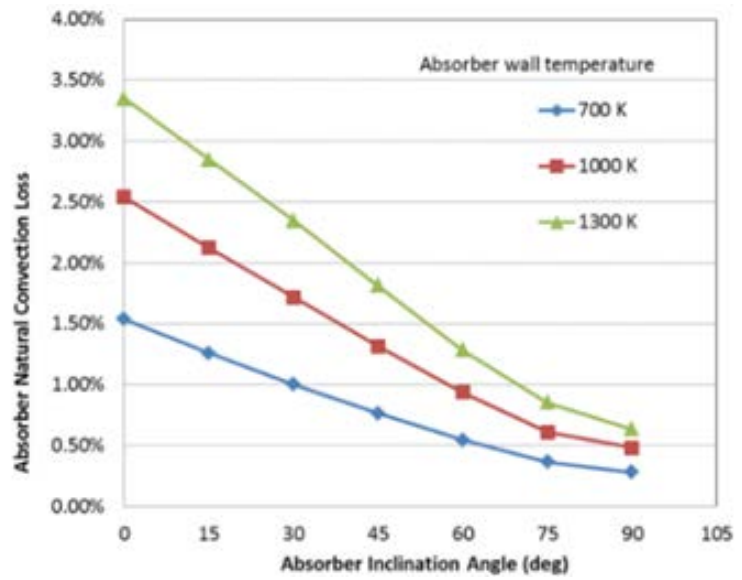

Figure 17. Absorber natural convection losses for different angles and temperatures.

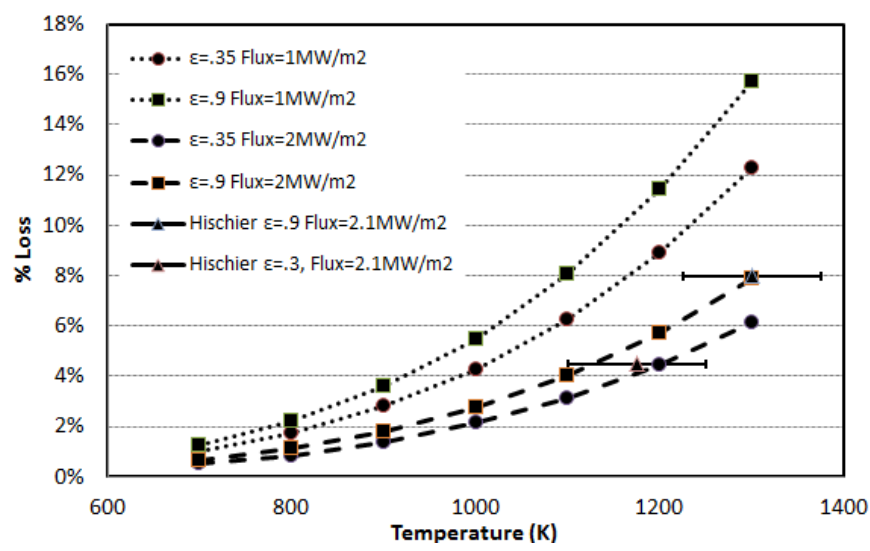

Figure 18. Infrared radiation loss from the receiver as a function of temperature, given for one of the geometries modeled.

All absorber geometries display similar trends, while absolute values vary with optical and thermal properties. The aperture flux will vary with location on the receiver. As plotted in Figure 18, the IR re-radiation depends heavily on the operating temperature at that location. The values reported in Figure 18 show the sensitivity of IR-loss independent of flux, absorber temperature, and emissivity of the absorber material. The parameter range is expected to be representative of the receiver high-flux location. It can be seen that the IR re-radiation losses increase non-linearly with an increase in operating temperature. This is due to the Stefan-Boltzmann Law, which states that the radiation emission is proportional to the temperature to the fourth power [11].

Figure 21 plots the itemized loss and total efficiency as a function of aperture flux for easy, direct comparison of different losses. Results are provided for two different operating temperatures to display results for two temperature conditions in the receiver. The highest efficiencies for both convective and radiated losses occur at high aperture flux values with low operating temperatures. For a given surface temperature, the heat lost by radiation and convection increases with the aperture flux; however, the increased amount of power into the receiver increases at a faster rate and drives up the 
efficiency. This trend was shown to be true for all geometries studied in the aperture flux range shown. This trend depends heavily on the operating temperature of the receiver; if the receiver is not adequately cooled for the aperture flux received, the efficiency will decrease.

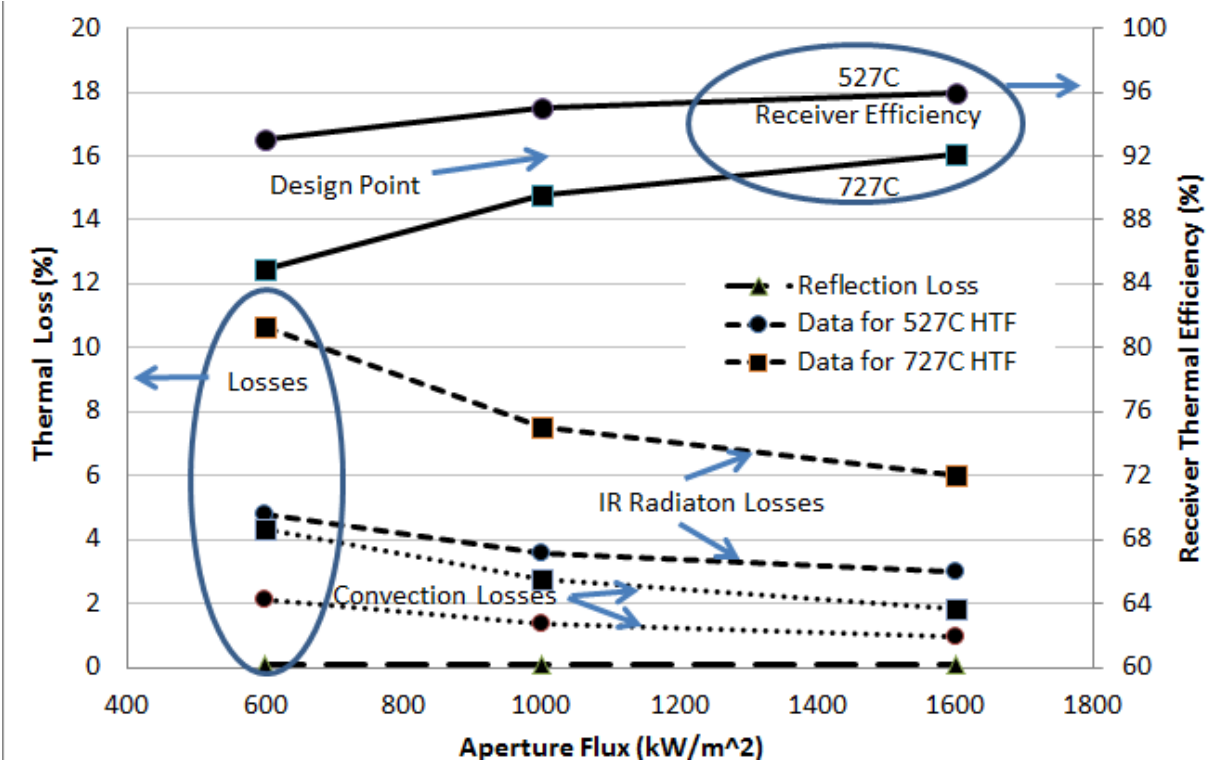

Figure 19. Itemized infrared re-radiation, convection, reflection loss from the receiver along with the total efficiency plotted as a function of aperture flux.

High-flux operation of a conventional tower receiver increases the receiver absorber skin temperature and corresponding material requirements. These higher temperature requirements then drive up the cost of the receiver. The design in this study uses flux spreading over the absorber walls to reduce flux intensity on the cavity wall, therefore allowing high aperture flux while reducing the flux on the absorber walls. The flux spreading capability is critical for the absorber to accept high flux. In order to verify the flux spreading, experiments were conducted on NREL's solar furnace to examine the effect of absorber design conditions on flux distribution.

\subsubsection{NREL High Flux Solar Furnace Testing of Flux Spreading on Absorber Tube}

The flux distribution on a single tube was modeled by SolTrace, and the first-cut tests were performed on the HFSF test setup. The simulated flux distributions were compared with the thermal images tested for different angular positions between the incident beam and the tube axis. The hexagonal tube position was varied from $0^{\circ}$ to $20^{\circ}$ angular orientation and simulated under different surface optical conditions. The hexagonal tube geometry was discretized into 68 triangular elements. Computer codes were developed to calculate the efficiency of the system.

The first tube tested was a bare stainless steel tube without surface treatment other than manufacturing grinding. The second tube (shown in Figure 20.b) was polished stainless steel with $67 \%$ specular reflectivity. In the third tube, tube length was divided into three sections distinguished by optical properties. Alanod (specular reflectivity $95 \%$ ) was glued on the front or the flare section, the middle section was sprayed with a highly diffuse-reflective $\mathrm{Al}_{2} \mathrm{O}_{3}$ ceramic aerosol paint (hemispherical reflectivity $92 \%$ ), and the 
back section was oxidized at $800^{\circ} \mathrm{C}$ to produce an absorptive surface. Specular properties of the flare section were aimed to help flux penetration and improve flux spreading inside the tube. The outside surfaces of all three tubes were sprayed with white high temperature silica based ceramic coating for IR camera imaging.

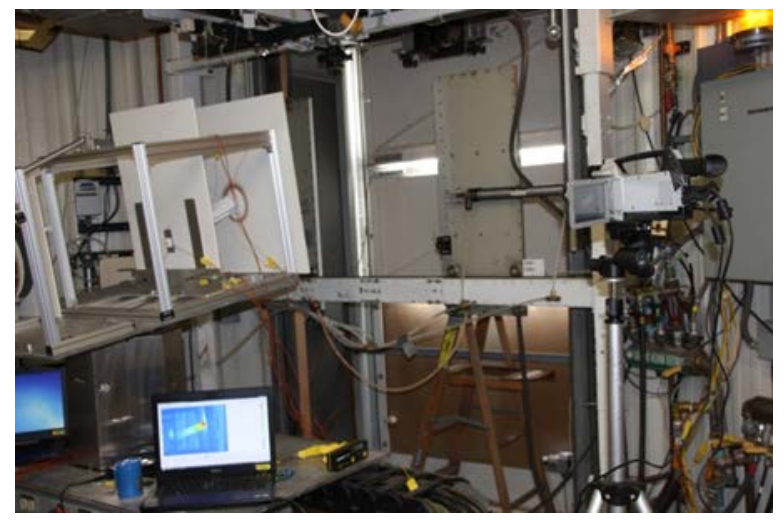

a. Side view of test setup.

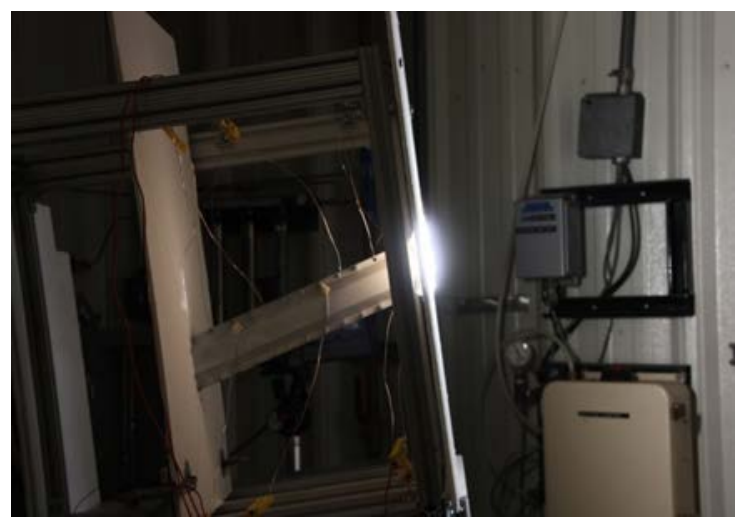

b. Tilted test setup with incoming flux.

Figure 20. Single tube solar-flux distribution test at NREL HFSF.

Figure 20.a shows the on-sun testing set up at the HFSF, and Figure 20.b shows the on-going testing with applied solar flux. The entire setup was located on a XYZ table and the frame tilted to adjust the direction of the beam into the receiver. The tilting device can change the angle between the incident beam and tube axis from $0^{\circ}$ to $22^{\circ}$. The focal point of the HFSF was located at the tube aperture. Two IR cameras were put on each side of tube aiming at the tube elevation, which record the thermal images across the tube with the solar heating process. Type $\mathrm{K}$ thermocouples were located at the tube entrance then 3 inches apart along the outside of the tube and one at the end cap, which is a thin stainless steel sheet placed at the back end of the tube to collect the solar flux on the tube end. The periphery outside the tube aperture was shielded with a high-temperature insulation board, such that the flux was only directed into the tube aperture, and the external sides of the tube were isolated from the solar flux.

The solar furnace testing set up allows testing different angles between the incident beam and the tube axis. The testing obtained the flux spreading for different coating conditions, and the flux penetration relative to the angles between the incident beam and the tube axis. Consecutive tests were performed on the bare stainless steel tube, polished stainless steel tube, and the tube with different coating sections consisting of Alanod, alumina ceramic paint. The temperatures range from $200^{\circ} \mathrm{C}$ to $400^{\circ} \mathrm{C}$ to prevent the surface from over-heating and oxidizing. Temperature distributions along the tube were measured by the thermocouples and recorded by the infrared cameras.

The significance of this first-cut on-sun testing for an absorber tube at the NREL HFSF was the validation of the NBB receiver design basis - flux spreading along the tube wall under certain incident angles between the incoming solar flux and the tube axis, and the optical properties on the tube inner surfaces. The flux distribution shows that a $10^{\circ}$ incident angle may be better than a smaller incident angle such as $0^{\circ}$ or $5^{\circ}$. This result contradicts our original thought from intuitive rationale that an aligned beam would penetrate deeper into a tube. The discovery that a larger incident angle could produce better flux spreading provides design flexibility in selecting the tube inclination angle. 
The tested flux distribution was compared with modeled results. SolTrace modeling calculates the efficiency of the system from the ratio of total rays absorbed in the tube to the ray hits on the aperture. Flux mapping facilitates determination of the number of thermocouples and their locations for solar furnace testing. SolTrace modeled flux distributions were plotted as Paraview contours in Table 3 to illustrate the flux spreading for the various incident angles. The contour plots depict that flux distribution spreads from the entrance at a small incident angle, to more spreading at the $10^{\circ}$ angle. SolTrace results show preliminary agreement with the on-sun testing, and the model can be further verified with refined testing and modeling. The verified SolTrace model can then determine the input flux and optimal tube inclination angle for prototype design and thus reduce on-sun testing risk and cost.

Table 3. Study of flux spreading on a polished stainless steel tube.

\begin{tabular}{|c|c|c|l|l|}
\hline $\begin{array}{c}\text { Angle of } \\
\text { Tube Axis } \\
\text { vs. Beam }\end{array}$ & $\begin{array}{c}\text { Tmax at } \\
5 \% \\
\text { Attenuator } \\
\text { Opening }\end{array}$ & $\begin{array}{c}\text { Spreading } \\
\text { Depth/ } \\
\text { Aperture } \\
\text { Size }\end{array}$ & Test Temperature Images & $\begin{array}{c}\text { SolTrace Modeled Flux } \\
\text { Images }\end{array}$ \\
\hline $15^{\circ}$ & $167^{\circ} \mathrm{C}$ & $\begin{array}{c}=\sim 4 \\
(2 / 3 \text { tube } \\
\text { length, } \\
\text { end cool })\end{array}$ & & \\
\hline
\end{tabular}

The testing results verified the flux spreading mechanism in the NBB receiver design with the assistance of reflective surfaces. It proves the near-blackbody flux spreading mechanism in extending the receiver heat transfer surface area. Experiments on tube inclination angles indicated the proper receiver-tube inclination angle.

\subsubsection{Particle Flow/Heat Transfer Analysis and Testing}

4.3.3.1. Solid Particle Selection: The modeled receiver performance in Section 4.3.1 was based on an assumed particle/absorber heat transfer coefficient. To validate the particle heat transfer, tests were conducted to measure the heat transfer coefficient between the particles and absorbers in Phase 1 at OSU and Phase 2 at NREL by a graduate student from CSM. Particle heat transfer is sensitive to the particle properties including size and flowability. We screened different particle candidates in Phase 1 and selected Calcined Flint Clay. The information on the particle material, size, and properties are shown in Table 10 and 11.

Table 10. Candidate particles and ranking.

\begin{tabular}{|c|cccc|c|}
\hline $\begin{array}{c}\text { Candidate } \\
\text { Material }\end{array}$ & $\begin{array}{c}\text { Resistance to } \\
\text { Sintering }\end{array}$ & $\begin{array}{c}\text { Thermal and Mechanical } \\
\text { Attrition Resistance }\end{array}$ & $\begin{array}{c}\text { Availability in } \\
\text { Desirable Size Range }\end{array}$ & $\begin{array}{c}\text { Cost } \\
\text { (Low) }\end{array}$ & $\begin{array}{c}\text { Overall } \\
\text { Score }\end{array}$ \\
\hline \hline Calcined Flint & 10 & 10 & 10 & 4 & 34 \\
Silica Sand & 7 & 9 & 10 & 6 & 32 \\
Lake Sand & 5 & 5 & 10 & 10 & 30 \\
Coal Ash & 3 & 10 & 2 & 8 & 23 \\
\hline
\end{tabular}

The particle sieve curves for two-size calcined flint particles less than 400 micron are given in Figure 21 where the cumulative fraction represents the portion of particles smaller than the given size. MCFC 605 was initially chosen as the desired particle 
distribution and was used for mass distribution testing. MCFC 300 contains fine particle powder that is undesirable from a handling perspective and reduces flow rate, but was shown to improve heat transfer.

Table 11. Calcined flint particles selected in our system are stable, low cost, and can be ball milled to a favorable size for heat transfer.

\begin{tabular}{|cc|cc|}
\hline Calcined Flint Clay Composition (\%) & \multicolumn{2}{|c|}{ Calcined Flint Clay Properties } \\
\hline $\mathrm{SiO}_{2}$ & $50-55$ & Heat capacity & $\sim 1,050 \mathrm{~J} / \mathrm{kg} \cdot \mathrm{C}\left(\right.$ avg. $200^{\circ} \mathrm{C}$ to $\left.800^{\circ} \mathrm{C}\right)$ \\
$\mathrm{Al}_{2} \mathrm{O}_{3}$ & $40-45$ & Density & $2,500 \mathrm{~kg} / \mathrm{m}^{3}$ to $2,700 \mathrm{~kg} / \mathrm{m}^{3}$ \\
$\mathrm{Fe}_{2} \mathrm{O}_{3}$ & $0.7-1.7$ & Particle size & Ball milled, sieved to desired size \\
$\mathrm{TiO}_{2}$ & $2.0-2.75$ & Material cost & $\sim \$ 180 /$ Ton \\
\hline
\end{tabular}



Figure 21. Particle sieve curves for different particle types.

4.3.4.2. Horizontal Tube Heat Transfer Test at OSU: To investigate the granular flow and heat-transfer characteristics within the solid-particle receiver (SPR), a test station at Ohio State University (OSU) was constructed in Phase 1 as shown in Figure 22.a. This single-pass cascading flow system consisted of a sand hopper that admits cold particles into the receiver, a receiver prototype that contains an array of heating tubes, a collection drum that captures the hot particles exiting the receiver, and a digital scale (Ohaus Defender 5000) for flow-rate measurements at gradients of $0.01 \mathrm{~kg} \pm 1 \%$ error in real time. The average solid flow rate was calculated by multiplying the dynamic weight-change of solids collected in the drum at steady state by the data frequency.

The design intention of granular flow over a hexagonal tube array is to use the tube array to agitate particles and create fluidized-bed equivalent particle/tube interactions. The periodic particle flow can break down the particle flow stream and induce particleflow instability that beneficially increases particle/tube heat transfer. Particle-flow instability was observed for the horizontal tube configuration of the OSU test setup, and resulted in heat transfer coefficients nearly as high as those in a typical fluidized bed. The test setup and testing results are elaborated below.

During the granular flow tests, the front of the receiver was replaced with a piece of glass to allow visual observations of the flow behavior. A high-speed camera (Photron SA-1) capable of recording $1050 \times 1050$ pixels at $250 \mathrm{fps}$ was used to track the particle 
velocity during the flow study. The focus of the flow test was to characterize the solid flow rate and solid/surface contact pattern with respect to the tube arrangement, which could be varied by adjusting the side-gap distance or the bottom-gap size around the tubes. Three different array arrangements were produced by using three back panels with dimensions as shown in Figure 22.c. The thermal and flow properties of the solid material were another important criterion of this study. In particular, particle size is a critical parameter that heavily influences both the heat-transfer coefficient and solid flowability. Experiments were performed on four solid materials that are different in both particle size and composition, as shown in Table 13.
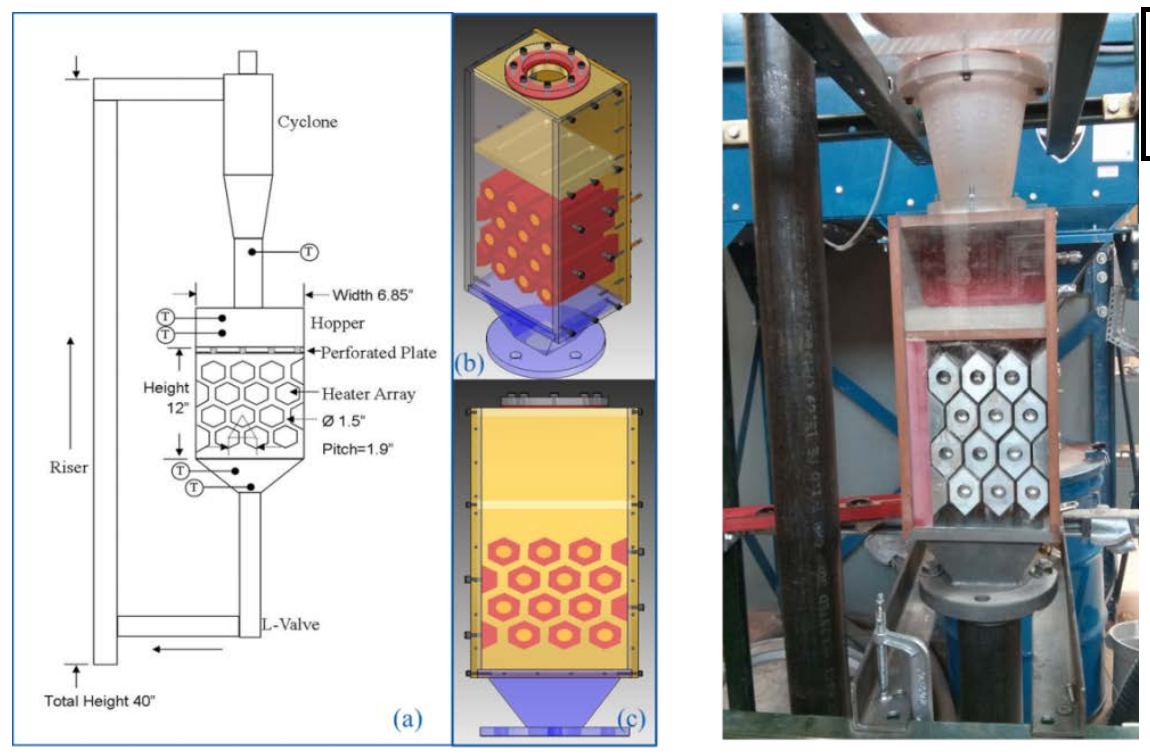

(d) Hexagonal heating tube with cartridge heater in the center

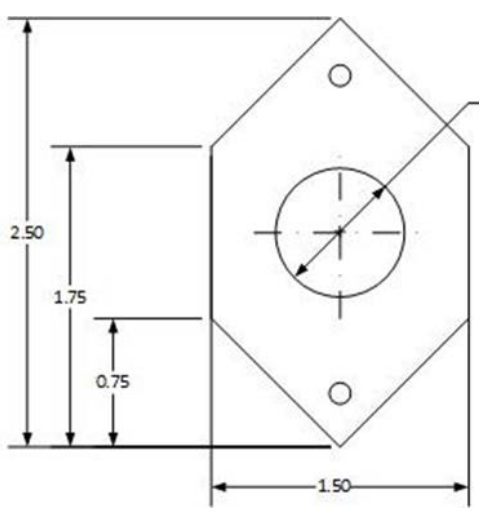

Figure 22. (a) Testing Station, (b,c) side, rear, and front view, (d) Testing tube design.

The heat-transfer test results in Table 12 indicate that the horizontal tube array has adequate contact with particles and obtains desired heat transfer coefficient. The heat transfer test showed initial positive outcome in the tubular absorber design without the need of fluidizing gas. However, since no local heat transfer measurement on each surface, the heat transfer distributions on each face, which need to match the flux distribution, were unknown.

Table 13. Selected heat-transfer test results from OSU horizontal tube setup.

\begin{tabular}{|c|l|l|l|l|c|c|c|}
\hline $\begin{array}{l}\text { Gap } \\
\text { Distance }\end{array}$ & $\begin{array}{l}\text { Particle } \\
\text { Type }\end{array}$ & $\begin{array}{l}\text { Tin } \\
\left({ }^{\circ} \mathrm{C}\right)\end{array}$ & $\begin{array}{l}\text { Tout } \\
\left({ }^{\circ} \mathrm{C}\right)\end{array}$ & $\begin{array}{l}\text { Th } \\
\left({ }^{\circ} \mathrm{C}\right)\end{array}$ & $\begin{array}{l}\text { Solid Flow } \\
\text { Rate }(\mathrm{kg} / \mathrm{s}- \\
\text { tube })\end{array}$ & $\begin{array}{l}\text { Heat-Transfer } \\
\text { Coefficient } \\
\left(\mathrm{W} / \mathrm{m}^{2} \mathrm{~K}\right)\end{array}$ & $\begin{array}{l}\text { Standard } \\
\text { Error } \\
\left(\mathrm{W} / \mathrm{m}^{2} \mathrm{~K}\right)\end{array}$ \\
\hline \multirow{4}{*}{$.45 "$} & Silica & 28.27 & 51.32 & 217.19 & 1.3 & 563.85 & \pm 12.3 \\
\cline { 2 - 8 } & Silica & 38.35 & 60.96 & 216.99 & 1.2 & 541.29 & \pm 12.3 \\
\cline { 2 - 8 } & CFC & 27.82 & 52.29 & 218.78 & 0.99 & 452.52 & \pm 9.2 \\
\cline { 2 - 8 } & CFC & 38.66 & 59.89 & 219.57 & 1.02 & 424.4 & \pm 9.2 \\
\hline
\end{tabular}

After OSU obtained heat transfer results for horizontal tubes, the test was modified to more closely replicate the real receiver design using inclined tubes. The effect of this change in tube configuration on the particle flow and heat transfer needed to be further 
understood, and the goal of Phase 2 particle flow/heat transfer testing was to determine the overall heat transfer coefficient from the heated tubes to the flowing particles with respect to the inclination angle. This was done by assuming that the heat transfer rate is proportional to the mass flow rate. The total heat transfer through a small array of horizontal tubes was measured for several different flow rates. The mass flow distribution was measured for various inclination angles. The test was set up in an NREL lab and performed by a CSM student. Figure 23.b shows the array configured for heat transfer testing with tube numbering scheme for instrumentation placement.

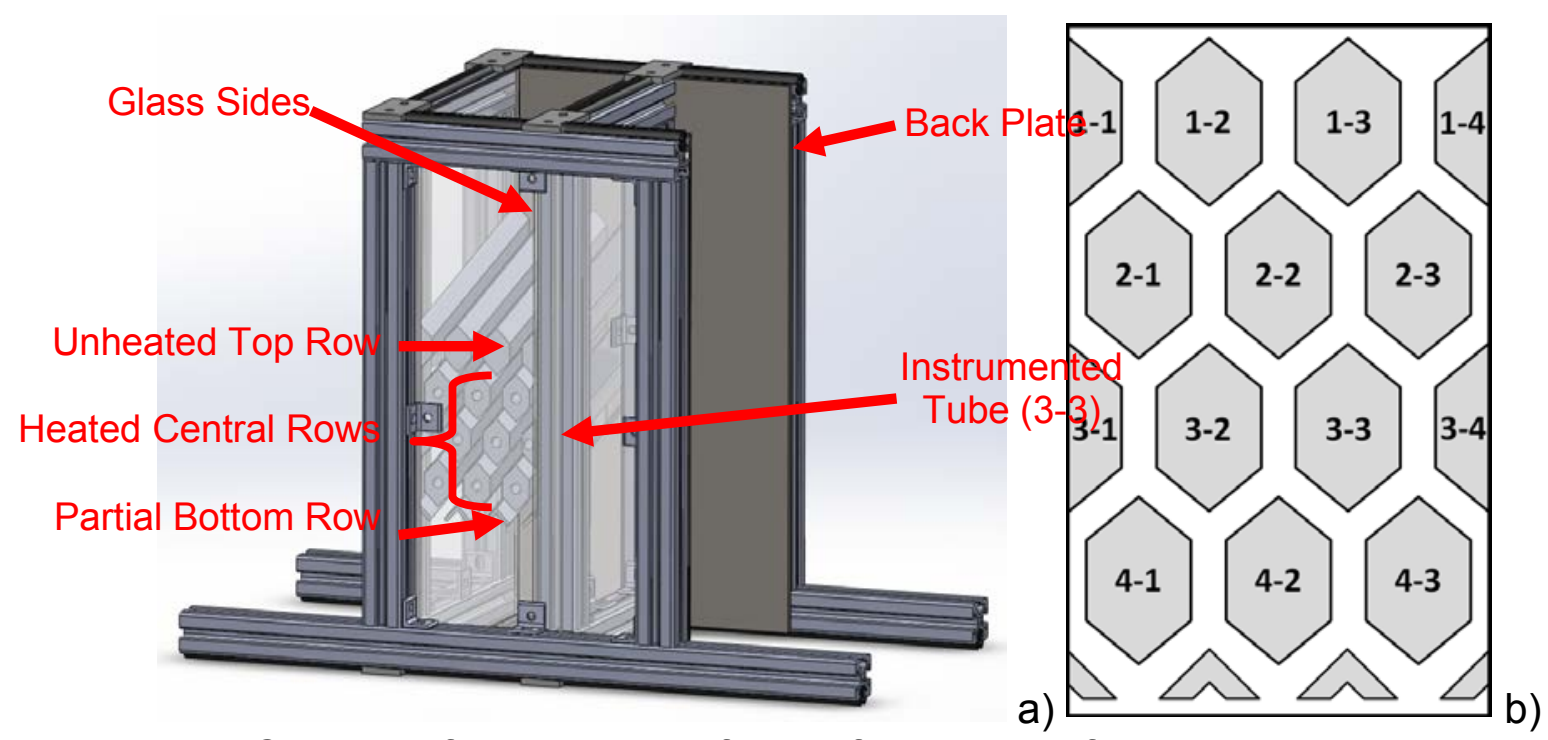

Figure 23. Close up of tube array configured for heat transfer testing with the heated-tube numbering scheme.

A secondary objective was to measure the heat transfer coefficient for each face of a single heated hexagonal tube. This was done by measuring the surface temperature and deriving heat flux from heat transfer modeling for each face as well as the temperature of the particle flow and directly calculating an $\mathrm{h}$ value. Figure 24Figure 24 shows the heated tube assembly with cartridge heaters and embedded thermocouples. Heated tubes were insulated on the end of the test section panels, and the whole test section was insulated from the environment.

The tube array consisted of 5 rows of aluminum tubes. Internal cartridge heaters were used to heat the middle 3 rows to simulate solar flux. The top row was left unheated but was in place to establish a steady state flow pattern over the heated tubes. Only partial unheated tubes were used in the bottom row and were mainly in place to maintain the proper flow pattern along the bottom face of the last row of heated tubes. Partial tubes were used for a lower surface area to limit heat loss from the already heated particles. Heat transfer testing was conducted for $15^{\circ}$ tubes. This testing allowed the measurement of heat transfer coefficients for tubes at inclination angles closer to that proposed for the final design.

Testing was conducted using a LabView program that integrates data collection with control of the electrical equipment. Each heater is connected to the LabView program through the electrical control box and can be controlled individually. The thermocouple 
inserted into the tube is used as the tube temperature. The particle temperature is measured by funneling and mixing particles. A PID algorithm within the LabView software maintains each heater at a constant set point by adjusting the power input. Due to the temperature constraints of the construction materials, the maximum set-point temperature was $230^{\circ} \mathrm{C}$. The lower testing temperature avoids radiative heat transfer and heat transfer is attributed to only conduction/convection.

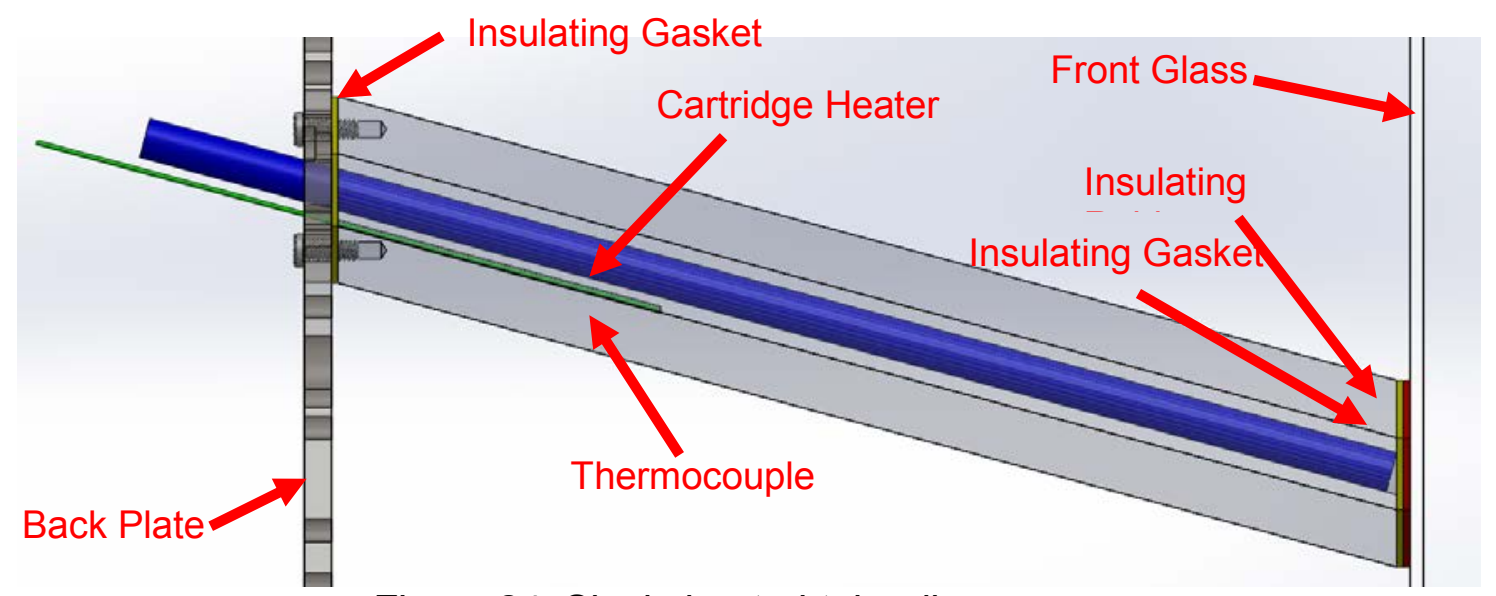

Figure 24. Single heated-tube diagram.

Heat transfer experiments were conducted by first heating the tubes to a constant temperature. Control of the tubes is then switched to constant power while particle flow is started simultaneously. This generates a first order decrease in temperature towards a steady-state value. The flow rate is sufficient to exhaust our entire $200 \mathrm{~kg}$ particle supply in as little as 1-2 minutes. Constant power control was used to heat up the particles as long as the starting temperature is above the steady-state temperature for each tube. The particle heating process does not reach steady state temperature on the tube, but the first order nature of the resulting signal allows for extrapolation to steadystate values with the heating conditions trying to reach a pseudo steady state. The bulk heat transfer coefficient for each tube can then be calculated by:

$$
h=\frac{q}{A\left(T_{s}-T_{p}\right)}
$$

where $q$ is the heat rate through the tubes, $A$ is the surface area, $T_{S}$ is the tube surface temperature and $T_{p}$ is the particle flow temperature. Only the power supplied to tube 3-3 is explicitly measured, the others must be inferred. To do this, the voltage applied is back calculated from the measured power, known heater resistance and heater duty cycle. This voltage is then used with the known resistance and duty cycle of each heater to calculate its power. A more direct measurement of input heater power was obtained from a power meter; however, the power meter reading was up to $20 \%$ lower than that calculated from direct measurements of current, voltage and resistance. This could lead to an increase of $h$ values by $20 \%$ over the results in the following figures. Calibration in the NREL Metrology Lab was performed to verify the power meter. Further investigation of these heat transfer issues was cut short due to the elimination of heat transfer activity in the last two phases. For the future development, we recommend using heat-flux sensors attached to the tube surfaces to directly measure the heat transfer rate. The 
calorimetric method used by OSU, which multiplies the particle heat capacity and measured inlet/exit particle temperatures also provided reasonable results for an evenly heated flow.

Figure 25 shows the typical heat transfer results from OSU and CSM testing compared with the calculated fluidized-bed heat transfer coefficients (including radiation heat transfer at the particle temperature of $800^{\circ} \mathrm{C}$ ) as a benchmark. The heat transfer on the horizontal tube is about twice as high as the inclined tube, though this discrepancy may be induced by differences in measurement and calculation techniques in addition to differences in particle flow distribution. Both values are significantly below the fluidizedbed heat transfer, indicating that agitating particles with a fluidizing gas could guide future research directions and provide potential to improve the heat transfer.



Figure 25. Heat transfer coefficient as a function of heater power at max flow rate for each particle type.

The inclined tubes may impede the MCFC 300 particle flow more than the horizontal tubes tested in Phase 1 at OSU. The difference in mass flow rate, particle size, and tube orientation may contribute to the observed difference in heat transfer coefficients from the OSU test value of around $450 \mathrm{~W} / \mathrm{m}^{2} \mathrm{~K}$. The results indicate that using smaller particles or including some smaller particles into the particle mixture may improve heat transfer. However MCFC 300, which contains fine particles, showed poor flowability as compared to the narrowly-sieved particles of MCFC 60S. The fine particles need a large gap to reach the same mass flow rate in an inclined-tube condition. The MCFC 300 particle batch also showed less uniform flow over inclined tubes and led to excessive heating of the bottom tubes during some test runs.

Heat transfer to the insulation and surrounding frame through metal fasteners which link the metal plate and aluminum frame may be a significant factor which contributes to the low heat transfer coefficient calculated in the inclined tube test. A portion of power supplied to the heater may be transferred through these metallic pieces and either lost 
to the surrounding environment, or used to heat up the thermal mass of the entire test station. The latter transient effect may be of particular significance during the short time scale of the test. A complete heat transfer uncertainty analysis was not conducted due to the shift in effort towards coating development. However, detailed analysis of a smallscale electrically heated test for NREL's $\mathrm{s}-\mathrm{CO}_{2}$ receiver indicated that loss through alternative conduction pathways can be substantial, particularly over short time scales. We believe the low calculated heat transfer coefficients for the inclined tube array may be partially caused by external heat losses. Calorimetric measurements similar to those used by OSU are insensitive to the presence of alternative heat loss mechanisms and, when applied to the inclined tube data, produced results much closer to the OSU data.

Additional testing on the inclined tube array measured the local average heat transfer coefficients on three surface types of the hexagonal tubes: the top, side and the bottom surface. The results indicate the top surface has a heat transfer coefficient which is about three to five times that of the side surface, and five to six times that of the bottom surface. The bottom heat transfer coefficient is inadequate to maintain a reasonable absorber wall temperature given the predicted solar flux distribution. The insufficient heat transfer on the tube bottom is lessons learned from the tubular-absorber design and a major barrier for proper receiver performance.

\subsubsection{Planar-Cavity Receiver Design for Enhancing Flux Spreading and Heat Transfer}

Although we have certain design metrics for a specific design for the coating requirements, after screening the available coating technology, the other option is to modify the receiver so as to adapt to the available coatings. Our approach in receiver design and development is to avoid using coating for flux spreading, so as to minimize coating reliability concern for 30-year service life as well as the maintenance of the coating surface for proper operation. Therefore our development in late phase of project also opened up the design receiver options that using geometric configuration to achieve flux spreading instead of using reflective coatings. The receiver working mechanism is presented in this report as a feasible way to design an enclosed particle receiver without coating material needs.

With the progress made in analyzing the reflective coating and particle heat transfer for the tubular-absorber design, the following lessons were learned:

- Tubular absorbers with the large aspect ratio between the tube depth and the aperture size $(>5)$ need highly-reflective coatings to spread solar flux to a level amenable for particle heat absorption.

- High-temperature coating reliability, maintenance, and cost are concerns in receiver application.

- Granular flow particles lack contact with the bottom of the absorber tubes. Thus heat transfer is inadequate for solar flux absorption.

To overcome the above concerns and shortcomings associated with the tubular absorber receiver design, a novel planar cavity was suggested as shown in Figure 26. The planar cavity design exploits the lessons learned, and uses a simplified geometric cavity design to distribute incident solar flux over a large surface area, consequently avoiding requirements for reflective materials which hindered our previous design. The 
planar cavity contains tapered panels to allow nearly-collimated incident flux to penetrate deep inside the cavity and spread along the panel walls. To cope with the direct incident flux, the receiver front edge incorporates a solar-flux absorption surface to accept high flux near the receiver aperture.

The planar-cavity design retains performance attributes of the tubular-absorber NBB-receiver design by shielding high temperature surfaces from direct exposure to the ambient environment for reduced thermal losses. Meanwhile, the cavity formed by simpler planar panels minimizes structural and fabrication complexity, because the absorber panels can be formed from sheet metal and inexpensively assembled. The modeling techniques developed in this project can be adapted to analyze the design performance. The particle flow compartment formed by the planar panels also allows introduction of agitating air flow to enhance particle/panel heat transfer.

The planar-cavity design mitigates challenges for solar flux distribution and heat shield design as compared to the



Figure 26. Planar-cavity receiver concept. initial tubular absorber design by:

- Using simplified planar-cavity geometry to distribute solar flux and to transfer heat to particles.

- Avoiding use of high-temperature coatings while preserving receiver thermal performance.

- Using integrated heat pipe to avoid the requirement for a reflective shield and eliminating exergy loss.

- Introducing mild fluidization to improve the particle/absorber panel contact and enhance particle heat transfer.

The identified panel design utilizes a simplified geometry to accommodate gas/solid two-phase fluidization. Preliminary SolTrace modeling has indicated the effectiveness of flux spreading by the planar cavity geometry on a raw material surface naturally oxidized by ambient air. The flux spreading was studied by a summer intern student based on the SolTrace tool modified from the tubular design. If the particle receiver is proven to have desired performance and manufacturability, the receiver design can be integrated with power cycles developed so far, including subcritical and supercritical steam power generation, advanced $\mathrm{s}-\mathrm{CO}_{2}$ power cycle, PFB GTCC, or air-Brayton steam power combined cycle. On the system and heat exchanger designs, B\&W has verified system development based on substantial expertise in designing and building commercial-scale power plants. The realization of these benefits of the particle-based CSP system hinges on the high-performance particle receiver design approach investigated in this project.

\subsection{System Development and Conceptual Designs of the Major Components}

A successful particle receiver is the key enabling component essential for realization of the projected system cost and performance benefits. The major development and component conceptual designs are illustrated in Figure 27. Further technology 
development is projected to overcome the technical challenges of a high-temperature, high-efficiency particle-receiver design.



a.\& b. Steam FB-heat exchanger

c. s- $\mathrm{CO}_{2} \mathrm{FB}$-heat exchanger

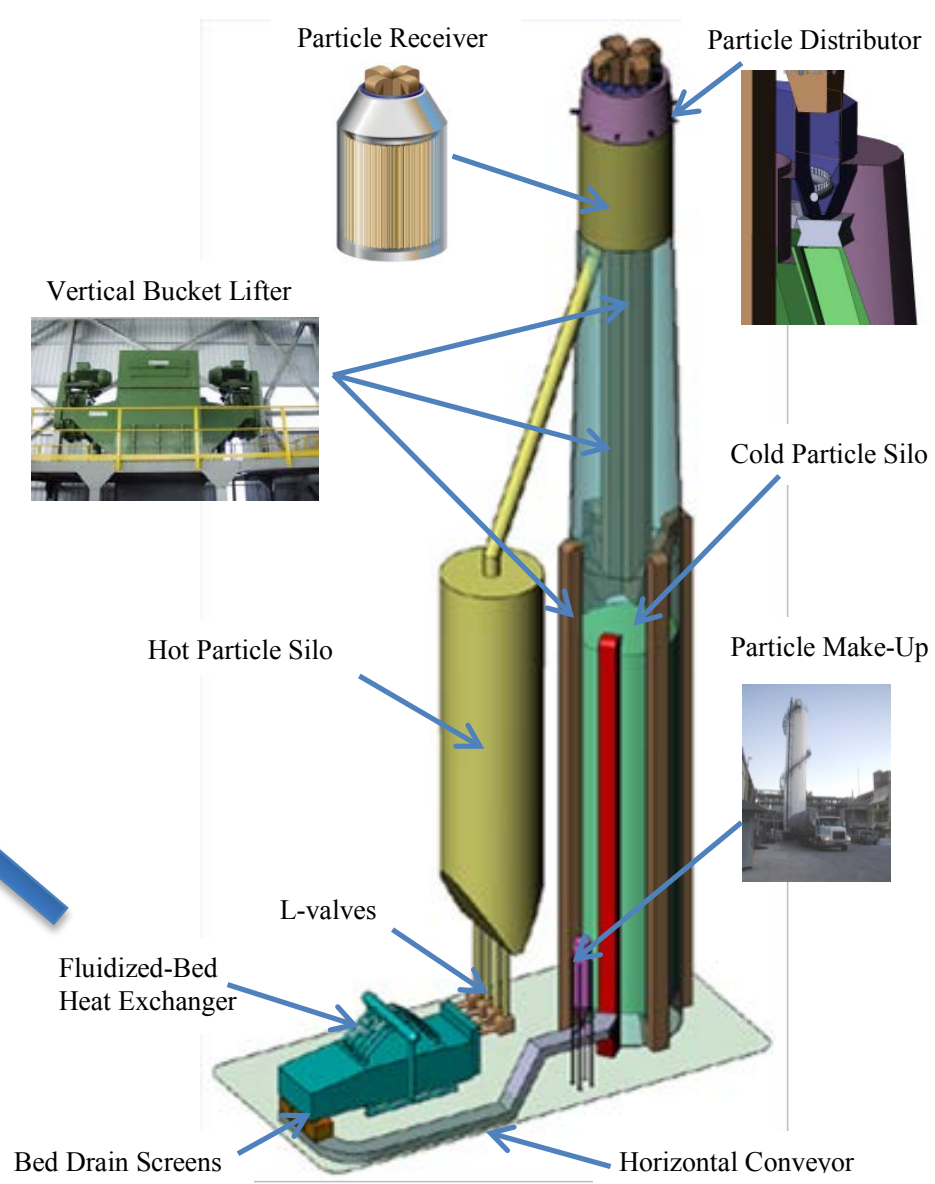

\section{d. Pressurized-air/particle heat exchanger}

e. Major components of the particle thermal system

Figure 27. Major components of the particle-based FB-CSP thermal system for various power cycles.

In the three-year project, we have made significant progress on particle-TES, heat exchanger, and auxiliary system components. The particle-TES that was developed prior to the particle receiver project uses a concrete structure for containment, with special refractory liners and insulation material to hold the high-temperature particles. A CSP system that operates at $600^{\circ} \mathrm{C}$ to more than $900^{\circ} \mathrm{C}$ is possible because of stable materials and minimized thermal losses due to thermal self-insulation of particles in the storage mode. The particle-TES can hold large-capacity thermal energy for a longer time period without the need for expensive metal alloys and insulation. Thus, the particle-TES should enable CSP $[12,13]$ to provide dispatchable power. Upon finding no technical barriers with these components using known technology and equipment through the NREL AOP study in 2012, we identified critical technology development needs and continued investigation in the current project for an in-depth feasibility study of the particle-based thermal system integrated with a CSP plant and different power cycles. 
The low-cost and high-temperature TES was studied for the FB-CSP system with major components shown in Figure 27. NREL's earlier works under our Annual Operating Plan (AOP) generated the overall system configuration and major component designs for a particle-based FB-CSP thermal system as shown in Figure 11. Within the SunShot project, B\&W has transferred the conceptual designs into a realizable system configuration with practical components. Heat exchangers capable of driving hightemperature, high-performance power cycles were conceptually designed, and most of the designs meet the cost and performance targets. Therefore, the particle-based FBCSP thermal system shows promise of meeting SunShot cost and performance targets for TES, HTF, receiver, and heat exchangers. The following section introduces the major components for the FB-CSP system and the design considerations.

\subsubsection{Solids Conveyer/Bucket Elevator}

The commercial SPR system is envisaged to make use of a surround-field heliostat arrangement. Therefore, the receiver heat transfer surfaces are arranged circumferentially. A commercial SPR with heat input ratings of $400 \mathrm{MWt}$ to $800 \mathrm{MWt}$ would require a particle handling and delivery system that can transfer particles from the TES to the SPR and subsequently deliver and distribute the particles circumferentially to all surfaces of the SPR. Figure 27.e depicts a system comprised of four elevator pairs consisting of a first elevator located on the outside of the tower that draws "cold" solids from the cold particle silo, and discharges the solids directly into a second elevator. The second elevator carries the solids to the top of the tower and discharges the solids into the particle hopper (transition hopper). The cold particle silo is assumed to be located inside the tower. Each of the second elevators is located inside the silo. Four sets of elevators are located at the compass points around the tower. Each elevator has a minimum capacity of $33.3 \%$ of the required full load solids flow, thereby allowing full load operation with one elevator train down. High temperature particle transportation could be a challenge. Although an initial design of high-temperature bucket lifters was developed for these high temperature operating conditions, further work is needed to develop a reliable system.

\subsubsection{Solid Hopper/ Particle Distributor}

The solids hopper and distribution system above the receiver is needed to provide a consistent and controlled flow of solids to the receiver. The hopper is also required in order to provide enough reserve of particle inventory to respond to system dynamics. For example, in case of a situation where the plant experiences power loss, the particle reserve would provide the necessary inventory to prevent the surfaces from overheating while the mirrors are defocused away from the receiver. Therefore, the design philosophy for the solids hopper and particle distribution system has considered the following factors:

- The inventory of solids in the hopper must be sufficient to keep the receiver cooled during plant trips and equipment failures while mirrors are defocused

- Allow control of solids flow through SPR to accommodate circumferential variations in incident flux

- Prevent stagnation, accumulation and buildup of solids to avoid sintering and blockage of particle flow path 
- Prevent starvation of SPR due to maldistribution

- Minimize heat loss and parasitic power

An aeration ring fluidizes the lower half of hopper to evenly distribute the particles around the full circumference of the hopper, so that even with one of the elevators offline, the system would provide adequate supply of particles throughout the SPR to maintain full load. This proposed design redundancy scheme provides reliable operation in the event that one elevator breaks down or both elevators for a single pair of elevators are inoperable. Additional modifications to the design can be made to offer even higher level of reliability. The solids flowrate to each vertical section of the receiver can be adjusted and controlled using mechanical discharge valves (e.g. gate valves, rotary valves) or non-mechanical aerated distribution systems. The solids distributor below the discharge gate then provides the means to further distribute the particle flow into a given segment of the receiver. The distribution cavity is enclosed and particle tight.

\subsubsection{Fluidized-Bed Heat Exchanger and Power Cycle}

While it is critical to develop an SPR that can produce the desired hot particles, enabling the transfer of energy from the hot particles to the working fluid is critical to the success of the system as the working fluid drives the power cycle. System efficiency gains with the use of advanced power cycles would translate to a significant reduction in the size of the mirror field, thereby reducing the overall CSP plant cost and consequently the levelized cost of electricity (LCOE). Fluidized Bed Heat Exchanger (FBHX) technology, which leverages B\&W's expertise and know-how on gas-solid two phase flow and heat transfer, is then used to extract the energy from the hot particles to heat up the working fluid which then drives the power turbine of choice. The fluidized bed design was developed with the following characteristics in mind:

- Suitable for particle sizes desired by the receiver

- High heat transfer

- Lower parasitic power consumption than alternative designs

- Low sensible heat loss

- Potential for lowest cost design

Design efforts on the FBHX were focused on subcritical (Sub-C) and supercritical (SC) steam Rankine cycles, advanced cycles including supercritical $\mathrm{CO}_{2}\left(\mathrm{~s}-\mathrm{CO}_{2}\right)$ Brayton cycles, and Air Brayton Combined Cycles. The project has generated designs of two of the FB heat exchangers for subcritical and supercritical steam power cycle application, including the arrangement of surface for water preheating and steam generating, superheating and reheating. The FB designs are capable of transporting the HTM through the heat exchanger surfaces, extracting energy in an efficient manner. For example, the $\mathrm{FB}$ for the s- $\mathrm{CO}_{2}$ cycle has been sized to yield $\mathrm{CO}_{2}$ at $650^{\circ} \mathrm{C}$ in order to support an advanced s- $\mathrm{CO}_{2}$ cycle. The initial optimization efforts on the FB design have considered the implications of the design on cost and operation and factored in its layout and arrangement in the plant.

4.4.3.1. Fluidized-Bed Heat Exchanger- Subcritical Steam

An overall view of the subcritical heat exchanger is presented in Figure 27.a. The 
subcritical FBHX utilizes a low-velocity fluidized bed of fine solids $(<200$ micron average size) to transfer heat acquired by the solids in the solar receiver to the working medium of the power cycle. Heat transfer surfaces in the bed are arranged in a way that provides a general countercurrent flow pattern between the bed material and the working medium. This means that the last set of heat transfer surfaces on the working medium route, i.e. superheater $(\mathrm{SH})$ and reheater $(\mathrm{RH})$, are the first ones in the solids path, and the first surface in the working medium route (economizer) is the last one in the solids path. The countercurrent flow setup is also provided within each type of surface. This arrangement maximizes overall mean temperature differentials between the solids and the medium allowing for a reduction in total heating surface area for a given amount of heat duty. In addition, utilization of a FBHX to generate superheated and reheated steam significantly reduces the amount of high grade alloy compared with the amount of absorption surface (and consequently material) in a conventional boiler convection pass, since the heat transfer coefficient is nearly 10 times that in a convection pass.

Solids flow through the first part of the FBHX is split in two parallel individually controlled streams, one for the $\mathrm{SH}$ section, another for the $\mathrm{RH}$. Water spray along with solids flow rate adjustment is used for controlling $\mathrm{SH}$ steam temperature. However, spraying water into $\mathrm{RH}$ steam reduces the cycle efficiency since the steam generated from this water does not pass through the high pressure turbine. Therefore, adjusting solids flow through the path containing reheat heating surface is the main means for $\mathrm{RH}$ steam temperature control. Water spray at the $\mathrm{RH}$ inlet is provided for emergencies only.

The particle streams from the $\mathrm{SH}$ and $\mathrm{RH}$ combine into a common flow and then subsequently pass through the generating bank surfaces and the economizer section. Typical solids temperatures along the way are as follows: $760^{\circ} \mathrm{C}$ to $815^{\circ} \mathrm{C}$ entering FBHX (SH \& RH), $538^{\circ} \mathrm{C}$ to $593^{\circ} \mathrm{C}$ entering the generating surface, $315^{\circ} \mathrm{C}$ to $370^{\circ} \mathrm{C}$ entering the economizer, and $260^{\circ} \mathrm{C}$ to $315^{\circ} \mathrm{C}$ leaving $\mathrm{FBHX}$ (economizer).

The sides and top of the $\mathrm{SH}, \mathrm{RH}$ and the generating bank have water-cooled membrane enclosures. The economizer is enclosed with a plate casing which is allowed due to the sufficiently low solids temperature. The bed is fluidized with air delivered through a distribution grid and air flow is controlled individually to each section of the bed to account for the local bed temperature (and corresponding air specific volume) for maintaining a preset bed superficial velocity. Since vigorous lateral mixing is not required to facility combustion as in a typical commercial fluidized-bed boiler, the air flow required to achieve good heat transfer can be significantly less, so less sensible heat loss occurs through the vented hot air. The air is vented from the HX through a bag house and vented to the atmosphere. The sensible heat in the hot vented air can be recovered to preheat feedwater or to satisfy other low-grade heat duties. The heat exchanger is fed with bed material from the hot solids silo with a flow rate matching power demand. The silo is located above the HX, allowing solids to feed by gravity. The metering is accomplished by either mechanical valves (such as a conical valve) or nonmechanical valves (such as an L-valve); both types are widely used in fluidized bed boilers.

The subcritical FBHX features a water circulation system which has been designed and optimized to operate without a circulation pump and with natural circulation 
characteristics. The circulation system uses a traditional steam drum as the vessel where steam is separated from the steam/water mixture leaving the evaporating components. Once separated, dry steam is sent to the superheater while water is recirculated within the evaporating components.

The circulation system has been modeled using B\&W's proprietary circulation analysis program with the predicted heat absorptions applied, and the design has met required B\&W limits for outlet quality, tube velocity, and stability at both normal operating conditions and upset conditions. Finally, the sensitivity of the circulation system to varying heat inputs was modeled and shown to be acceptable.

\subsubsection{Fluidized-Bed Heat Exchanger - Supercritical Steam}

Figure 27.b depicts the design of the supercritical steam FBHX that would be incorporated in a SPR based CSP plant that uses a supercritical steam turbine power cycle. This design, in many ways is similar to the sub-critical steam fluidized bed boiler described earlier. One of the main differences between the two designs is in the generating bank section of the fluid bed. Since this is a supercritical steam system, during full load operation there is no real phase change that supercritical fluid experiences. Therefore, there is no need for a steam drum or separator during full load operation. However, during part load operation, it would be desirable for the system to operate in variable pressure mode. Variable pressure operation would allow better control of the temperature gradients that the heat exchanger and turbine components would be subjected to. This is the basis of the current design. The supercritical steam FBHX uses B\&W's vertical steam separator (VSS) system for steam separation from the steam/water mixture during startup and low load operation. The VSS would be used in lieu of the steam drum component utilized for the subcritical steam cycle.

\subsubsection{Fluidized-Bed Heat Exchanger for $\mathrm{s}-\mathrm{CO}_{2}$}

Advanced turbine cycles have the potential to raise the efficiencies of CSP plants, thereby allowing for further reductions in LCOE. With this in mind, the SPR is being designed in order to generate higher temperature HTF to be able to support these more advanced turbine cycles. A number of supercritical $\mathrm{CO}_{2}$ cycles are currently being investigated by various researchers and turbine developers, to determine their potential and ways of incorporating them into CSP plants. Under consideration are simple cycles, recompression and partial-cooling cycles (which apply different compression and heat recuperation schemes). A number of simulations have been performed based on the partial-cooling s- $\mathrm{CO}_{2}$ cycle.

The turbine cycle efficiency of the $\mathrm{s}-\mathrm{CO}_{2}$ is impacted by several parameters. Compressor inlet temperature was one that was looked at in previous simulations with results obtained for compressor inlet temperature of $32^{\circ} \mathrm{C}$ and $50^{\circ} \mathrm{C}$. A temperature of $700^{\circ} \mathrm{C}$ was chosen as the target $\mathrm{FBHX}$ fluid outlet temperature as it offered the potential of hitting the desired turbine cycle efficiency target of $50 \%$ with a compressor inlet temperature of $50^{\circ} \mathrm{C}$ including allowances for some losses for reasons such as pressure drop in the heat recuperators. Due to the higher operating temperatures, this heat exchanger requires the use of higher alloy materials especially in the hotter sections. The initial design efforts have displayed a number of advantages that the fluidized-bed system offers for s-CO $\mathrm{CO}_{2}$ SPR systems. For example higher heat transfer coefficients not 
only help reduce the overall footprint of the vessel, but also help to minimize the amount of high alloy surface that would be used in the construction of the vessel which would ultimately factor into the capital cost of the equipment. As components of the s- $\mathrm{CO}_{2}$ power cycle continue to be designed, developed and tested, the FBHX design as shown in Figure 27.c can also be further advanced and optimized to meet the design desired performance characteristics set by the cycle and the CSP plant.

\subsubsection{Fluidized-Bed Heat Exchanger- Air Brayton Combined Cycle}

The SPR system can also support an Air Brayton or a Natural Gas Combined Cycle (NGCC) type power generation system. This plant would therefore incorporate an advanced high temperature SPR much like the prior scenarios however the heat exchanger in this case would need to be a pressurized FBHX. The pressurized FBHX, as shown in Figure 27.d, would be designed to allow the transfer of the thermal energy to the pressurized air. Unlike the previous designs, the heat exchange would be performed by allowing the direct contact of solids and air as opposed to using pressure pipes for the fluid loop. For this reason, the entire vessel would become a pressurized vessel whereas in the prior scenarios, the fluidized bed was not a pressure vessel itself. The heated pressurized air is then sent to an air/natural gas turbine to drive a combined cycle power generation system similar to a natural gas combined cycle. With supplemental heat provided by natural gas firing, this system would be capable of approaching efficiencies of that achieved by NGCC plants while requiring a fraction of the natural gas. It is conceivable that as the receiver technology advances further to be able to yield even higher-temperature particles from the receiver, the use of natural gas could be further reduced or perhaps even eliminated. The preliminary design of the heat exchanger has been developed to determine the means of performing the heat exchange between the pressurized air and solid particles, the methods of transferring particles in and out of the PFBHX vessel as well as methods of maintaining the desired pressure and filtering the air prior to its entry into the gas turbine.

\subsubsection{Power System Heat and Mass Balance Analysis}

B\&W conducted two system configuration analyses: a steam-Rankine power system and a $\mathrm{s}-\mathrm{CO}_{2}$ power system. The process flow diagram of a particle-receiver solar energy plant integrated with a steam-turbine power block is depicted in Figure 28. The concept involves the transfer of particles from the cold silo $\left(200^{\circ} \mathrm{C}\right.$ to $\left.250^{\circ} \mathrm{C}\right)$ to an intermediate hopper above the receiver. The cold particles then flow through the solids receiver and are heated to temperatures of $800^{\circ} \mathrm{C}$ or above and are then sent to the hot silo for storage. The hot particles from the hot silo are then sent to a heat exchanger where the thermal energy is extracted.

In the process schematic illustrated in Figure 28, the energy is extracted to heat up pressurized water to produce steam. Steam from the superheater is sent to a highpressure (HP) turbine. Steam exiting the high pressure turbine is then reheated and subsequently sent to the intermediate-pressure (IP) and low-pressure (LP) turbines. The figure depicts five feedwater heaters $(\mathrm{FWH})$. However, the number and configuration of heaters can change depending on the cycle of choice and degree of optimization. The analysis considers various cases to determine possible means of integrating the 
particle-receiver system with subcritical/supercritical steam-turbine cycles and a preliminary study at advanced cycles (s- $\mathrm{CO}_{2}$ Brayton power cycle).

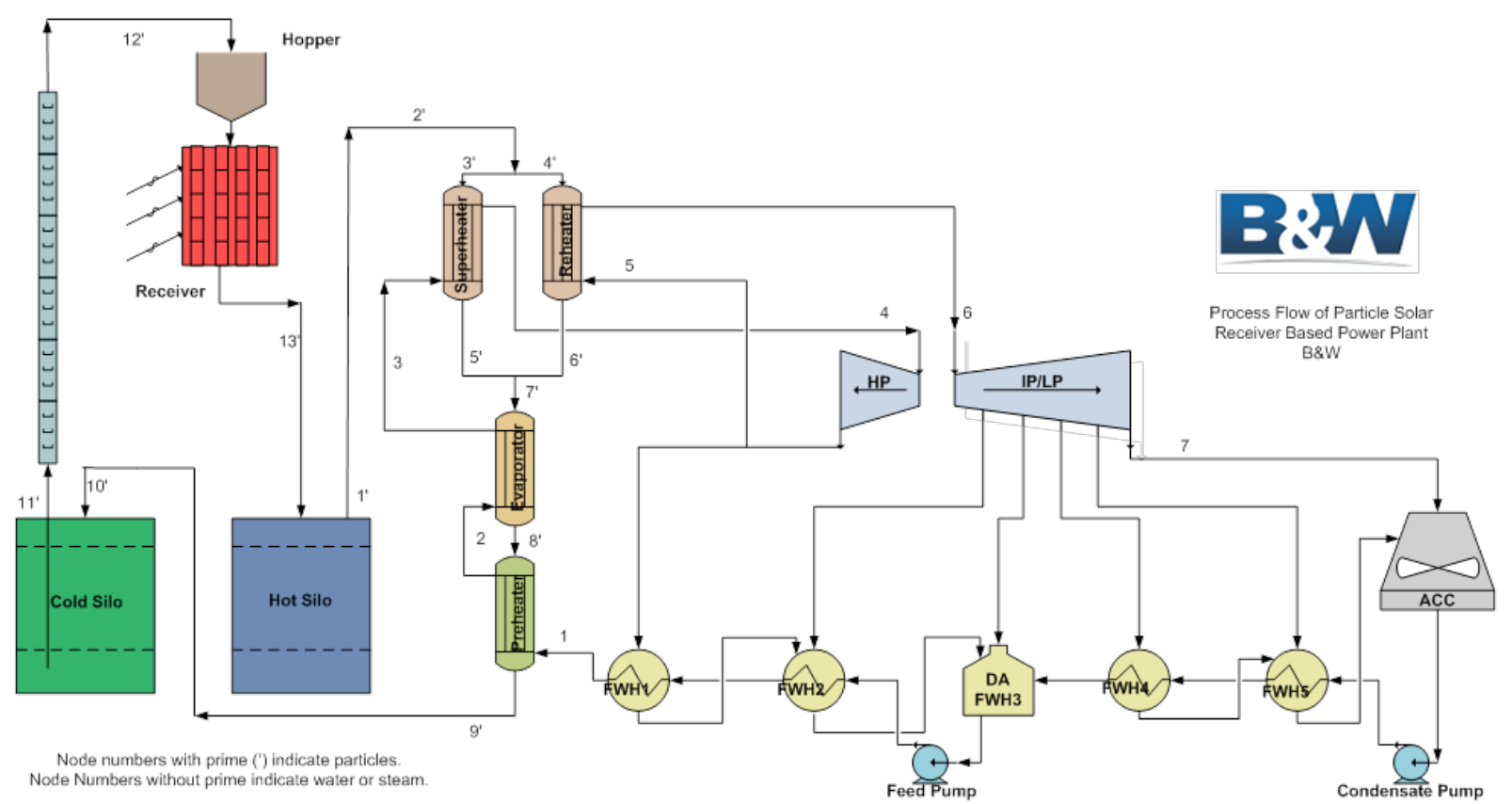

Figure 28. Process flow diagram (PFD) of a particle receiver solar energy system integrated with a steam turbine power generation system.

The process flow information that corresponds to Figure 28 for a $100 \mathrm{MWe}$ net plant with a subcritical steam-turbine power block is calculated by Aspen-plus software. The fluid-bed heat exchanger (HX) is depicted as four different vessels. Whereas the fluid bed will include a heating surface associated with each of the vessels (i.e., superheater, reheater, evaporator, and preheater), the vessel will not look like four individual standalone heat exchangers. The design of the fluid-bed heat exchanger is further elaborated in the early part of Section 4.4.3.

Figure 29 depicts a conceptual process flow diagram that shows the simplest way the partial-cooling s- $\mathrm{CO}_{2}$ cycle can be integrated with a particle-receiver plant. In Figure 29, the hot particles exiting the receiver are split to flow into the superheater and reheater sections of the fluid bed. They then recombine and enter the $\mathrm{s}-\mathrm{CO}_{2}$ heater, which is used to provide thermal energy to the incoming s- $\mathrm{CO}_{2}$ stream from the power cycle. The $\mathrm{s}-\mathrm{CO}_{2}$ stream leaving the superheater is sent to the HP turbine. The outlet is returned back to the fluid bed for a single reheat loop. The reheated $\mathrm{s}-\mathrm{CO}_{2}$ stream then enters the LP turbine for additional power generation. The stream exiting the LP turbine then goes through two sets of recuperators, which includes the high temperature recuperator (HTR) and low temperature recuperator (LTR). The cycle also includes two air-based coolers, which are depicted as the precooler and intercooler. The compression of the s$\mathrm{CO}_{2}$ involves three compressors, shown as the precompressor (P-C), recompressor ( $R$ $\mathrm{C})$, and the main compressor (C).

$\mathrm{B} \& \mathrm{~W}$ performed a process analysis on the $\mathrm{s}-\mathrm{CO}_{2}$ operating parameters for the partialcooling cycle with HP and LP turbine inlet temperatures of $650^{\circ} \mathrm{C}$ and a $25-\mathrm{MPa}$ pressure. The analysis also assumes a 93\% turbine efficiency and an $89 \%$ compressor 
efficiency and uses a $5^{\circ} \mathrm{C}$ pinch point in the recuperators. Heat-exchanger sizing and cost implications should be factored in when considering the appropriate pinch point for the system. The simulation uses a 0.6 split ratio to the main compressors. The compressor inlet temperatures are set to $32^{\circ} \mathrm{C}$. The cycle does not take any pressure drop into consideration. The results show that for a gross electric output of $106 \mathrm{MWe}$, the system would need a receiver with a $529 \mathrm{MWt}$ rating for a 13-hour storage system and a $407 \mathrm{MWt}$ rating for an 8-hour storage system. The corresponding mass flows of particle are $10.4 \mathrm{Mlb} / \mathrm{h}$ and $8 \mathrm{Mlb} / \mathrm{h}$, respectively. The Aspen Plus simulation results in a turbine cycle efficiency of $51.5 \%$. Although this would be a favorable result, the pressure drop across the heaters and recuperators had not yet been included. Also, the solids return temperature was quite high at $498^{\circ} \mathrm{C}$, which triggered concerns in the area of solids transport.

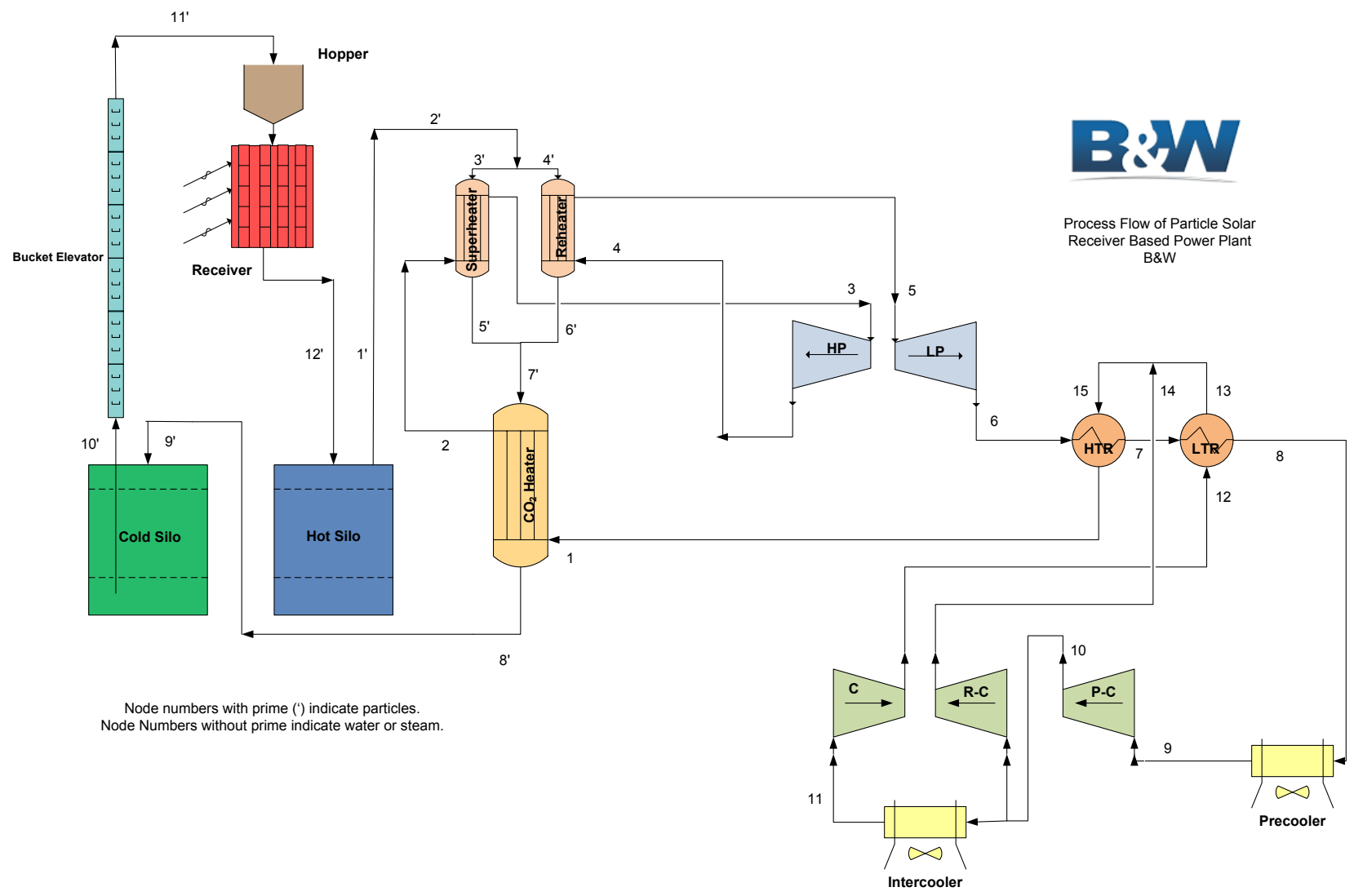

Figure 29. Conceptual PFD of a particle-receiver solar energy system integrated with a partial-cooling s- $\mathrm{CO}_{2}$ Brayton cycle.

B\&W then carried out further simulations to further understand the effect of variables such as compressor inlet temperature and pressure drop. For example the study considered a compressor inlet temperature of $50^{\circ} \mathrm{C}$ and pressure drop was varied between $0-1.4 \mathrm{MPa}$ for the superheater and $\mathrm{s}-\mathrm{CO} 2$ recuperator sections and $0-0.7$ $\mathrm{MPa}$ for the reheater section.

The turbine-cycle efficiency is the gross generated power over the heat supplied to the working fluid. The gross-cycle efficiency accounts for the thermal losses in the system and is based on the heat available in the hot particles. These measures do not take the 
parasitic energy such as the air-cooled condenser-fan power or bucket-lifter power consumption into consideration. These sets of simulations also use $25 \mathrm{MPa}$ as the main pressure.

The FBHX designs are capable of transporting the particles through the heat exchanger surfaces, extracting energy in an efficient manner. Design efforts on the FBHX were focused on subcritical (Sub-C) and supercritical (SC) steam Rankine cycles, advanced cycles including s- $\mathrm{CO}_{2}$ Brayton cycles, and Air Brayton Combined Cycles. The desired conditions are summarized in Table 14. Table 14 shows the obvious advantages of particle-based CSP system over the traditional molten-salt-based CSP system - the ability to drive advanced power cycles but also to be immediately used for traditional steam-Rankine power cycles, in addition to low-cost, high-temperature TES.

Table 14. Baseline molten-salt CSP plant compared with the advanced CSP systems [14].

\begin{tabular}{|c|c|c|c|c|}
\hline System Variable & Molten Salt & SPR & SPR & SPR \\
\hline Turbine Cycle & $\begin{array}{l}\text { Subcritical } \\
\text { Rankine }\end{array}$ & $\begin{array}{c}\text { Supercritical } \\
\text { Rankine }\end{array}$ & Brayton $\left(\mathrm{s}-\mathrm{CO}_{2}\right)$ & Brayton (Air) \\
\hline Turbine Working Fluid & Steam & Steam & $\mathrm{CO}_{2}$ & Air and Steam \\
\hline Receiver/TES HTF & Nitrate Salt & Solid Particles & Solid Particles & Solid Particles \\
\hline Receiver Exit Temp & $566^{\circ} \mathrm{C}$ & $750^{\circ} \mathrm{C}$ or higher & $750^{\circ} \mathrm{C}$ or higher & $800^{\circ} \mathrm{C}$ or higher \\
\hline Heat Exchanger & Shell and Tube & Fluidized Bed & Fluidized Bed & $\begin{array}{c}\text { Pressurized } \\
\text { FBHX }\end{array}$ \\
\hline HP Turbine Inlet & $540^{\circ} \mathrm{C} / 13 \mathrm{MPa}$ & $580^{\circ} \mathrm{C} / 24.2 \mathrm{MPa}$ & $700^{\circ} \mathrm{C} / 25 \mathrm{MPa}$ & Up to $1420^{\circ} \mathrm{C}$ \\
\hline $\begin{array}{l}\text { Turbine Cycle } \\
\text { Efficiency }\end{array}$ & $42 \%$ & $45 \%$ & $51 \%$ [14] & $52 \%[14]$ \\
\hline Energy Storage (hr) & $6-13$ & $6-13$ & $6-13$ & $6-13$ \\
\hline TES Cost (\$/kWht) & $20-30$ [15] & $5-8[12]$ & $10-15^{*}$ & $5-8^{*}$ \\
\hline Receiver Cost (\$/kWt) & $140-180$ [15] & $100-130$ & $120-150^{*}$ & $100-140^{*}$ \\
\hline
\end{tabular}

Note: * - Estimated for $\mathrm{s}-\mathrm{CO}_{2}$ power cycle with small temperature differences.

Techno-economic analysis indicates that the system can achieve about a $20 \%$ cost reduction over a molten-salt CSP plant, assuming identical operating conditions for a traditional steam-Rankine cycle. The FB-CSP system can further reduce the CSP power generation cost when the system drives a high-efficiency power cycle such as an s$\mathrm{CO}_{2}$-Brayton power cycle or an $\mathrm{ABCC}$ power generation.

Advanced power cycles with $47 \%$ thermal efficiency and near-term, low-cost solar collector systems (priced at $\$ 100 / \mathrm{m}^{2}$ ) are expected to reduce the LCOE for CSP to below $9 \phi / \mathrm{kWh}$. Further reduction in LCOE of CSP requires a lower solar-field cost $\left(\$ 75 / \mathrm{m}^{2}\right)$ and higher power-cycle efficiency (> 50\%) based on the SunShot targets. Together with the cost reduction of the solar field, the FB-CSP system can facilitate the future CSP plant to reach the SunShot LCOE goal.

\section{Intellectual Property Outcome and Technology Development Path}

As reported in the RPPR2, in the SunShot Particle Receiver Project, NREL and its partners published or submitted 13 papers, including papers listed in references [12-14, 16-18]. NREL filed three U.S. patents that cover the particle-TES design and construction, heat exchanger configuration for steam, s- $\mathrm{CO}_{2}$, and air-Brayton power 
cycles, and the enclosed particle receiver [19-21]. Several NREL records of invention (ROIs) were generated from the SunShot particle receiver project [22-25]. The intellectual property agreement for optional licensing has been signed between NREL and B\&W. The project leads to two other projects under the DOE BRIDGE (with the University of Colorado) and ELEMENTS (with Colorado School of Mines) awards.

Ten students from five universities were trained for conducting research in the CSP area and supported the project. Those students contributed to the project in dealing with relevant modeling and testing problems. Some of the students elevated the research contributions into thesis works to support their degree requirements.

Within the project, B\&W filed applications for four U.S. provisional and non-provisional patents on particle receiver and heat exchanger designs [26-28]. Our technology commercialization tactics seek to maximize benefits to the CSP industry as a whole by directly partnering with a commercial technology (e.g. B\&W) and promoting technology transfer through intellectual property (IP) agreements. The auxiliary system and heat exchanger have been designed preliminarily in the SunShot project with no technical hurdles using conventional technology. However, further improvements are needed for the particle receiver, and the planar cavity configuration is suggested for continued design, analysis, fabrication, and testing. The particle-based thermal system would then need to progress towards a pilot-scale demonstration for additional validation testing. After demonstration of the particle thermal system, an entry step for particle-based CSP into the market could involve substitution of molten salt with the particle CSP system and a conventional power cycle, and pave the way for LCOE competitiveness with the conventional power generation. Prior to field deployment of the advanced s- $\mathrm{CO}_{2}$ power cycle, baseload power generation could also be accomplished with the high-efficiency particle-based system and a solar/hybridization design using PFB and GTCC technology. The particle-based thermal system integrated with PFB and GTCC technology could reach high CSP-plant efficiencies as indicated in Table 14, and function as an important stepping stone towards reaching the SunShot LCOE goal. Successful commercial implementation of the technology could allow for higher renewable grid penetration of CSP with a higher-efficiency power cycle and large-scale particle thermal energy storage [29-32].

The value added by a low-cost, high-performance CSP system can be attractive with the rapid growth of photovoltaic and wind power installed. CSP with TES can play a pivotal role in future power supply consisting of a major percentage of renewable sources, and significant distributed power and electrification of transportation, as illustrated in Figure 31. CSP TES can even play a role in storing the electricity from these variable-generation resources and shifting the power supply to peak demand hours. By improving the efficiency of the thermal cycle, TES can potentially help with renewable electrical energy storage (EES) needs. A comparative advantage of TES over pumped storage hydro and compressed air energy storage is that TES is not limited by the storage site's geological conditions. Another advantage is its low cost and ease of grid integration when coupled with mature power generation technologies. The TES technology may continue to advance as TES operating temperatures increase and the technology costs provide the means to store energy at a fraction of battery energy storage, making it an economically viable option in EES applications. TES in CSP 
provides utility-scale electricity storage capacity and could greatly improve the reliability and grid stability of renewable power generation. Using TES for EES to shift peak generation can generate additional revenue for a CSP plant, because the TES capital cost is included in the CSP system, and the TES can be the economic energy storage for electricity storage.

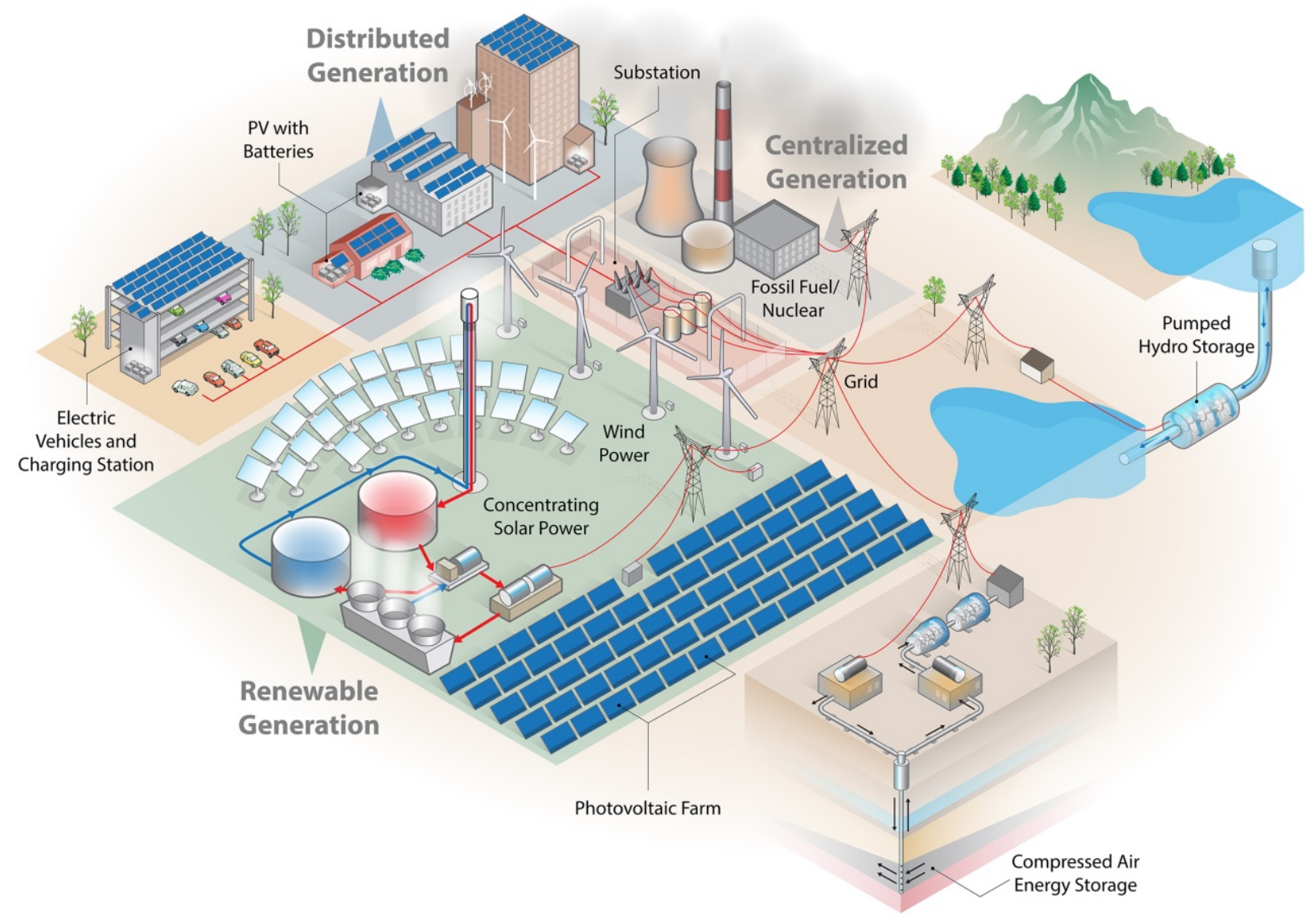

Figure 30. An illustration of CSP with TES for a scenario of different energy storage technologies integrated with centralized grid, distributed generation, and transportation (source: Alfred Hicks, NREL, [33]).

\section{Summary of the Overall Project Development:}

The three-year project has accomplished the following task goals:

- We developed a product receiver and analyzed its performance. The modeled results showed the receiver could meet the original performance target with idealized design conditions. In realizing the tubular-absorber fabrication, coating methods and reliability need to be further developed and verified.

- Modeling and testing tools were developed and used to verify the design configuration that promotes high-temperature and high efficiency.

- The project team successfully developed heat exchanger and integrated system components for the FB-CSP system. 
- We investigated intermediate- and high-temperature coatings. Promising coating methods of sol-gel protected silver and TST alumina and zirconiabased coatings were found to have high stability in 2,500 hours, and longterm applications need to be verified

- An alternative planar-cavity receiver design was introduced based on lessons learned from analysis of the tubular design. The suggested configuration is intended to promote solar flux spreading and to improve overall heat transfer. Ray-tracing analysis showed desirable flux spreading without the need of reflective coatings.

- We filed six patent applications and four NREL Records of Invention for relevant intellectual property. Results of research were published in highvisibility, high-impact, peer-reviewed journal(s) and six conference papers in the proceedings. Ten students contributed to the project and were trained to conduct research in the CSP area.

\section{References}

1. Morales, A.D., A.; Sol-gel protection of front surface silver and aluminum mirrors. Journal of Sol-Gel Science and Tech, 1997. 8: p. 451-457.

2. Brinker, C.J., et al., Sol-gel thin fim formation. Journal of Non-Crystalline Solids, 1990. 121: p. 294-302.

3. Brinker, C.J. and G.W. Scherer, Sol-gel science: The physics and chemistry of sol-gel processing. 1990: Academic Press Limited.

4. Aránzazu Fernández-García, et al., Durability of solar reflector materials for secondary concentrators used in CSP systems. Solar Energy Materials and Solar Cells, 2014. 130: p. 51-63.

5. Solar, A., Alanod MIRO-SUN®. 2010.

6. D. Duhl, K. I. Hirano, and M. Cohen, Diffusion of Iron, Cobalt, and Nickel in Gold. Acta Metallurgica, 1963. 11((1)): p. 1-6.

7. F. E. Jaumot Jr. and A. Sawatzky, Diffusion of Gold in Single Crystals of Silver. Journal of Applied Physics, 1956. 27: p. 1186-1188.

8. Pinnel, M.R., Diffusion-Related Behaviour of Gold in Thin Film Systems. Gold Bulletin, 1979. 12((2)): p. 62-71.

9. Poate, J.M., Diffusion and Reactions in Gold Films. Gold Bulletin, 1981. 14((1) ): p. 2-11.

10. Hischier, I., P. Poživil, A. Steinfeld, A Modular Ceramic Cavity-Receiver for HighTemperature High-Concentration Solar Applications. ASME Journal of Solar Energy Engineering, 2012. Vol. 134.

11. Bergman, T.L., F.P. Incropera, A.S. Lavine, and D.P. DeWitt, Fundamentals of Heat and Mass Transfer. 2011: John Wiley \& Sons.

12. Z. Ma, G.C.G., and M. Mehos, Development of solid particle thermal energy storage for concentrating solar power plants that use fluidized bed technology. Energy Procedia 2014. 49 p. 898 - 907.

13. Z. Ma, G.G., Mark Mehos, Fluidized Bed Technology for Concentrating Solar Power with Thermal Energy Storage. ASME Journal of Solar Energy Engineering, August, 2014. Vol 136. 
14. B. Sakadjian, S.H., M. Maryamchik, T. Flynn, K. Santelmann, Z. Ma Development of a Concentrating Solar Power System Using Fluidized-Bed Technology for Thermal Energy Conversion and Solid Particles for Thermal Energy Storage. Energy Procedia, 2015. 69.

15. J. Gary, C.T., and N. Siegel, CSP and the DOE SunShot Initiative, in Proceedings of SOLARPACES 2011. September, 2011: Granada, Spain.

16. Austin Fleming, C.F., Heng Ban, Zhiwen Ma, , A General Method to Analyze the Thermal Performance of Multi-Cavity Concentrating Solar Power Receivers. Solar Energy Journal, 2015. Submitted.

17. J. Martinek, Z.M., Granular Flow and Heat Transfer Study in a Near-Blackbody Enclosed Particle Receiver, in ASME 2014 8th International Conference on Energy Sustainability \& 12th Fuel Cell Science, Engineering and Technology Conference. 2014: Boston, Ma.

18. Austin Fleming, Z.M., Tim Wendelin, Heng Ban, Charlie Folsom, Thermal Modeling of a Near-Blackbody Receiver Design for Concentrating Solar Power Generation. ASME Journal of Solar Energy Engineering, July, 2015. Submitted.

19. Z. Ma, R.Z., Solid Particle Thermal Energy Storage Design for a Fluidized-Bed Concentrating Solar Power Plant. 2013.

20. Ma, Z., Methods and Systems for Concentrated Solar Power, NREL. 2013.

21. Ma, Z., Chemical Looping Fluidized-Bed Concentrating Solar Power System and Method. 2014.

22. Z. Ma, T.W., Janna Martinek, Mark Mehos, Craig Turchi, Judy Netter, HighTemperature, High-Efficiency Fluid Bed Particle Receiver. March, 2015.

23. Zhiwen Ma, T.W., Janna Martinek, Mark Mehos, Judy Netter, U-Cavity Receiver Design and Operation for Solid-Particle-Based Concentrating Solar Power Plant. December, 2014.

24. Filing, N.I., Embedded-cavity and cooled-flare particle receiver design. 2014.

25. Filing, N.I., Particle Receiver Design and Module Fabrication Methods. April, 2014.

26. B\&W, Power Generation Plant Integrating Concentrated Solar Power Receiver and Pressurized Heat Exchanger. 2014.

27. Wasyluk, D.T., Water Jacket for Solid Particle Receiver. 19-May-2014.

28. Wasyluk, D.T., Method to Construct and Support Tube Module Assemblies for Solid Particle Solar Receiver. 21-Apr-2014.

29. Z. Ma, G.G., C. Kutscher, Thermal Energy Storage and Its Potential Applications in Solar Thermal Power Plants and Electricity Storage, in ASME ES2011. June, 2011: Washington, D.C.

30. M. Mehos, D.K., and P. Smithers, Planting the seed - Greening the grid with concentrating solar power. IEEE Power \& Energy Magazine, 2009.

31. C. Turchi, Z.M., Gas Turbine / Solar Parabolic Trough Hybrid Design Using Molten Salt Heat Transfer Fluid, in SolarPACES2011. September, 2011: Spain.

32. C. Turchi, Z.M., and T. Neises, M. Wagner, Thermodynamic Study of Advanced Supercritical Carbon Dioxide Power Cycles for Concentrating Solar Power Systems. J. Sol. Energy Eng., 2013. 135(4). 
33. Z. Ma, A.P., Vahan Gevorgian, Don Gwinner, and William Kramer, Energy Storage, Renewable Power Generation, and the Grid - NREL capabilities help to develop and test energy storage technologies. IEEE Electrification Magazine, September, 2015. Volume 2 